Portland State University

PDXScholar

TREC Final Reports

Transportation Research and Education Center

(TREC)

8-1-2016

\title{
Utilizing Egocentric Video and Sensors to Conduct Naturalistic Bicycling Studies
}

Feng Liu

Portland State University, fliu@pdx.edu

Miguel A. Figliozzi

Portland State University, figliozzi@pdx.edu

Follow this and additional works at: https://pdxscholar.library.pdx.edu/trec_reports

Part of the Transportation Commons, Transportation Engineering Commons, and the Urban Studies and Planning Commons

Let us know how access to this document benefits you.

\section{Recommended Citation}

Liu, F. \& Figliozzi, M. Utilizing Egocentric Video and Sensors to Conduct Naturalistic Bicycling Studiest. NITC-RR-805. Portland, OR: Transportation Research and Education Center (TREC) 2016. https://doi.org/ 10.15760/trec.154

This Report is brought to you for free and open access. It has been accepted for inclusion in TREC Final Reports by an authorized administrator of PDXScholar. Please contact us if we can make this document more accessible: pdxscholar@pdx.edu. 


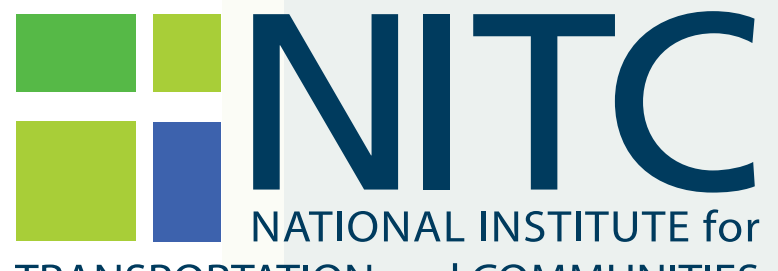

TRANSPORTATION and COMMUNITIES

FINAL REPORT

Utilizing Egocentric Video and Sensors to Conduct Naturalistic Bicycling Studies

NITC-RR-805 — August 2016

NITC is the U.S. Department of Transportation's national university transportation center for livable communities.

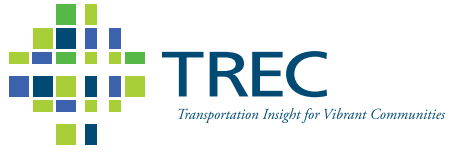




\section{UTILIZING EGOCENTRIC VIDEO AND SENSORS TO CONDUCT NATURALISTIC BICYCLING STUDIES}

\section{Final Report}

\section{NITC-RR-805}

by

Feng Liu, Ph.D.

Miguel Figliozzi, Ph.D.

Wu-chi Feng, Ph.D.

Alvaro Caviedes, Hoang Le, Long Mai (GRAs)

Portland State University

for

National Institute for Transportation and Communities (NITC)

P.O. Box 751

Portland, OR 97207
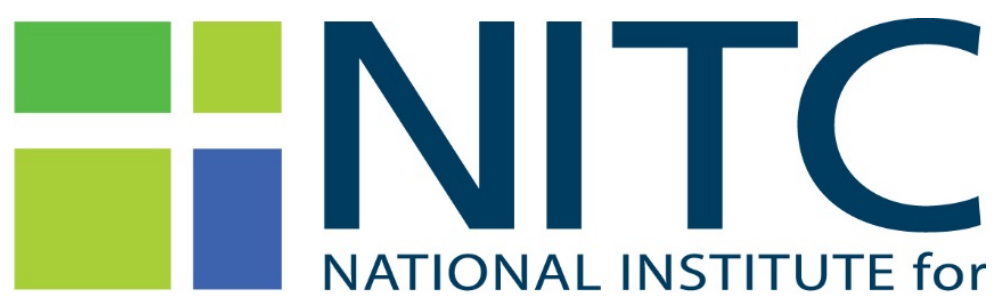

TRANSPORTATION and COMMUNITIES

August 2016 



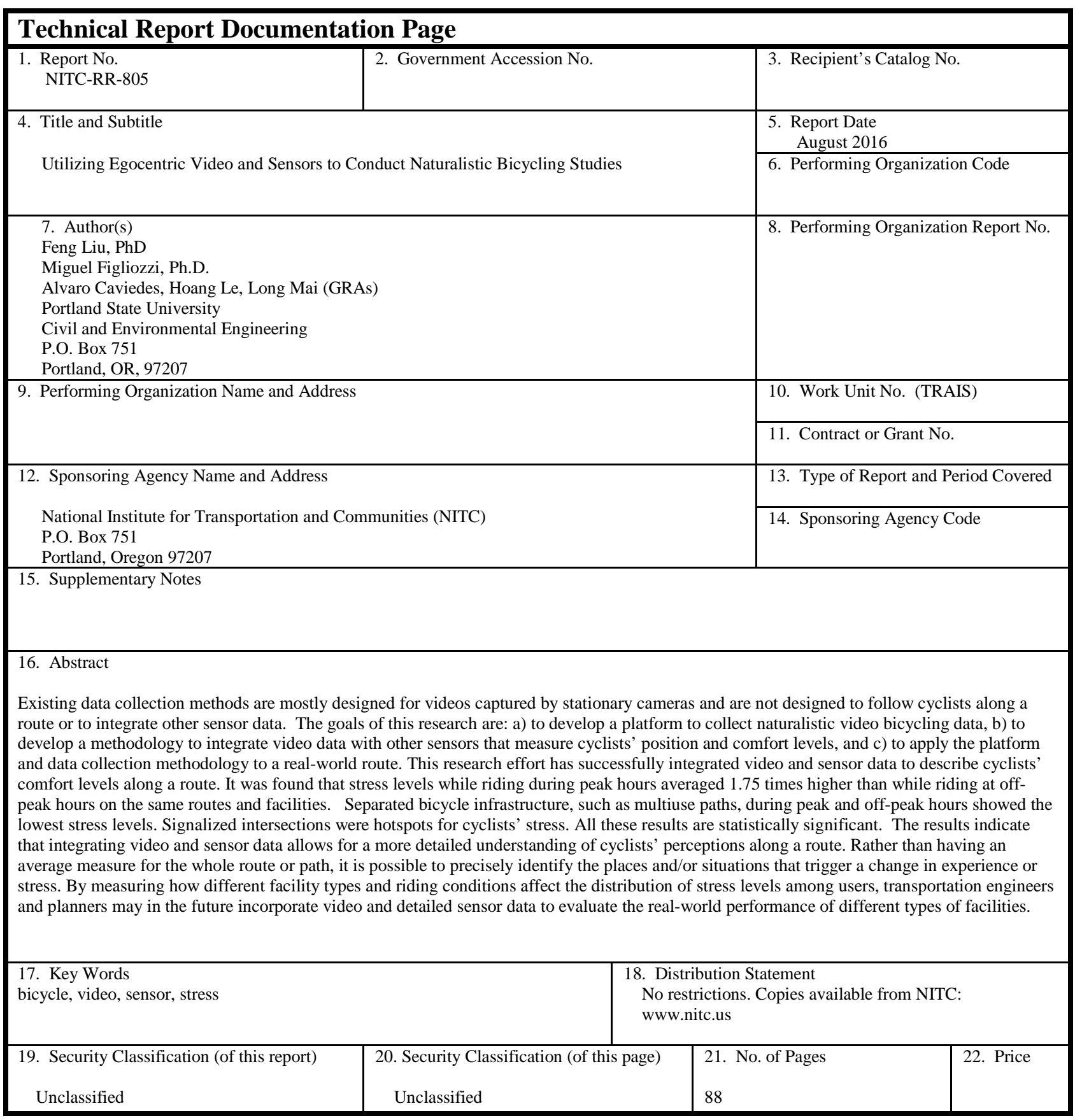





\section{ACKNOWLEDGEMENTS}

The National Institute for Transportation and Communities (NITC) funded this research project. The authors acknowledge the Transportation Technology and People (TTP) and the Maseeh College of Engineering and Computer Science for purchasing the GSR equipment and the instrumented bicycle. The computer graphics and vision lab provided the video equipment. Any errors or omissions are the sole responsibility of the authors.

\section{DISCLAIMER}

The contents of this report reflect the views of the authors, who are solely responsible for the facts and the accuracy of the material and information presented herein. This document is disseminated under the sponsorship of the U.S. Department of Transportation University Transportation Centers Program in the interest of information exchange. The U.S. Government assumes no liability for the contents or use thereof. The contents do not necessarily reflect the official views of the U.S. Government. This report does not constitute a standard, specification, or regulation. 



\section{TABLE OF CONTENTS}

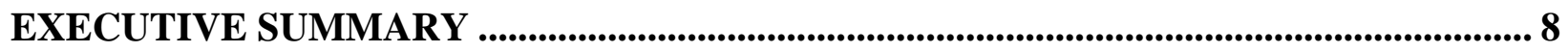

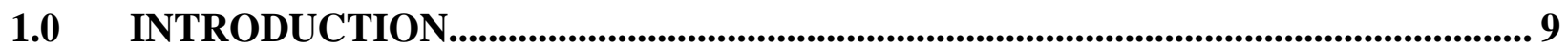

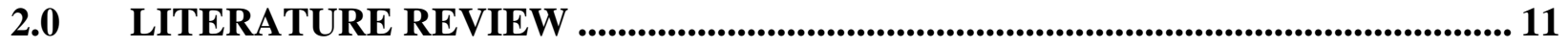

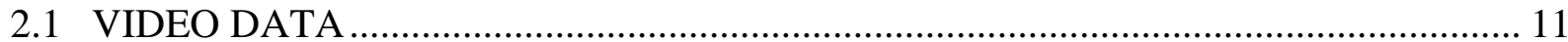

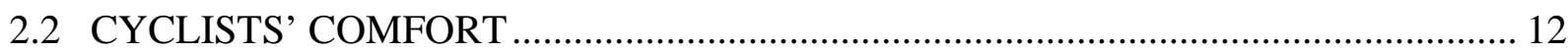

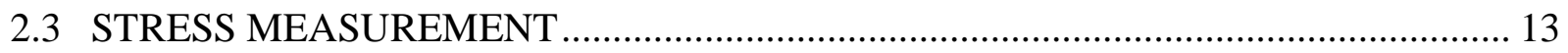

3.0 DATA COLLECTION EQUIPMENT ...................................................................... 15

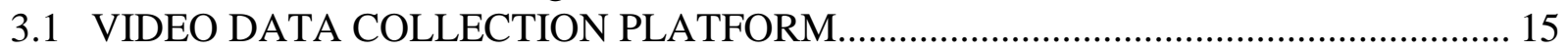

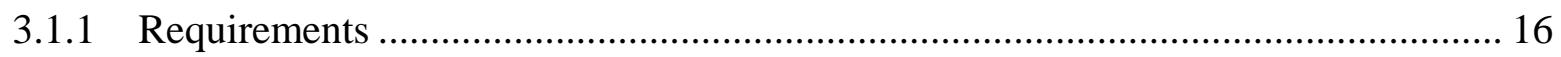

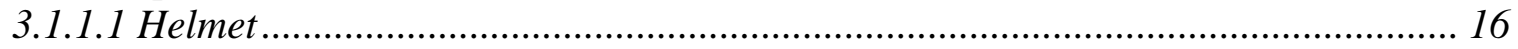

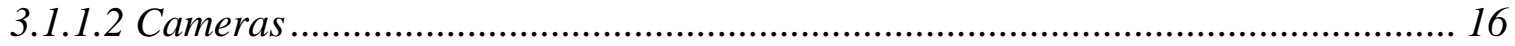

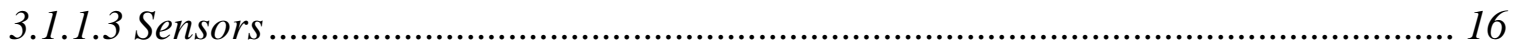

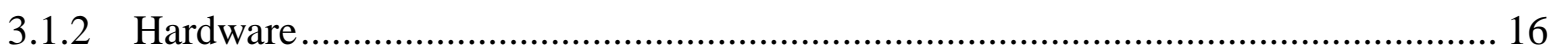

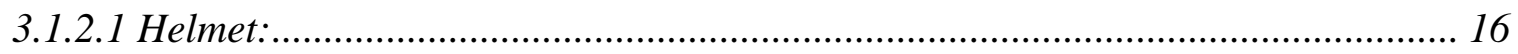

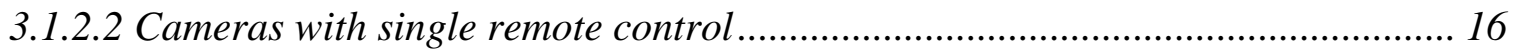

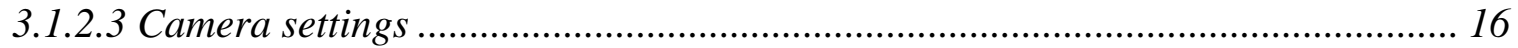

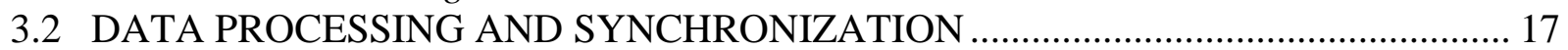

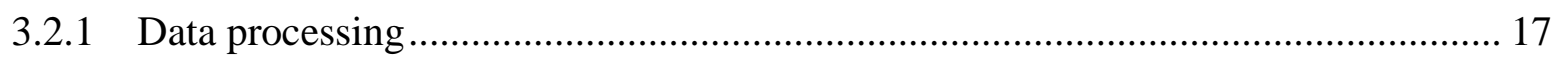

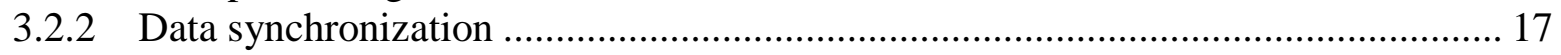

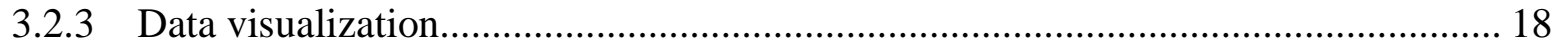

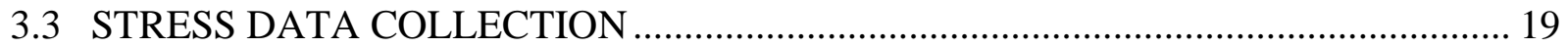

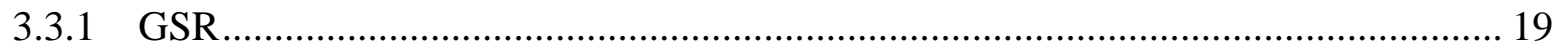

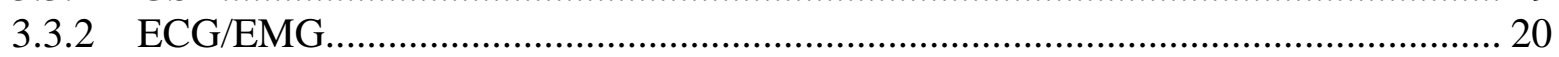

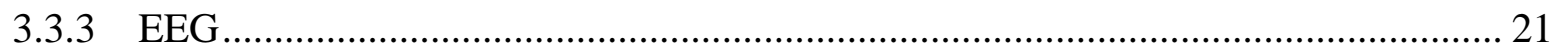

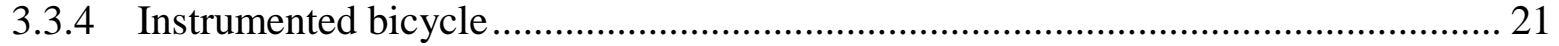

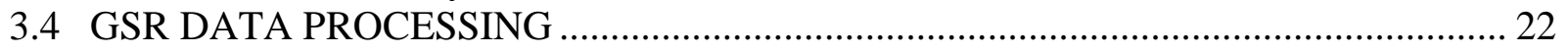

4.0 DATA COLLECTION METHODOLOGY .............................................................. 25

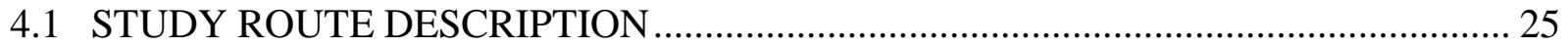

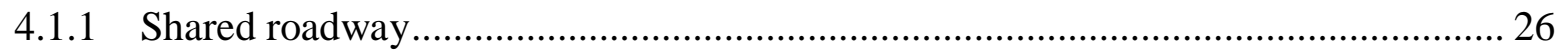

4.1.2 Bike lane ............................................................................................... 26

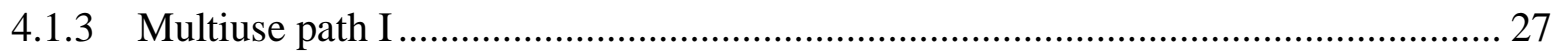

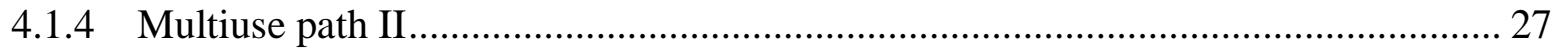

4.2 DATA COLLECTION I: MULTIPLE SUBJECTS .................................................... 27

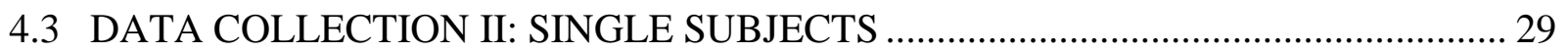

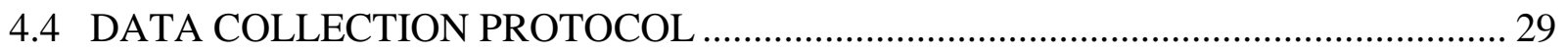

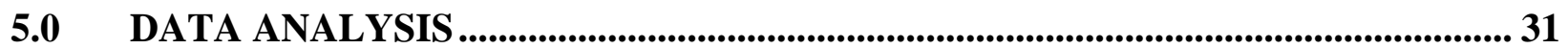

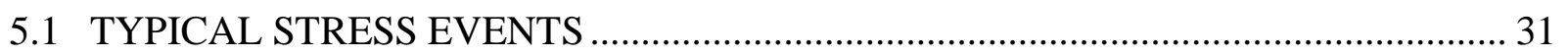

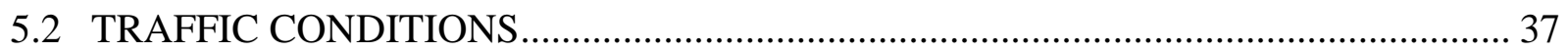

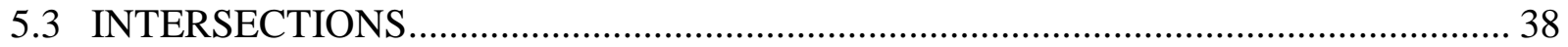

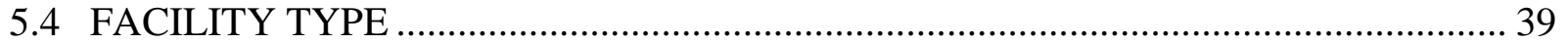

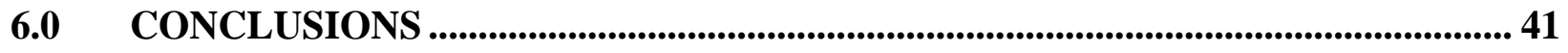

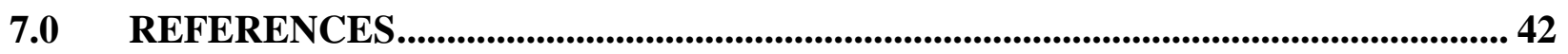




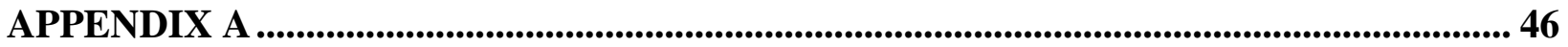

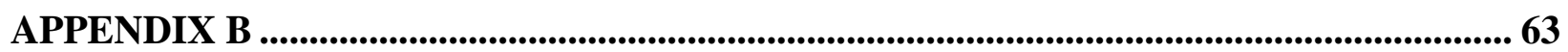




\section{LIST OF FIGURES}

Figure 3.1: Video data collection helmet (VDCH) .......................................................... 15

Figure 3.2: Software GoPro Studio is used to correct distortion in our collected videos............. 17

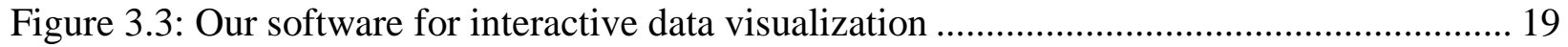

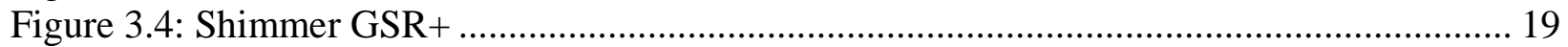

Figure 3.5: Shimmer ECG/EMG ............................................................................... 20

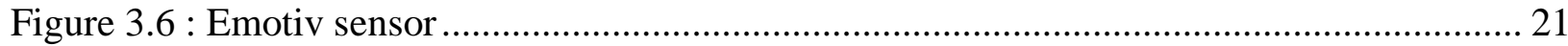

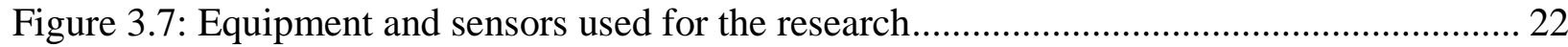

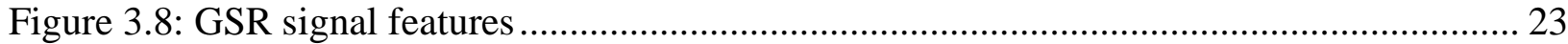

Figure 3.9: Overlapping GSR signals (based on Healy and Picard, 2000)................................ 23

Figure 4.1: Research route ...................................................................................... 25

Figure 4.2: Shared roadway facilities - peak (left) and off-peak hour (right)........................... 26

Figure 4.3: Bike lane facilities - peak (left) and off-peak hour (right) .................................... 26

Figure 4.4: Multiuse path I facilities - peak (left) and off-peak hour (right) ............................. 27

Figure 4.5: Multiuse path II facilities - peak (left) and off-peak hour (right)........................... 27

Figure 5.1: Multisubject stress levels across bicycle facilities ............................................... 37

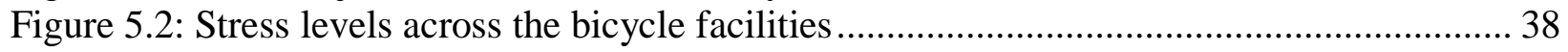

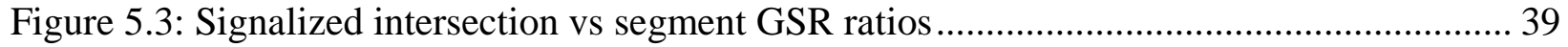

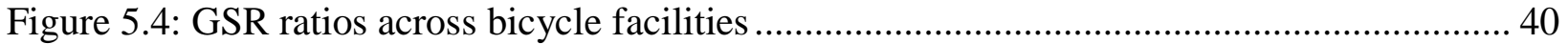

\section{LIST OF TABLES}

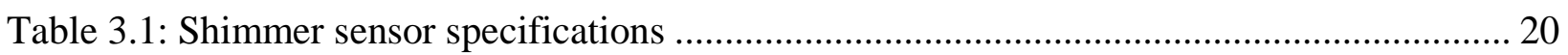

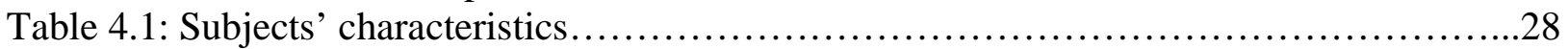

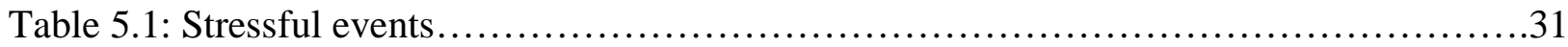




\section{EXECUTIVE SUMMARY}

Safety research has progressed substantially with the development of instrumented vehicles and naturalistic driving studies; however, these advances have been mostly limited to motorized vehicles.

A limitation of many cyclist studies is the lack of evaluation of cyclists' experiences while the cyclist is riding in real-world settings; the approach presented in this project allows the researcher to have a better picture of what the cyclist is actually experiencing. Egocentric videos captured by cameras mounted on a cyclist's helmet can capture the first-person cycling experience and contain rich information for understanding cyclist comfort levels and behavior. This research integrates egocentric videos, route data and position, and stress sensors to better understand cyclists' comfort levels along a route.

Existing data collection methods are mostly designed for videos captured by stationary cameras and are not designed to follow cyclists along a route or to integrate other sensor data. The goals of this research are: a) to develop a platform to collect naturalistic video bicycling data, b) to develop a methodology to integrate video data with other sensors that measure cyclists' position and comfort levels, and c) to apply the platform and data collection methodology to a real-world route.

This research effort has successfully integrated video and sensor data to describe cyclists' comfort levels along a route. It was found that stress levels while riding during peak hours averaged 1.75 times higher than while riding at off-peak hours on the same routes and facilities. Separated bicycle infrastructure, such as multiuse paths, during peak and off-peak hours showed the lowest stress levels. Signalized intersections were hotspots for cyclists' stress. All these results are statistically significant.

The results indicate that integrating video and sensor data allows for a more detailed understanding of cyclists' perceptions along a route. Rather than having an average measure for the whole route or path, it is possible to precisely identify the places and/or situations that trigger a change in experience or stress. By measuring how different facility types and riding conditions affect the distribution of stress levels among users, transportation engineers and planners may in the future incorporate video and detailed sensor data to evaluate the real-world performance of different types of facilities. 


\subsection{INTRODUCTION}

Bicycle transportation has become an attractive option for dense and congested urban areas due to low environmental impacts, improved quality of life, and numerous health benefits. Many cities around the country have ambitious plans to increase bicycle mode share in the short and long term. Addressing this goal brings many challenges, from limited transportation budgets and roadway space to difficulty in attracting new users due to concerns about safety and comfort while riding in urban areas. These challenges have motivated researchers to better understand where and what types of bicycle improvements yield the maximum net benefit in terms of increased ridership, comfort, and safety.

For the last decades, transportation engineers and planners have been attempting to estimate cyclists' safety, comfort, stress levels, and level of service using two experimental design approaches: naturalistic and non-naturalistic studies. In a naturalistic approach the subject is observed or analyzed in his or her natural environment (on-road) while cycling, without any significant manipulation or interference. Although there has been great research progress with the development of instrumented vehicles and naturalistic driving studies, these advances have been mostly limited to motorized vehicles.

In contrast, a non-naturalistic study refers to the method by which the subject is analyzed in an artificial setting, or provides data executing an activity that is not cycling; for example, in a laboratory or through a web-survey. Most non-naturalistic studies have used surveys to understand cyclists' preferences. The subjects evaluated different environments or facilities by looking at pictures of intersections and/or corridors. Laboratory analyses were also conducted in which researchers tested the physical activity of cyclists under various conditions in an attempt to simulate those encountered in natural (on-road) environments.

A limitation of many cyclist studies is the lack of evaluation of cyclists' experiences while the cyclist is riding in real-world settings; the approach presented in this project allows the researcher to have a better picture of what the cyclist is actually experiencing. Egocentric videos captured by cameras mounted on a cyclist's helmet can capture the first-person cycling experience and contain rich information for understanding cyclist comfort levels and behavior.

Existing cyclist data collection methods are mostly designed for videos captured by stationary cameras and are not designed to follow cyclists along a route or to integrate other sensor data. The goals of this research are: a) to develop a platform to collect naturalistic video bicycling data, b) to develop a methodology to integrate video data with other sensors that measure cyclists' position and comfort levels, and c) to apply the platform and data collection methodology to a real-world route.

This report is organized as follows: Section 2 presents a literature review of video data collection methods, cyclists' comfort, and sensors that can be utilized to collect naturalistic cyclist data. Section 3 presents the details of the developed video analysis platform. Section 4 presents the details of the stress sensors utilized. Section 5 presents the research method followed. Section 6 presents data analysis, Section 7 is a discussion of the findings, and the report ends with conclusions in Section 8. Appendix A includes photographs of locations around the four different 
facilities: Bike Lane, Multiuse path I and II, and Shared roadway during peak and off-peak times. Appendix B includes photographs of locations where stressful events took place; events are described and categorized by subject. 


\subsection{LITERATURE REVIEW}

To answer the research questions it is necessary to review the research literature related to video data collection methods, cyclists' comfort, and stress measurements; this section has been divided into three subsections that address these topics.

\subsection{VIDEO DATA}

A number of studies have been conducted to improve cyclist safety (Monsere, McNeil, \& Dill, 2012) (Figliozzi, Wheeler, \& Monsere, 2013). These studies often need to collect the data on how vehicles respond to cyclists. There are a number of ways to collect such data, ranging from field manual observations to fully automatic video collection with computer vision algorithmic processing. The data, however, is only collected from fixed locations, and moreover, only a snapshot of passing vehicles and cyclists is captured. Rich information about how cyclists interact with vehicles while they are travelling over an extended period cannot be obtained using these traditional data collection solutions.

For motorized vehicles, the U.S. Department of Transportation has been developing portable, vehicle-based data collection technologies since the early 1990s. For example, the 100-Car Naturalistic Driving Study was a National Highway Traffic Safety Administration project to measure driver behavior and performance simultaneously. The vehicle instrumentation provided “continuous video recording of forward and rear views, of the driver's face, and of the instrument panel; in addition, forward- and rearward-looking radar units were concealed in the license plate brackets, and the vehicle was equipped with a machine-vision lane-position monitor, a Global Positioning System (GPS) locator, and connections to the vehicle data network, communications, and data storage” (Campbell \& Linda, 2008). The data collected in the 100-Car study was utilized to produce several reports and papers1. A recent SHARP 2 field study has collected detailed driver, vehicle, and environment data from six different locations across the USA; the data collection effort was finished in November 2013 and focused exclusively on motorized vehicles (Forrest, 2013).

There have been limited efforts to use naturalistic methods to study cyclist behavior. A search in the TRID database revealed that Johnson et al. (2010) and Chuang et al. (2013) developed "quasi-naturalistic" studies since they attached cameras to bicycles or helmets but they did not track head or pupil movement. A review commissioned by the European Union (Sagberg \& Backer-Grondhal, 2010) indicates that although naturalistic driving studies "have their primary focus on driver (or rider) behavior, the data can indirectly give information about behavior of vulnerable road users as well, such as pedestrians and bicyclists.” This recent review does not even consider the possibility of focusing on the behavior and perspective of cyclists whey they interact with traffic and bicycle facilities. There are a range of computer vision algorithms that can be used to analyze traffic videos to extract motion of cyclists and vehicles (Chi, Dill, \& Monsere, 2009) (Durrant-Whyte \& Bailey, 2006) (Harley \& Zisserman, 2004) (Le, Dang, \& Liu)

\footnotetext{
${ }^{1}$ See http://www.nhtsa.gov/Research/Human+Factors/Naturalistic+driving+studies:
} 
(Li, et al., 2012). However, these algorithms are designed for videos captured by stationary cameras. They cannot be used to handle egocentric videos that are captured by fast-moving cameras worn by cyclists.

\subsection{CYCLISTS' COMFORT}

Cyclists' comfort and safety at intersections is an active area of study because more than $50 \%$ of crashes involving bicycles and other motorized vehicles take place at or near intersections (Kim, Kim, Ulfarsson, \& Portello, 2007). Using a rating survey, Carter et al. found that cyclists' comfort at an intersection depends on bike lane presence, number of lanes, cross-street traffic volume, main-street volume, main-street speed limit, on-street parking, and traffic signals (Carter, Hunter, Zegeer , \& Stewart, 2007). Landis et al. asked cyclists to rank various signalized intersections in terms of safety and comfort, finding that the main variables affecting level of service are traffic volume, total width of outside through lane and bike lane, and total crossing distance (Landis, et al., 2003). Garder et al. (1998) surveyed different experts on cyclists' safety across the world, and studied the speed and behavior of cyclists in a bike path before and after the implementation of different types of bicycle crossings. The findings suggest that cyclists have a higher risk of injury at intersections that are part of bike lanes than shared roadways; intersections on shared roadways likely force the cyclist to take the lane, making him/herself more visible to the driver who is turning. When the bicycle path is raised, the vehicles are likely to reduce their speed, thus reducing the risk of a crash. (Garder, Leden, \& Pulkkinen, 1998).

Dill et al. (2007) identified that the perception about availability of comfortable bicycle facilities is a strong factor affecting bicycle ridership and bicycle mode share (Dill \& Voros, 2007). Other studies that collected information from surveys found that weather conditions, route conditions, interaction with motorized traffic, street parking, and characteristics of bicycle facilities have an impact on the motivation to bicycle (Winters, Davidson, Kao, \& Teschke, 2011) (Sener, Eluru, \& Bhat, 2009).

Non-naturalistic studies are very useful to investigate cyclists' perceived comfort and preferences for various types of bicycle facilities. Nonetheless, this approach may result in bias due to the subjectivity of the metrics and the nature of stated versus revealed (or measured) preferences (or responses). Surveys and laboratory settings do not always reflect the mental and physical responses than occur in a natural environment.

Healy and Picard suggest that when measuring human emotions and perceptions, the researcher has to be aware that when asking questions related to a subject's personal feelings, answers can vary "according to her awareness of her feelings, her comfort in talking about feelings, her rapport with the administrator of the experiment and more" (Healy \& Picard, 2005). Hong et al. (2012) recommend investigating human responses in uncontrolled scenarios due to the limits of applications of findings in controlled scenarios.

Naturalistic studies are designed to collect data by investigating the subject in his or her natural riding environment without any significant interference. Dozza et al. (2012) supported the validity of this approach for collecting data to investigate cyclists' perception and comfort. These studies have been focused on studying cyclists' behavior and preferences by analyzing videos or collecting data of actual conditions. Using data collected from videos, Johnson et al. (2001) 
found that the main variables associated with red-light infringement are a function of cyclists' safety perceptions of opposing traffic volumes. Kai Hsiang et al. (2013) collected actual field data using a bicycle equipped with various sensors and cameras. The authors found that cyclists' behavior changes with proximity to motorized vehicles. They also found that a demarcated bike lane generates a higher distance between the cyclist and the motor vehicle (Chuang, Hsu, Lai, Doong, \& Jeng, 2013); cyclists also perceive this to be safer than a road with no such separation [3]. The bicycle level of service of the 2010 Highway Capacity Manual measures the performance of bicycle users and facilities using data directly collected in the field (Transportation Research Board, 2010). However, this methodology is not based on naturalistic data as defined in this paper; users were asked to rate different types of facilities after watching video clips filmed from a bicycle. Alternately, using revealed GPS data from on-road, real-world bicycle trips, Harvey et al. (2008) found that cyclists are willing to take longer travel distances to their destinations in order to achieve high levels of safety and comfort.

A limitation of the cited naturalistic studies is the lack of consideration on stress measurements while the subject is cycling (e.g., videos and bicycle sensors cannot measure the level of stress that a cyclist is experiencing while making a route decision or just simply biking).

\subsection{STRESS MEASUREMENT}

The term "stress" can be defined as "the non-specific mix of physiological and psychological responses of the body to any demand of change" (Seyle, 1956). It is a reaction from a calm state to an excited state for the purpose of being alert during a situation in which the subject feels threatened or attacked (Healy J. , 2000). Bicycle level of stress (BLS) and level of traffic stress (LTS) have been described as a function of safety levels, physical/mental effort and age (Sorton \& Walsh, 1994), traffic/geometric variables, and the different user groups' characteristic within the population (Mekuria, Furth, \& Nixon, 2012). Despite their names, neither BLS nor LTS are actually based on real-world, on-road stress measurements.

Collecting physiological data to describe stress levels has been studied for nearly four decades by psychologists. Various studies have found a definitive association between specific human emotions and physiological responses (heart rate, skin conductance, blood pressure, breathing rate, etc.) (Boucsein, 2012). Physiological responses can also be used to predict the emotional state of the human. Fridlund and Izard were the first to recognize emotions from physiological features, attaining rates of 38-51\% accuracy using electromyogram signals (an electromyogram, or EMG, measures the electrical activity of muscles at rest and during contraction) (Friedlund \& Izard, 1983). It is possible to differentiate states of anger and fear (Ax, 1953) and states of conflict and no-conflict using galvanic skin response (GSR) and heart rates (Kahneman, 1973). Ekman et al. found evidence for distinctive patterns of autonomic nervous system activity for anger, disgust, and possibly sadness (Ekman, Levenson, \& Friesen , 1983).

GSR sensors measure the changes in the conductance of the skin caused by ionic sweat secretion (related to stressful events). "The resistance of the skin is usually large, however, momentary changes in the level of the sweat gland activity causes changes in resistance that can be measured by passing a small electrical current across two electrodes placed on the surface of the skin" (Healy J. , 2000). Studies in other fields, mainly psychology and medicine, have demonstrated 
that emotional arousal (such as stress) leads to an increase in skin conductance (Prokasy \& Raskin, 1973) (Picard, Vyzas, \& Healy, 2001) (Lisetti \& Nasoz, 2004).

Helander found that GSR was the best predictor to measure the impact of stressful events in the subject (Helander, 1978). Labbé et al. and Liao found that when an individual is under stress, skin conductance increases due to an increase in sweat activity (Weihong, Zhu, \& Quiang Ji, 2005) (Labbe', Schmidt, \& Babin, 2007). Physiological responses have the potential to represent internal human states less influenced by cognitive and social variables (Picard, Vyzas, \& Healy, 2001); some internal human emotions can be measured using noninvasive methods (Sharma \& Gedeon, 2012).

In previous studies, GSR yielded the most accurate data for measuring stress in human subjects. Skin conductance (also known as GSR) is one of the most robust noninvasive physiological measures of ANS and electrodermal activity (Healy J. , 2000) to investigate stress (Labbe', Schmidt, \& Babin, 2007) (Healy \& Picard, 2005) (Seyle, 1956).

Ekman et al. and Lanzetta and Orr found that emotions like fear and disgust produce a larger increase in GSR than happiness (Ekman, Levenson, \& Friesen , 1983) (Lanzetta \& Orr, 1986). Pecchinenda and Smith measured GSR in subjects at the beginning of a problem-solving task and found that the signal increased significantly from the baseline; then, when the subjects were more comfortable and confident with the situation, the signals started to decrease again, as expected (Pecchinenda \& Smith, 1996). Lisetti and Nasoz used movie clips and difficult mathematics questions to elicit various emotions, finding that GSR signals could explain fear (Lisetti \& Nasoz, 2004). Using GSR measures, Labbé et al. found that listening to classical music and self-selected relaxing music after being exposed to a stressor will lead to a reduction in the state of anxiety and alert, as opposed to those individuals who sit in silence or listen to heavy metal music (Labbe', Schmidt, \& Babin, 2007). Hong et al. found that it is possible to use GSR sensors to recognize stress by ignoring activity context (walking vs cycling) (Hong, Ramos, \& Dey, 2012).

Stressful events (such as biking close to traffic) may cause dynamic changes in the autonomic nervous system; More specifically, stressful events cause an increase in sympathetic nervous system activity (Wilfrid \& McLachlan, 1992) and a decrease in the parasympathetic nervous system activity, which can be evidenced by changes in heart rate, blood pressure, breathing rate, and GSR (Sharma \& Gedeon, 2012). This study addresses the question of how characteristics of a bicycle trip affect stress levels using physiological data, specifically GSR. As detailed in this section, GSR-based studies have been successfully employed for many years in the psychological field to recognize and associate emotions and behaviors to physiological responses.

To the best of the authors' knowledge, physiological measures of GSR have not been explored yet in the bicycle transportation research field, although it has been used to measure stress levels in automobile drivers (Helander, 1978). Healy and Picard found that GSR sensors can be used to obtain signals processed by on-board car computers to give dynamic reliable measures about a driver's internal state while he/she is driving in a real on-road environment (Healy \& Picard, 2005). Helander found that GSR is a good predictor for driver stress in fast events, such as encountering a cyclist, pedestrian, or a car emerging in the street (Helander, 1978). 


\subsection{DATA COLLECTION EQUIPMENT}

The main challenge with egocentric video data collection is data acquisition, processing, and integration with other sensor data. This section details equipment and software development necessary to answer the research questions. Equipment and software were necessary to: (1) collect simultaneously 360-degree view video, (2) develop computer code to facilitate video processing, data extraction and integration, (3) collect bicycle trajectory data, and (4) collect cyclists' stress levels.

\subsection{VIDEO DATA COLLECTION PLATFORM}

For this project we develop hardware and software systems to create a video data collection helmet (VDCH). The VDCH is embedded with multiple (up to four) cameras, see figure below, and the video data can later be integrated to a bicyclist's trajectory data.

The VDCH prototype allowed 360 data collection capability along a cyclist’s route.
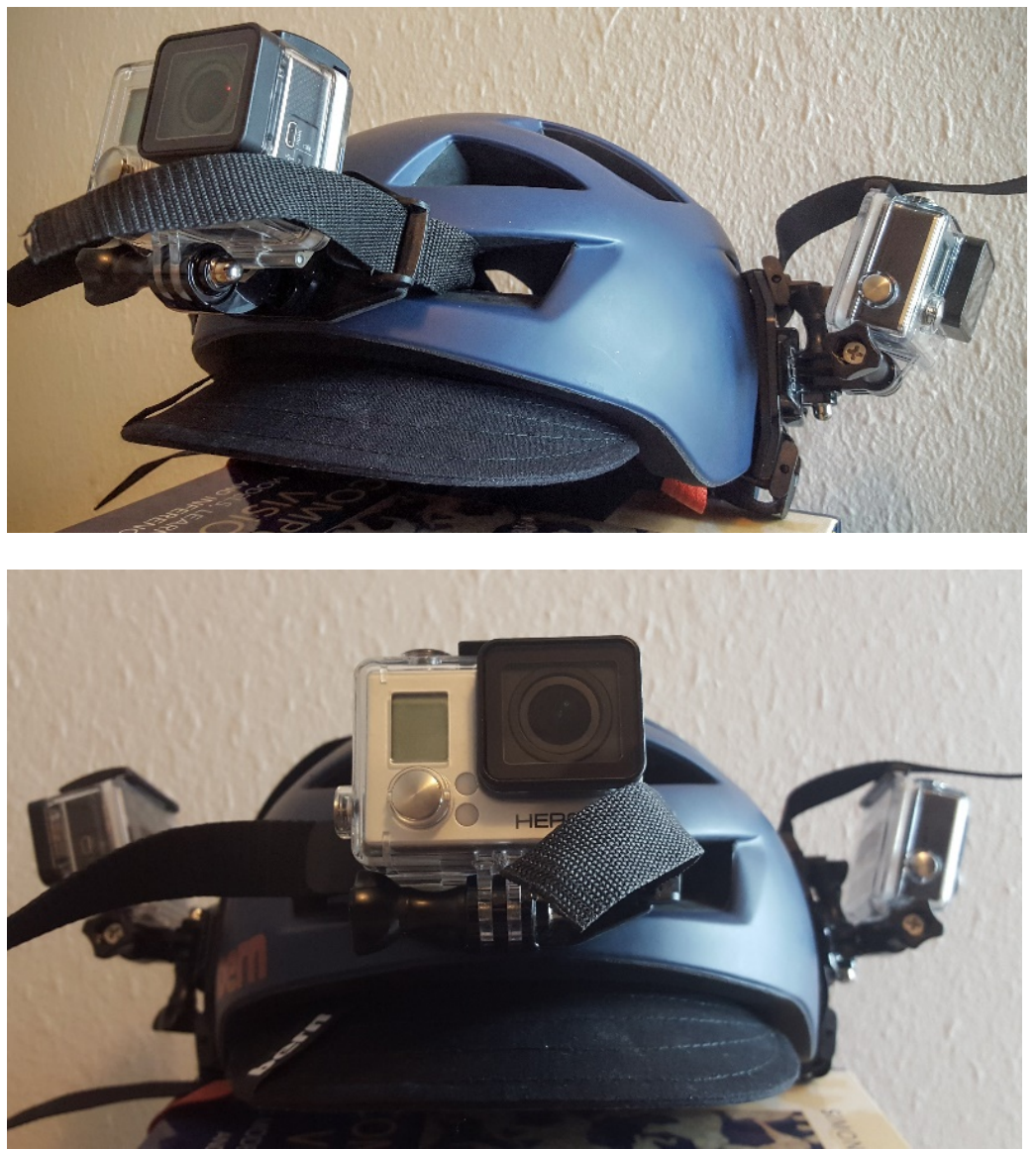

Figure 3.1: Video data collection helmet (VDCH) 
We built the first prototype of the VDCH only utilizing off-the-shelf components. After numerous trials and extensive testing, the following requirements and configuration are suggested for research studies.

\subsubsection{Requirements}

\subsubsection{Helmet}

- The helmet must be lightweight and similar to helmets worn by regular cyclists. The addition of cameras adds considerable weight, and ideally the cyclist must be as inconspicuous as possible so that drivers' behavior is not altered.

\subsubsection{Cameras}

- The VDCH must have enough cameras to provide a 360-degree view surrounding the cyclist.

- Cameras must also be lightweight and their battery must have enough energy to allow for two or more hours of continuous video recording.

- Cameras must have sufficient visual quality to support later data analysis and research studies.

- The videos captured from the helmet must be later synchronized at the research lab. Without synchronization it is not possible to take advantage of the 360-degree view.

- A remote control is necessary to easily start and stop recording video data.

\subsubsection{Sensors}

- It must be possible to attach various off-the-shelf sensors to the helmet or bicycle to collect data. Any sensor data must be later synchronized at the research lab. Without synchronization it is not possible to take advantage of the video plus sensor data.

\subsubsection{Hardware}

After numerous trials and extensive testing, the research team decided to use all the following off-the-shelf hardware components:

\subsubsection{Helmet:}

- A bike helmet: Bern, size L-XL, weight 370g

\subsubsection{Cameras with single remote control}

- Four cameras GoPro Hero 3 Black+, each weighs $163 g$ with case, battery, and micro SD card

- Each camera has a 32GB micro SD card

- One single remote GoPro control to control four cameras at the same time

\subsubsection{Camera settings}

- Videos are captured at wide-angle lens mode:

a. FOV 170 degree 
b. Framerate: $30 \mathrm{fps}$

c. Video resolution: $1920 \times 1080$

d. Estimated battery life for one continuous video: Three to four hours

- Four GoPro cameras are attached on the helmet so that it can capture the whole 360-degree scene surrounding the biker: One front camera, one rear camera, two side cameras: left and right

- Each GoPro camera records video independently and saves the video to its own micro SD card

\subsection{DATA PROCESSING AND SYNCHRONIZATION}

\subsubsection{Data processing}

The videos collected from the GoPro camera have a large field of view. While these videos offer a larger view of the scene surrounding the biker, it often suffers from the distortion artifact caused by the nature of wide-angle lens cameras. The distorted video can significantly affect the accuracy of data analysis and research studies. We therefore preprocess the data to remove the distortion effect. In particular, we use the software GoPro Studio provided by GoPro. Our experiment showed that this software can remove the distortion and the resulting videos have the high quality and clarity necessary for the purpose of this research (see Appendices with pictures that reflect the quality of the data).

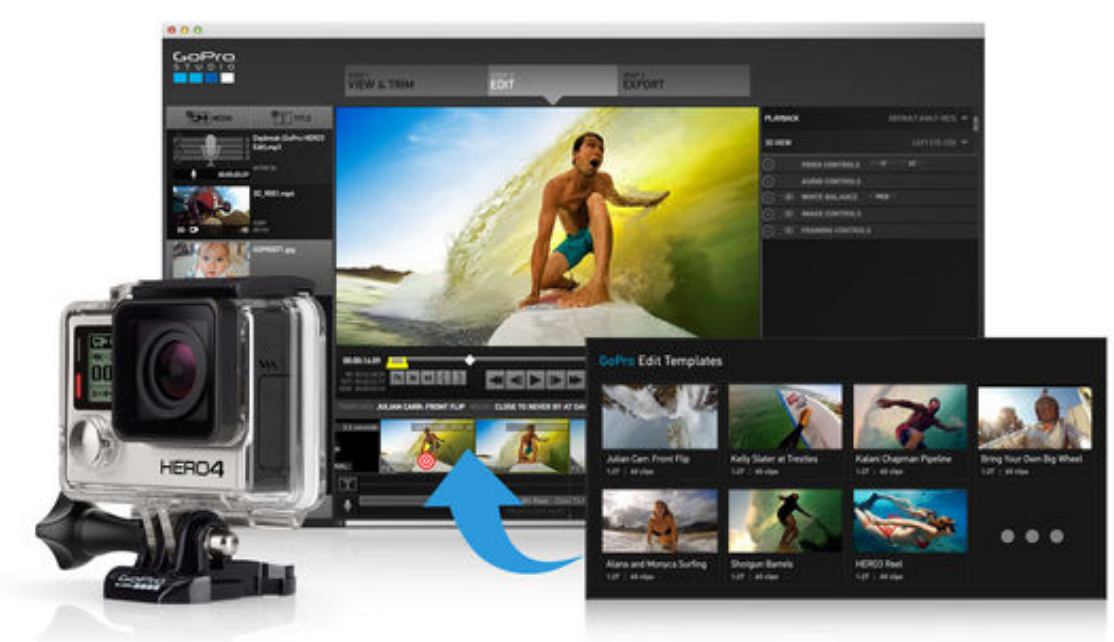

Figure 3.2: Software GoPro Studio is used to correct distortion in our collected videos

\subsubsection{Data synchronization}

We used the sound-based synchronization technique to synchronize data collected from multiple sources. For this reason, all of the independent sensor devices in the VDCH must have a built-in microphone to record sound while recording data. For example, we let the GoPro cameras record voice while capturing video. 
This sound-based synchronization method can sometimes lead to inaccurate results if there is an ambiguous sound or a noisy environment. To avoid this problem, we also made use of the wireless control technique to support data synchronization. In particular, we used the remote control to send signals to all cameras at the same time. Even though there are small differences (latency) across the different cameras, the data are roughly synchronized and ready to be fine tuned (synchronized) accurately using the sound-based synchronization techniques. We utilized off-the-shelf software Red Giant PluralEyes 3.5 to synchronize multiple videos.

Our experiments show that, by following the above described techniques, we can synchronize all four videos with an error of less than half of a second. This small error was sufficient for our current data analysis and research purposes.

\subsubsection{Data visualization}

We developed an interactive software system to help visualize and analyze data collected by the VDCH. This software has the following features:

- It can play multiple videos at the same time.

- It can show video and corresponding sensor data.

- It can visualize the geographical position of the cyclist on a map.

- It can support selecting video segments and taking notes or setting labels on each video segment.

- It can support highlighting object regions in video frames.

- It can support tracking objects in the video.

The figure below provides a screen shot of the video visualization tool. The screens on the left and right show the front video and the route location, respectively. On the right, green font, it is 
possible to read speed, power, torque and any other sensor reading that correspond to the time the left video image was taken.

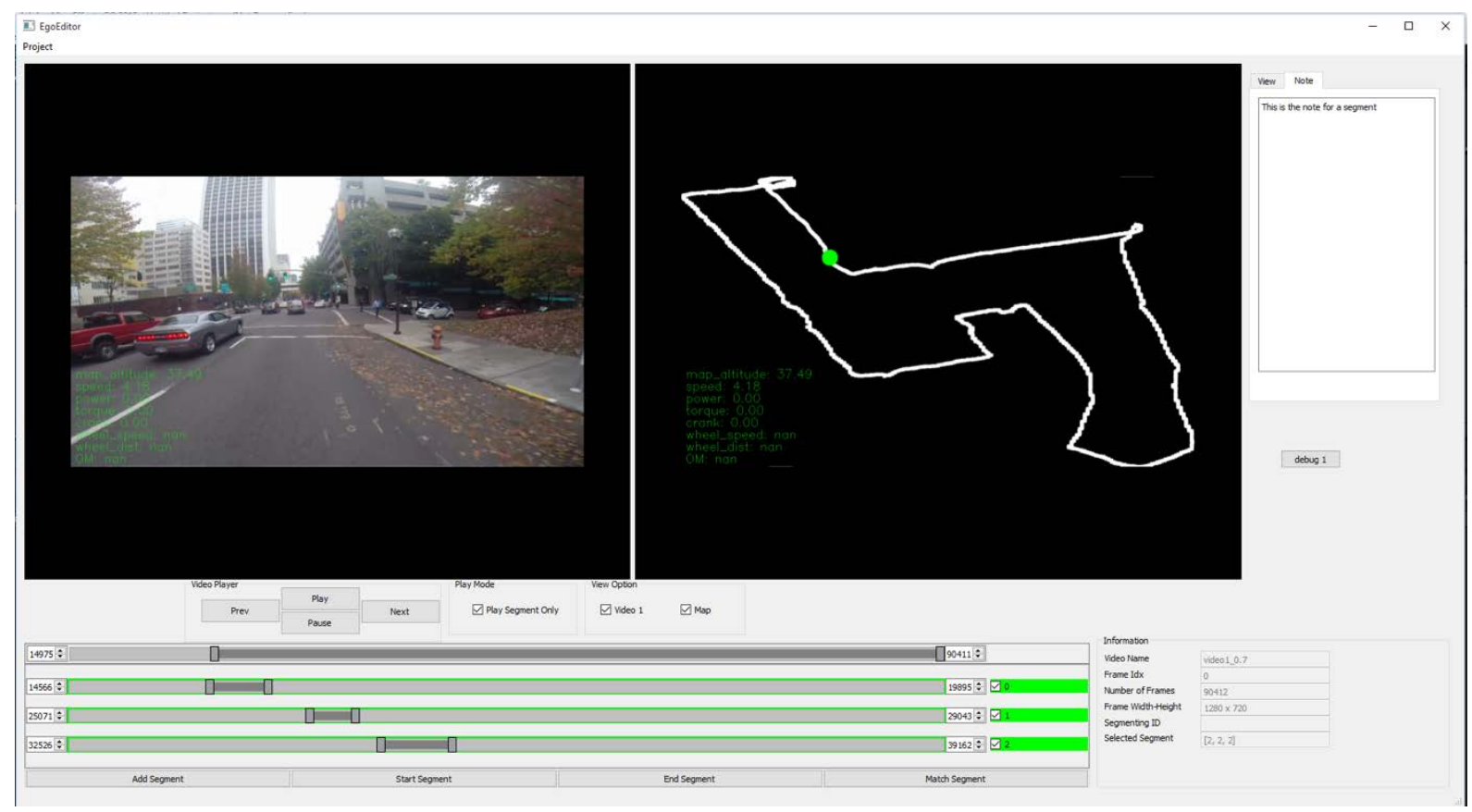

Figure 3.3: Our software for interactive data visualization

\subsection{STRESS DATA COLLECTION}

Based on the literature review, three main physiological measures were found to be relevant for this study: GSR, ECG/EMG and EEG.

\subsubsection{GSR}

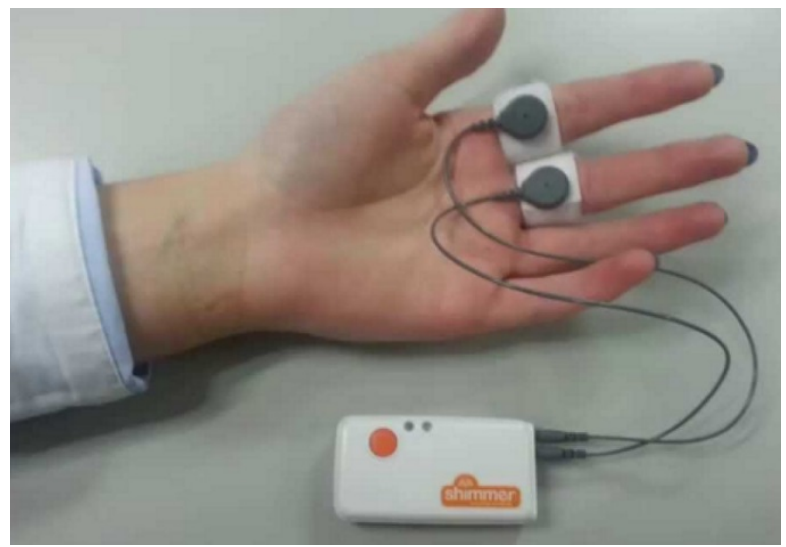

Figure 3.4: Shimmer GSR+

Electrodermal activity, also known as galvanic skin response (GSR), is a process in which skin becomes a better conductor of electricity due to the increase of sweat levels (resulting from an external or internal stimuli, such as biking along various facilities). To measure this 
physiological response, the shimmer GSR+ was used. It monitors skin conductance between two residual electrodes attached to two fingers on one hand. This device allows the user to stream and display real-time data.

The shimmer sensor contains an internal resistor network which works as a potential divider and provides a voltage that can be converted to a value that represents the external skin conductance. Typical skin resistance varies from $47 \mathrm{k} \Omega$ to $1 \mathrm{M} \Omega$ resistance ( $21 \mathrm{uS}$ to $1 \mathrm{uS}$ conductivity). The GSR+ unit was designed to resolve skin resistance levels from $10 \mathrm{k} \Omega$ to $4.7 \mathrm{M} \Omega(100 \mathrm{uS}$ to $0.2 \mathrm{uS})$. (Shimmer sensing, 2015)

Table 3.1: Shimmer sensor specifications

\begin{tabular}{l|l}
\hline Current draw & $60 \mu \mathrm{A}$ \\
\hline Measurement Range & $10 \mathrm{k} \Omega-4.7 \mathrm{M} \Omega(.2 \mathrm{uS}-100 \mathrm{uS})+/-10 \%, 22 \mathrm{k} \Omega-680 \mathrm{k} \Omega$ \\
& $(1.5-45 \mathrm{uS})+/-3 \%$ \\
\hline Frequency Range & $\mathrm{DC}-15.9 \mathrm{~Hz}$ \\
\hline Bias Voltage across GSR inputs & $0.5 \mathrm{~V}$ \\
\hline Weight & $30 \mathrm{~g}$ \\
\hline
\end{tabular}

\subsubsection{ECG/EMG}

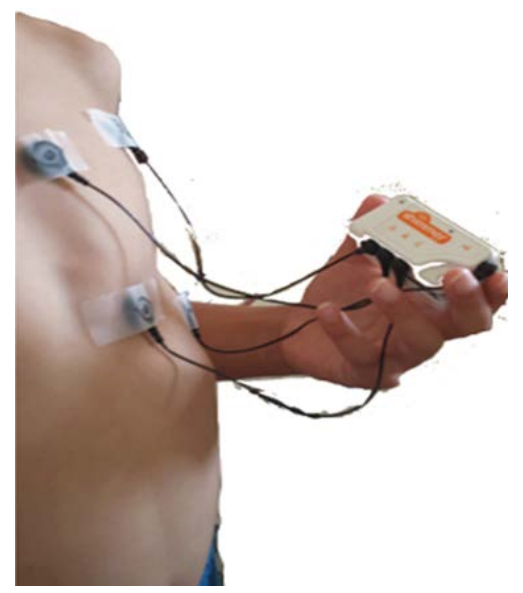

Figure 3.5: Shimmer ECG/EMG

The Shimmer ECG (electrocardiogram) records the pathway of electrical impulses through the heart muscle and can be recorded during exercise to provide information on the heart's response to physical exertion (Shimmer sensing, 2015).

The Shimmer EMG (electromyogram) measures and records the electrical activity associated with muscle contractions, assesses nerve conduction, muscle response in injured tissue, activation level, or can be used to analyze and measure the biomechanics of human or animal movement (Shimmer sensing, 2015). This device allows the user to stream and display real-time data. 


\subsubsection{EEG}
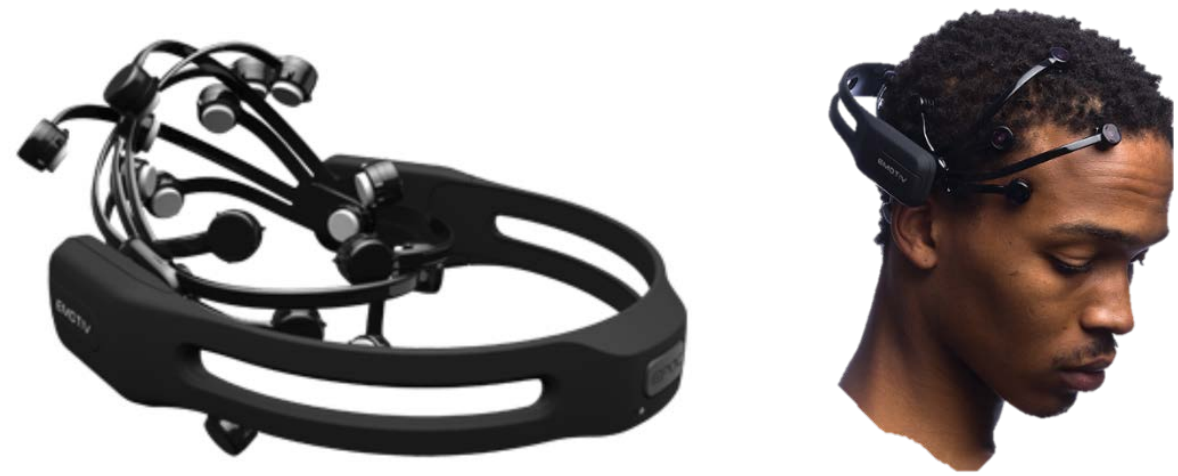

Figure 3.6 : Emotiv sensor

An electroencephalogram (EEG) detects and records electrical activity in the brain. Brain cells communicate via electrical impulses that can be measured and recorded utilizing an EEG. The electrical impulses can give information about the emotional state of the subject. Emotiv EPOC is a portable sensor with 14 channels that allow users to measure EEG (EMOTIV, 2015). It can monitor the subject's emotional states in real time, but unfortunately it is not possible to access the raw data easily.

After a careful review of the GSR, ECG, and EEG equipment and contacting the manufactures of the products, the researchers decided to only measure stress using a GSR device. GSR had several advantages such as user friendliness and, moreover, a proven track record in the stress literature. The authors acknowledge the Transportation Technology and People (TTP) and the Maseeh College of Engineering and Computer Science for purchasing the GSR equipment.

\subsubsection{Instrumented bicycle}

Cycling effort and sweating may affect stress levels. Hence, it was necessary to instrument a bicycle to measure speed, torque, and power along the cyclist's route. The bicycle used for this research was selected based on its adaptability (i.e., easy to customize) for cyclists of different heights and body shapes. The bicycle has a lowered top tube and handlebars for upright riding (see figure below). The bicycle was mounted with a power meter to measure the subject's cycling performance (power, torque, wheel speed and distance, and crank cadence). Performance data and temperature $\left({ }^{\circ} \mathrm{F}\right)$ measures were collected to separate stress GSR from energy input GSR (increase of sweating as a result of cycling activity and heat). Detailed GPS data with a frequency of $1 \mathrm{~Hz}$ was collected utilizing a smartphone. 


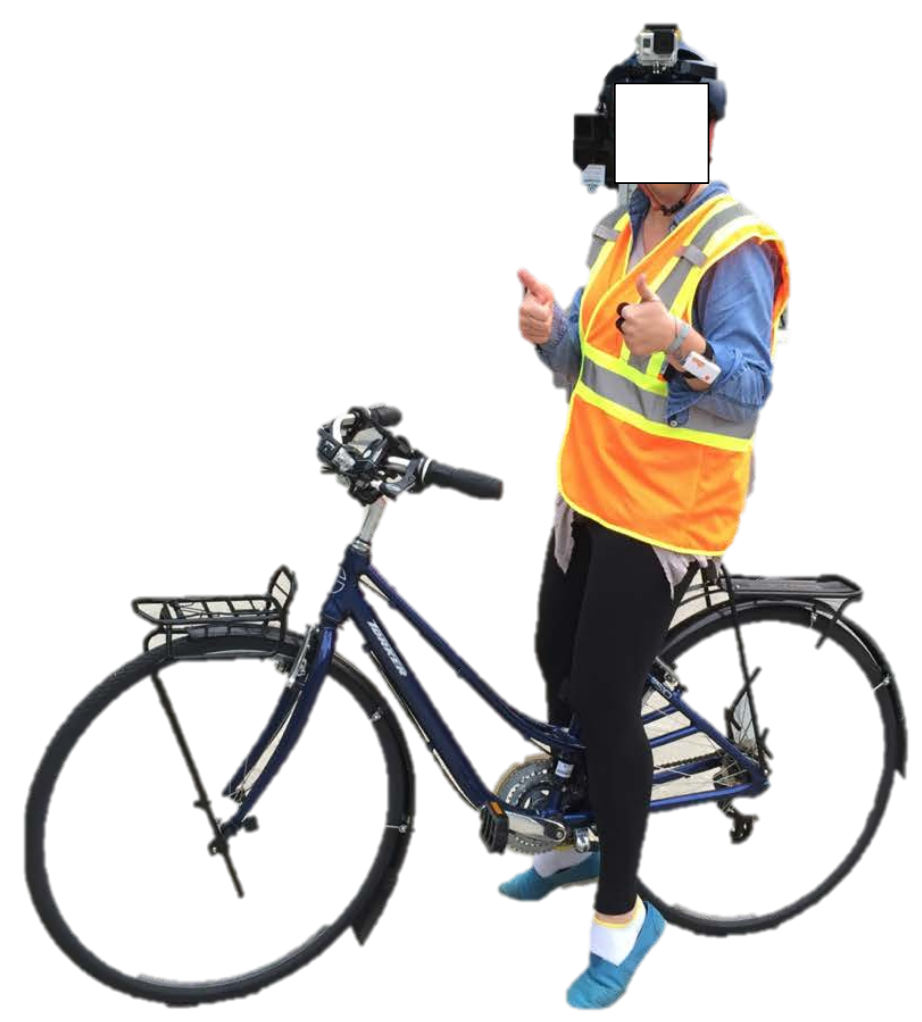

Figure 3.7: Equipment and sensors used for the research

\subsection{GSR DATA PROCESSING}

GSR data can show high-frequency fluctuations (Picard, Vyzas, \& Healy, 2001). Raw data was smoothed by a moving average with a size of five seconds. Then, GSR was normalized following the methodology used in most GSR studies:

$$
\text { Normalized_GSR }=\frac{\left(r a w_{-} G S R-\text { average_relaxation_GSR }\right)}{\text { average_relaxation_GSR }}
$$

Figure 3.8 shows typical features of a GSR signal: latency, amplitude, rise time, and half recovery time (Healy J. , 2000). GSR onset occurs a few seconds after (latency) the stimulus is experienced. Some studies suggest that GSR within a time window of 1-5 seconds are attributed to stimulus (Picard, Vyzas, \& Healy, 2001) (Prokasy \& Raskin, 1973). The amplitude (GSR) of the signal is the physiological response of the subject to the stimulus. It decreases until the subject achieves its normal physiological state if no more stimuli are experienced. 


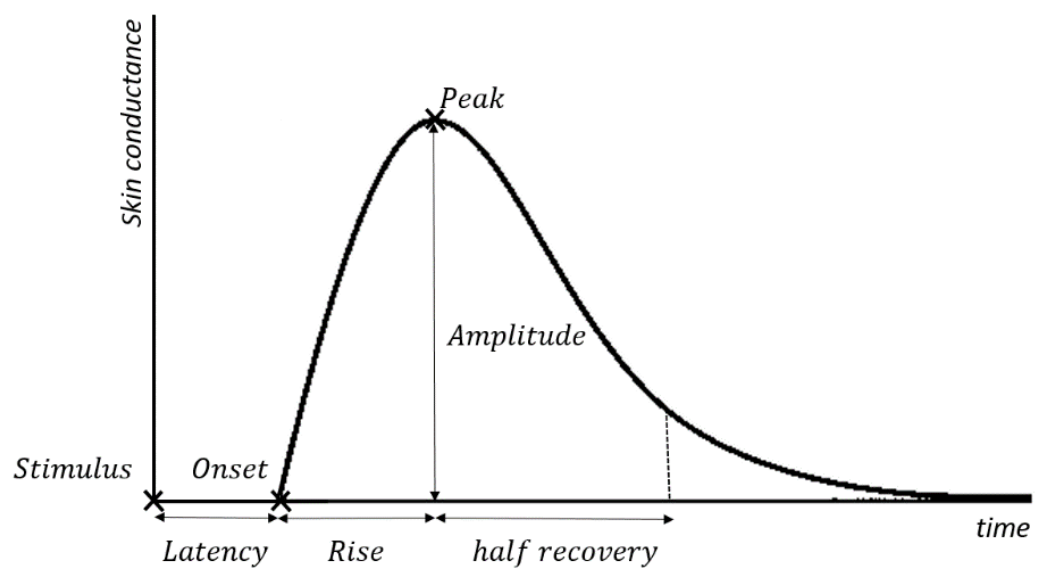

Figure 3.8: GSR signal features

In the case of overlapping curves, when GSRs occur on the recovery (or rise) of previous responses, the features were measured following the methodology proposed by Healy (2005), and Healy and Picard (2000): The stress responses (GSR) were identified by first detecting changes in slope, then finding the local minimum and local maximum preceding and following that point, respectively (as is shown in Figure 3.9).

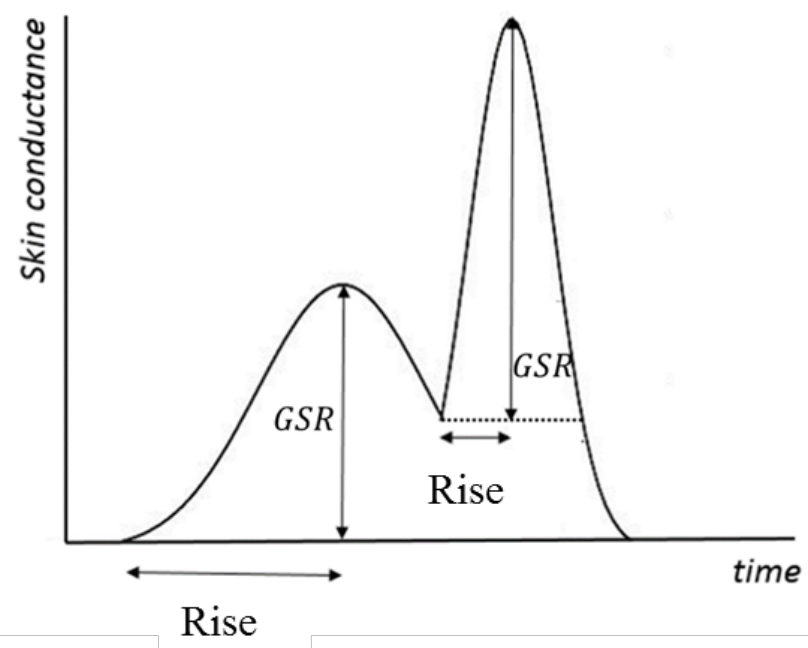

Figure 3.9: Overlapping GSR signals (based on Healy and Picard, 2000)

With this method four features were calculated: total number of responses, sum of responses, sum of the duration of responses (Rise) and frequency of responses. These features were used to investigate how various characteristics of the trip affect stress levels. 



\subsection{DATA COLLECTION METHODOLOGY}

To answer the three research questions, the data collection effort was designed to capture video data and at the same time monitor cyclists' physiological reactions (GSR) under real-world cycling situations, such as different types of bicycle facilities and varying traffic volumes. Multiple and single subject data collection efforts were undertaken. A rigorous data collection protocol was followed to reduce variability and to preserve data quality.

\subsection{STUDY ROUTE DESCRIPTION}

The researchers recorded bicycle videos in the Portland, OR, metropolitan area in both downtown and surrounding areas. During seven days in 2015 (including weekends), video, GSR and GPS data was collected for the same route in Portland. The route was comprised of segments with four distinct types of bicycle facilities: a shared roadway with mixed traffic conditions (1.49 $\mathrm{km})$, urban streets with bike lanes $(2.27 \mathrm{~km})$, a multiuse path I $(0.74 \mathrm{~km})$, and a multiuse path II $(3.20 \mathrm{~km})$; see figure below.

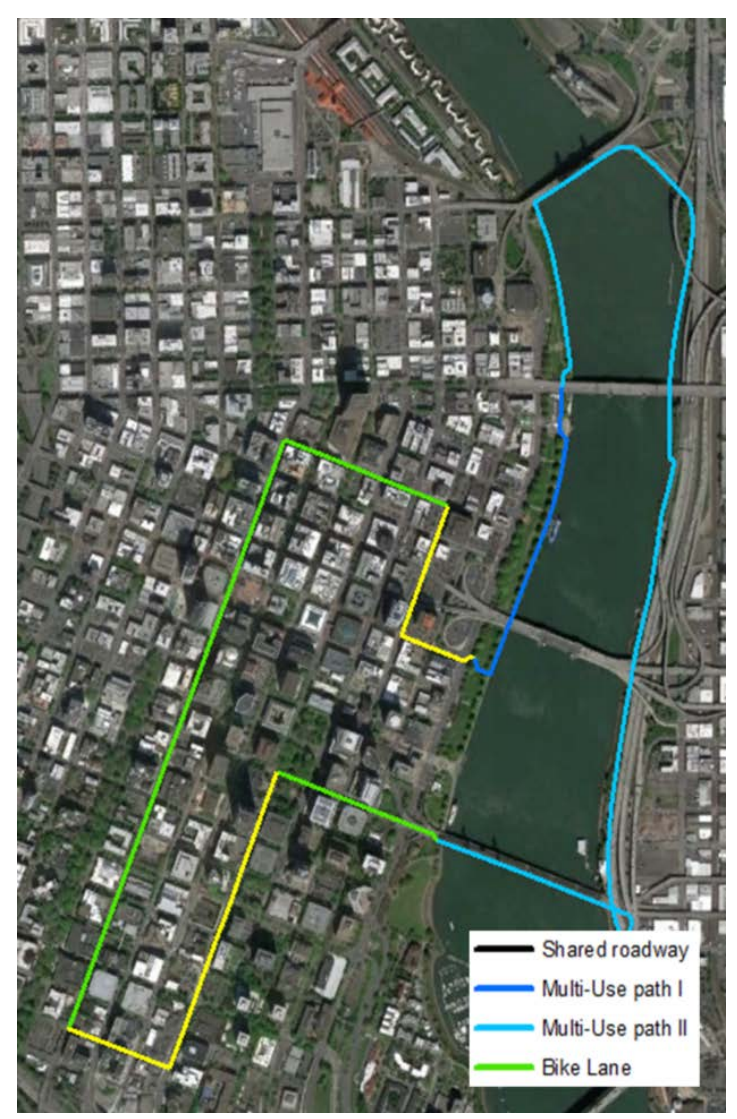

Figure 4.1: Research route 
Data was collected at morning peak and off-peak hours. Each of the facility types are defined and described herein; additional photos during peak and off-peak travel can be found in Appendix A.

\subsubsection{Shared roadway}

Shared roadways are the facilities where the cyclist has to share the street with motorized vehicles and there are no separated bicycle facilities. For this project this type of facility had a length of 1.49 kilometers.
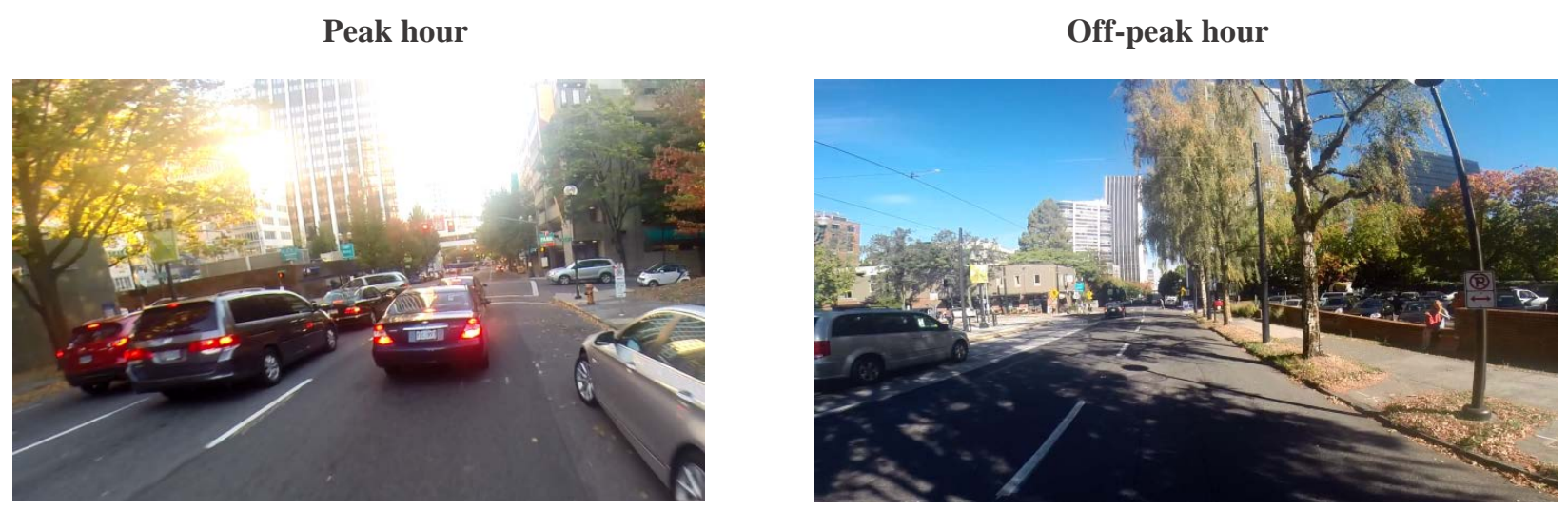

\subsubsection{Bike lane}

Figure 4.2: Shared roadway facilities - peak (left) and off-peak hour (right)

Bike lanes are facilities where the cyclists ride through a delineated exclusive bike lane; drivers cannot utilize this lane. For this project several types (widths) of bike lanes were included in this category, and the only restriction was having a clearly demarcated lane. For this project this type of facility had a length of 2.27 kilometers.

Peak hour

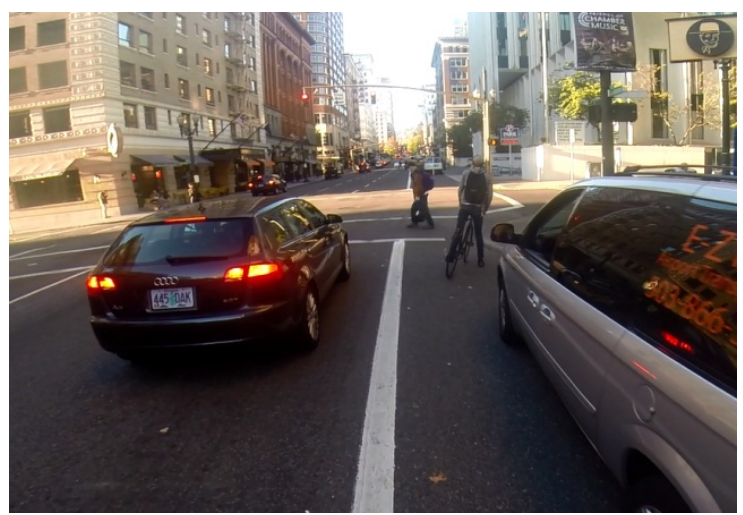

Off-peak hour

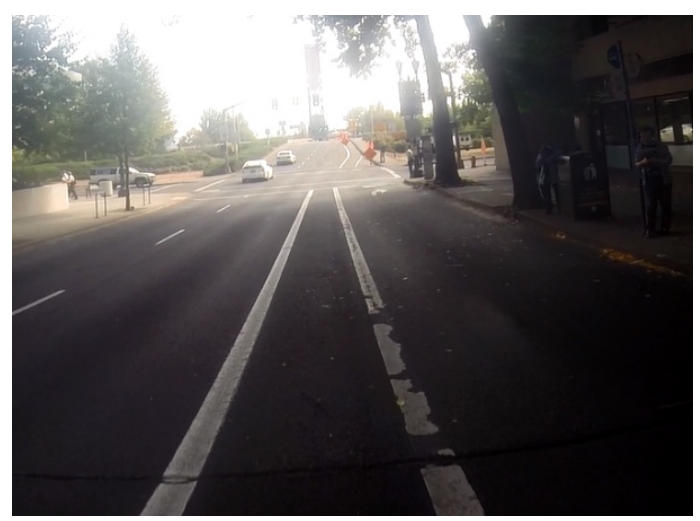

Figure 4.3: Bike lane facilities - peak (left) and off-peak hour (right) 


\subsubsection{Multiuse path I}

A multiuse path is physically separated from motorized traffic and used only by pedestrians and cyclists. This facility was categorized into two levels due to the significant differences in pedestrian volumes: multiuse path I had significantly higher volumes of pedestrians than multiuse path II. For this project this type of facility had a length of 0.74 kilometer.

Peak hour

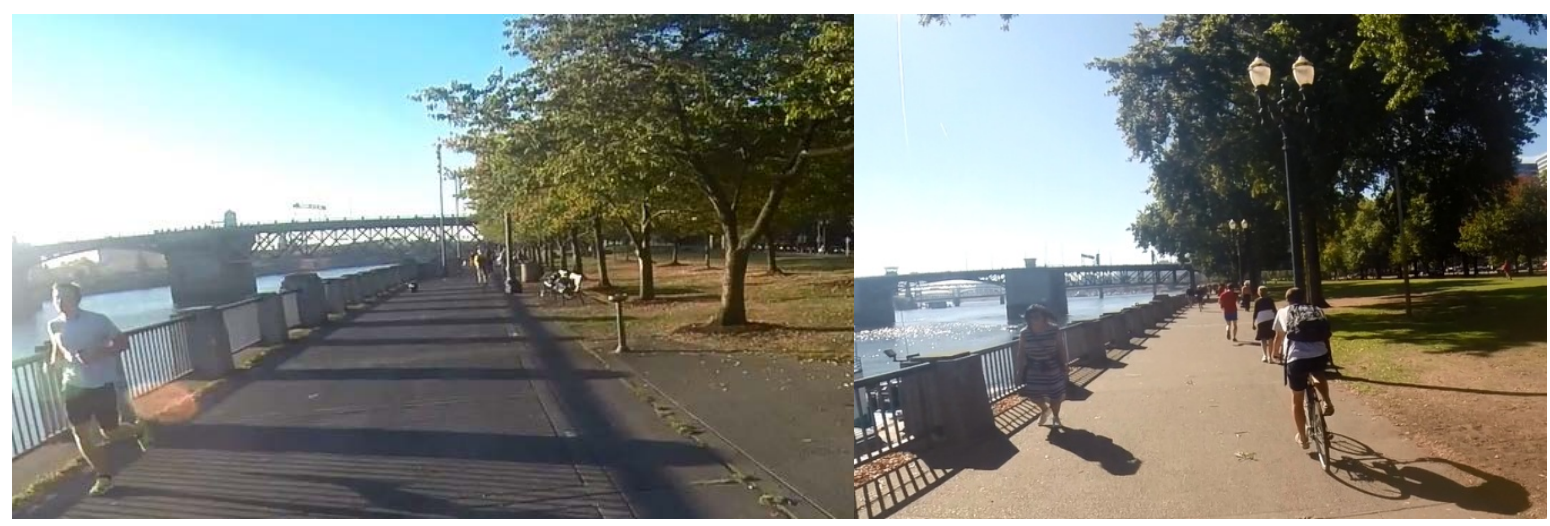

\subsubsection{Multiuse path II}

Figure 4.4: Multiuse path I facilities - peak (left) and off-peak hour (right)

Multiuse path I had significantly higher volumes of pedestrians than multiuse path II. For this project multiuse path II had a length of 3.20 kilometers.

Peak hour

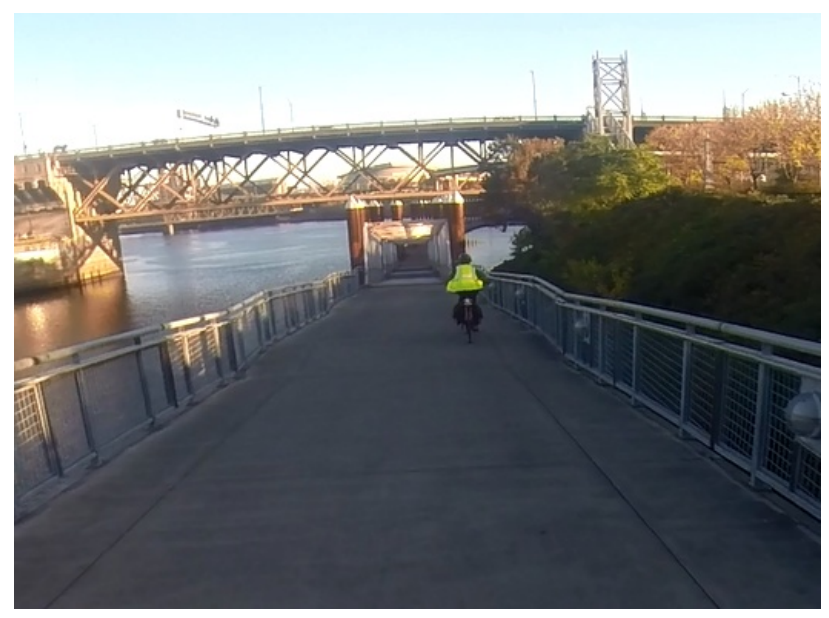

Off-peak hour

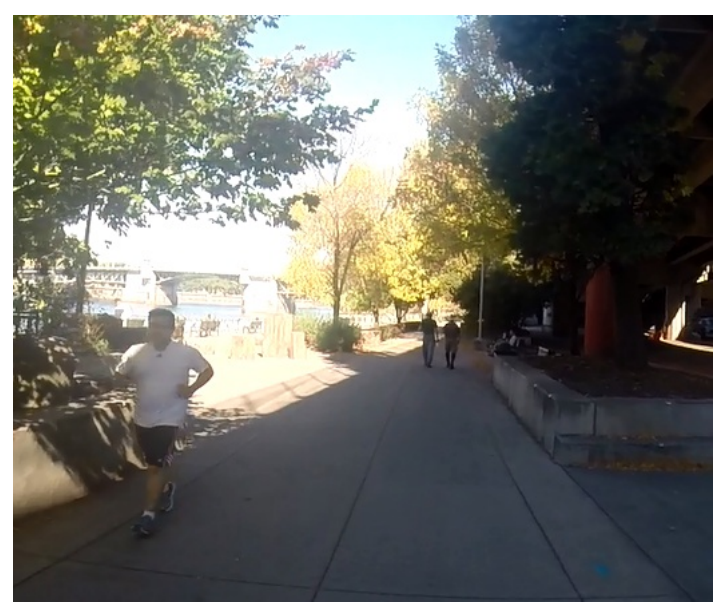

Figure 4.5: Multiuse path II facilities - peak (left) and off-peak hour (right)

\subsection{DATA COLLECTION I: MULTIPLE SUBJECTS}

This research and data collection was design -d to utilize video and also monitor cyclists' physiological reactions (GSR) under real-world cycling situations, such as different types of 
bicycle facilities and varying traffic volumes. Based on published findings previously discussed, GSR data collected from cyclists is assumed to be directly related to stress levels.

The experiment consisted of two parts. Firstly, we collected data for various subjects for one day per subject to understand the capabilities of GSR measuring methods in this specific field and to identify the main causes of stress. Secondly, we collected data for multiple days with only one subject. Studying stress responses for one subject for several days was helpful to reduce intersubject variability, as each subject may respond differently when faced with the same stressful event.

The first part was conducted during seven days in 2015 (including weekends). The route was already described earlier in this section. GSR signals were also collected for five minutes before the ride to establish a baseline state for the subject; subjects' characteristics are contained in Table 4.1. The subjects had to follow the same procedure and ride through the same route. It is important to observe that one of the subjects did not have any experience (i.e., the subject never utilized a bicycle for commuting). It was hypothesized that this subject would be more stress sensitive to external stimulus, such as traffic and vehicle speed.

Table 4.1: Subjects' characteristics

\begin{tabular}{l|l|l|l}
\hline Subject & Gender & Age & $\begin{array}{l}\text { Experience biking for } \\
\text { commuting }\end{array}$ \\
\hline Subject \# 1 & Male & 33 & More than 3 years \\
\hline Subject \# 2 & Male & 25 & More than 3 years \\
\hline Subject \# 3 & Male & 24 & $\begin{array}{l}\text { Between 1 and 3 years of } \\
\text { experience }\end{array}$ \\
\hline Subject \# 4 & Male & 30 & No experience \\
\hline Subject \# 5 & 22 & $\begin{array}{l}\text { Between 1 and 3 years of } \\
\text { experience }\end{array}$ \\
\hline
\end{tabular}

The subjects took between 24 to 27 minutes to complete each ride, depending on the day of the week and time of the day (peak vs off-peak hours), resulting in a total of approximately seven hours of video and GSR data.

Video and GSR peak data suggest that stress levels increase at locations where the riders feel more threatened, when the path is blocked, or where decision making is more complex. The quantification of stress levels is not only novel but also aligns well with previous research results. For example, researchers found that cyclist levels of comfort are directly related with proximity to motorized traffic (Kim, Kim, Ulfarsson, \& Portello, 2007) (Chuang, Hsu, Lai, Doong, \& Jeng, 2013). The findings suggest that bike lane presence, crossing traffic volume, speed limit, speed parking, traffic signals, and crossing distance affect levels of service and comfort at intersections (Carter, Hunter, Zegeer , \& Stewart, 2007) (Landis, Vattikuti, Ottenberg, Petritsh, Guttenplan, \& Crider). In terms of the route, bicycle paths separated from traffic have been found to be preferred by users (Garder, Leden, \& Pulkkinen, 1998) (Sener, Eluru, \& Bhat, 2009) (Winters, Davidson, Kao, \& Teschke, 2011). Models utilizing data from a smartphone app (ORcycle) that focuses on measuring comfort levels also show that traffic and commercial vehicles are the most important factors that decrease cyclists' comfort levels. 
Unlike previous research efforts, it is possible now to identify (see video and photo) of the specific event that triggered a response, e.g. a bus driver blocking the cyclist by invading the bicycle lane to reach a bus stop. Appendix B contains a description and photo of the most stressful events.

\subsection{DATA COLLECTION II: SINGLE SUBJECT}

For the second part of the experiment, we used another subject to collect data for seven days during peak and off-peak hours (including weekends) for the same route. This subject was a cyclist who commuted every day to and from work by bicycle (travel distance 4.5 kilometers, travel time 25 minutes).

\subsection{DATA COLLECTION PROTOCOL}

Video was recorded utilizing the helmet described in a previous section. GSR signals were recorded during the ride using the Shimmer3 GSR+ sensor, which has been validated for accuracy by many research studies in fields ranging from sports medicine to vehicular and environmental monitoring (Shimmer sensing, 2015). This sensor is a noninvasive device consisting of one monitor and two electrodes.

The GSR monitor was mounted on the arm of the subject's nondominant hand and the electrodes were attached to two fingers. Normally, electrodes are attached to the middle of the three segments of the first and middle finger, on the palm of the nondominant hand; however, this placement would cause problematic contacts that could interfere and distort signals while riding a bicycle. Fowles et al. (1981) found that GSR signals are not affected by the contact area, as long as areas of the skin with different potentials are not connected together. They suggest placing the electrodes on any site of the thenar and hypothenar eminences of the nondominant hand (Fowles, et al., 1981). Other factors, such as hand washing (Picard, Vyzas, \& Healy, 2001) (Fowles, y otros, 1981), were taken into account before placing the electrodes to decrease the error in the GSR measurements. GSR data was sampled at $50 \mathrm{~Hz}$. GSR signals were also collected for five minutes before the ride to establish a baseline state for the subject.

To participate in the experiment each subject was required to consent to cycle defensively and to obey all traffic signals during the rides. Before the first ride, the subject reviewed the study route with the researcher and had the opportunity to ask questions (if necessary).

All the riders were asked to follow these steps:

- Step 1: Biker wears the helmet, adjusts the helmet and the cameras to the most comfortable position.

- Step 2: Biker uses the remote control to start recording video and sensor data.

- Step 3: Biker rides the bike on the street collecting data.

- Step 4: Biker stops riding, and uses the remote control to stop recording data. 
After each ride the research assistant connects the sensors to a computer to store the data for posterior analysis. 


\subsection{DATA ANALYSIS}

This sections analyzes the data collected. The first subsection details the type of events that increased riders' stress levels; associated video was analyzed and a photo that illustrates the event is included. Later subsections analyze the impact of traffic conditions, intersections, and bicycle facilities on stress levels.

\subsection{TYPICAL STRESS EVENTS}

The multisubject data was analyzed to identify the main causes of cyclists' stress. The table below contains information about the subject, facility type, photo, and event type. Events are ordered by subject and within subject by decreasing level of relative stress (Ratio, which is calculated by dividing normalized GSR value by rise).

More than 20 events stood out based on their unusual level of stress. The results clearly show that close encounters with vehicles, other cyclists, or pedestrians show an increase in the stress levels. In addition, obstacles on the road tend to generate stress. Traffic signals can also be stressful, in particular if the subject is crossing during the yellow interval. In general, the most stressful events are situations where a vehicle blocks the cyclist's movement or moves dangerously close to the cyclist.

Table 5.1: Stressful events

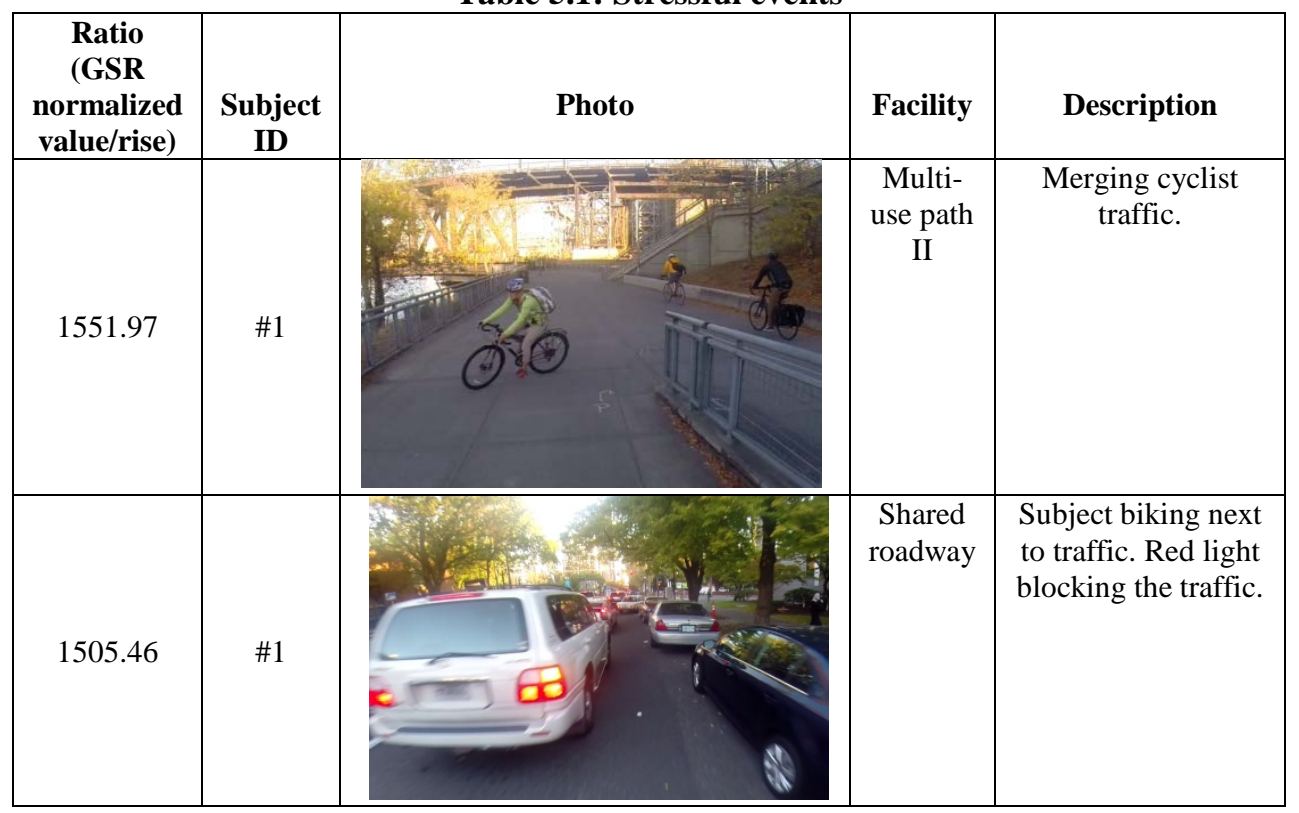




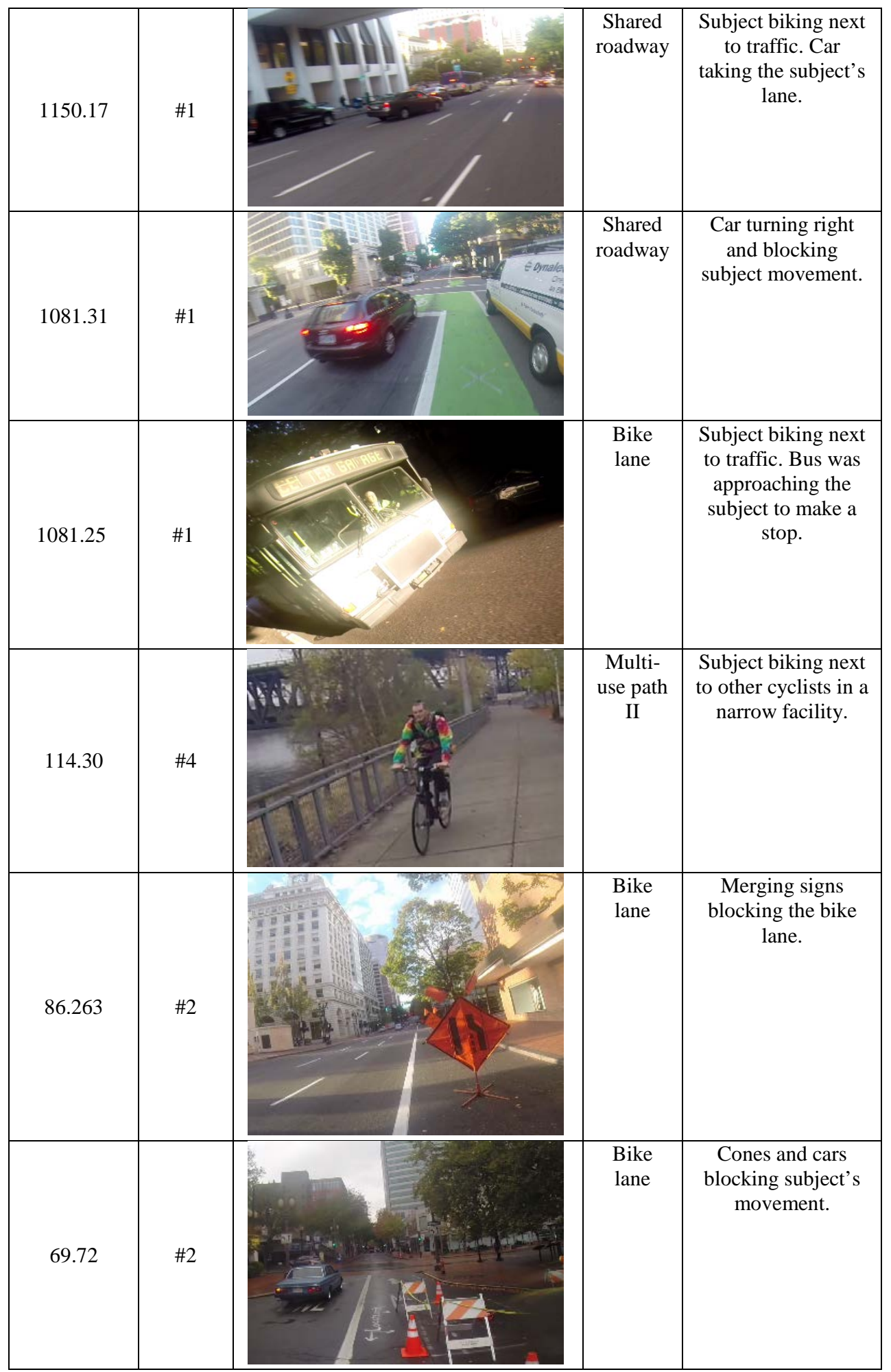




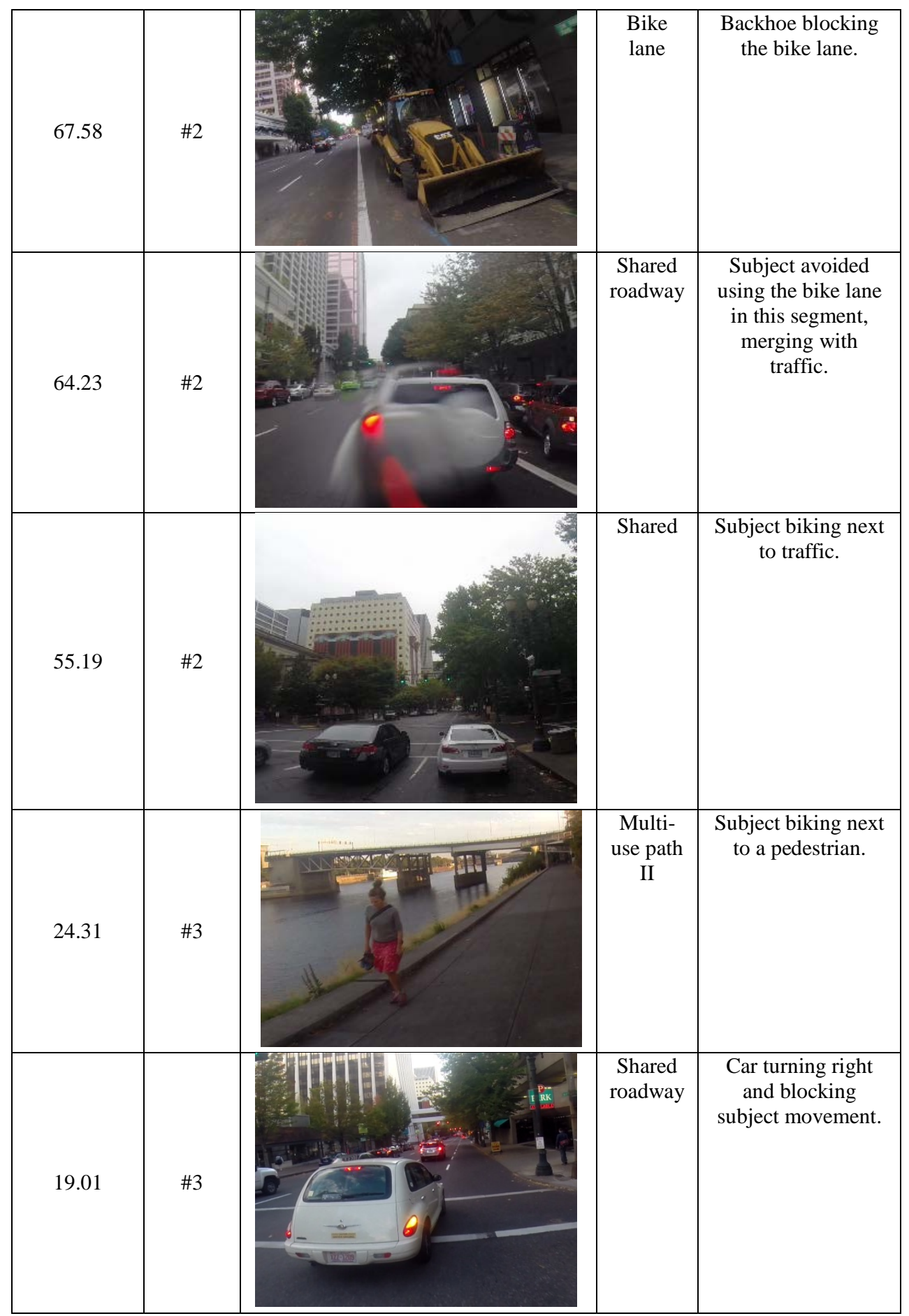




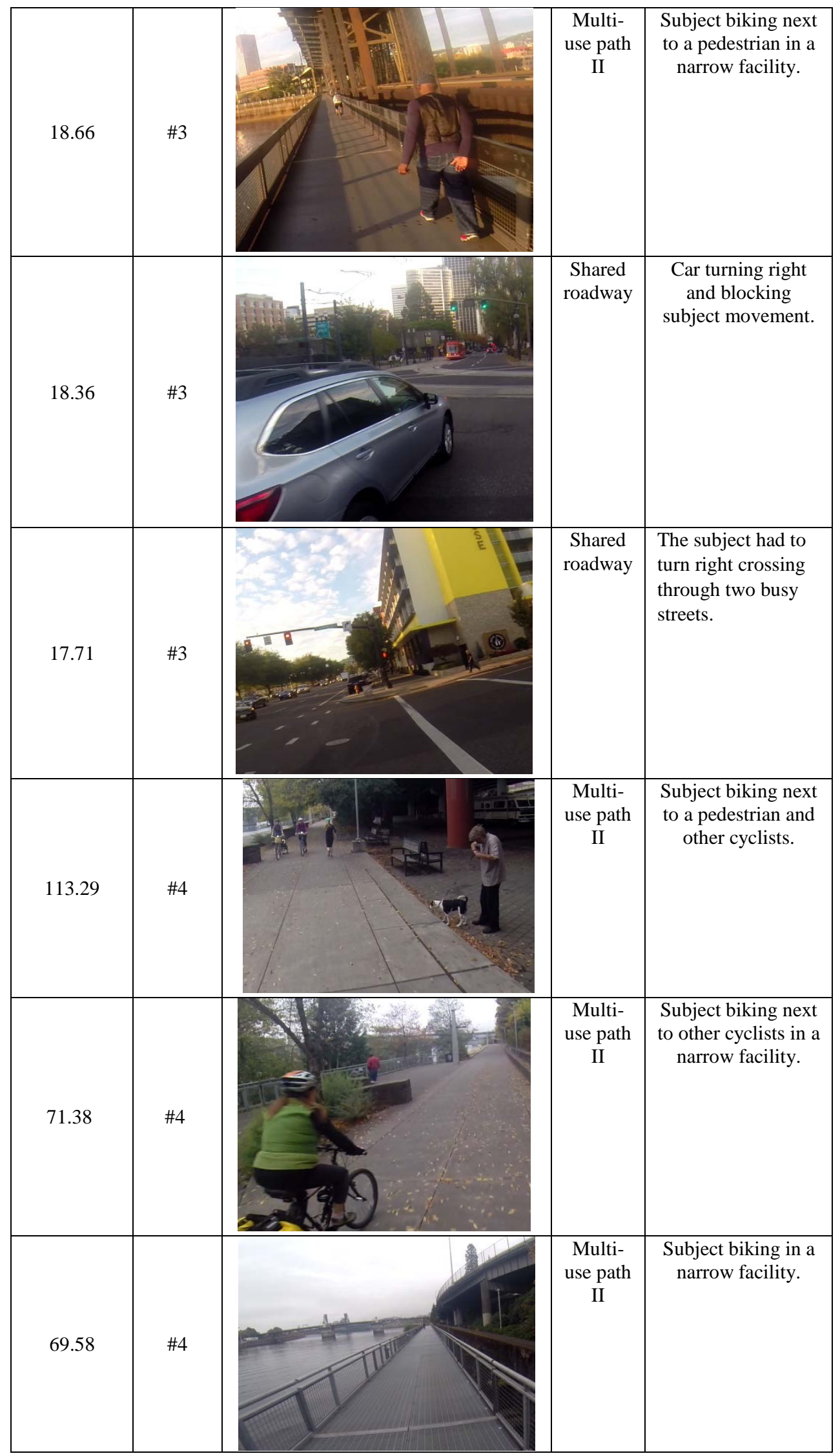




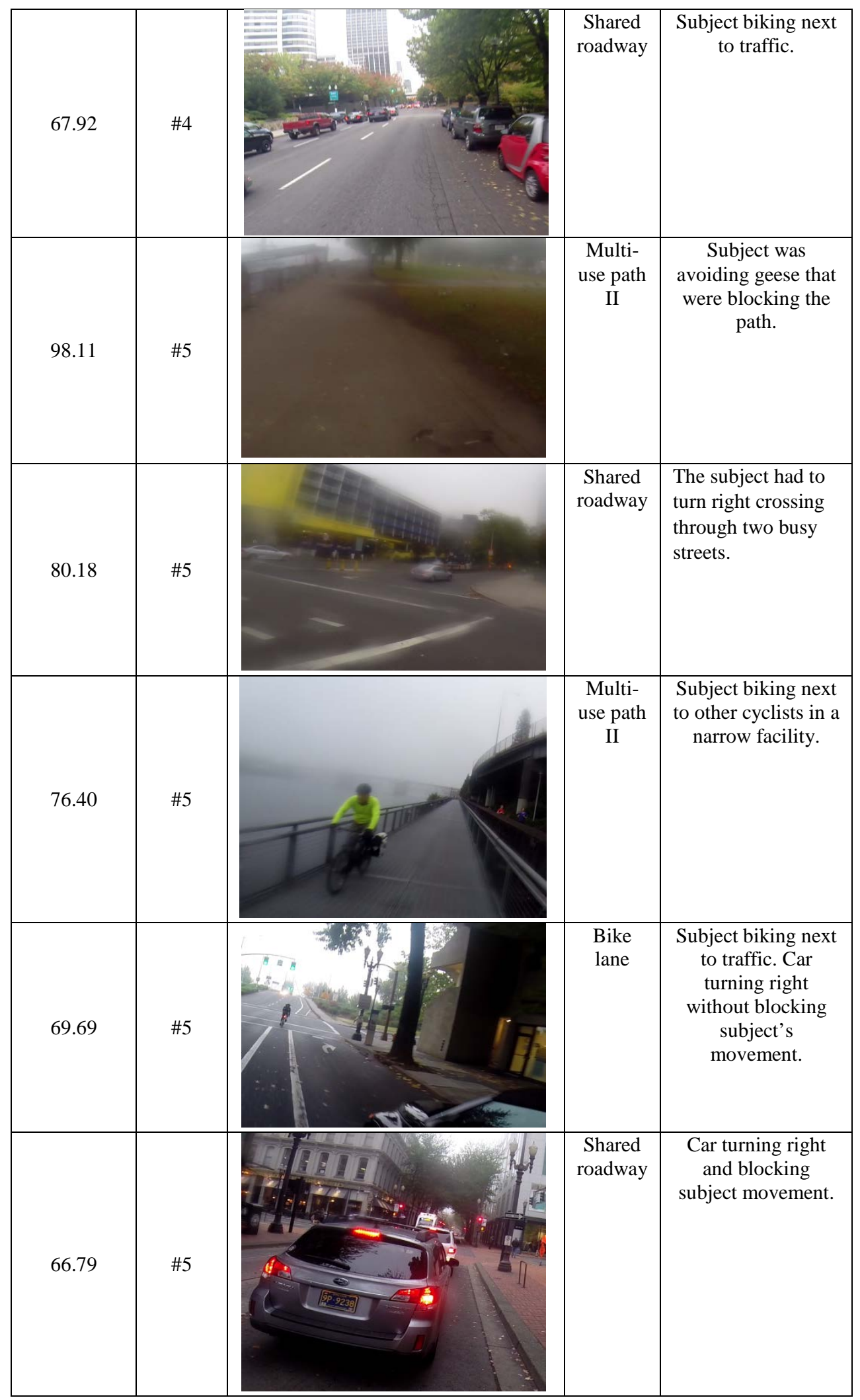


Comparing the stress measures with the videos recorded, we observed that the GSR sensor was able to capture stress responses to traffic conflicts. The findings suggest that most of the subjects felt stressed while biking next to traffic (shared roadway and bike lanes); when the bike lane was blocked by cars, people and traffic signs; and when the facility was narrow. When the subjects were biking in a multiuse path, the stress levels were relatively higher when other cyclists and pedestrians were moving closer to the subject's path. It is also interesting to notice that subjects felt particularly stressed when cars were turning ahead, even if there was a relatively safe distance between the cyclist and the vehicle. The majority of the stressful events took place at bike lanes. Summarizing, all the subjects showed increases in stress levels in events where the cyclist's path was obstructed or where vehicles were conflicting with the cyclist's trajectory. The least stressful events are related to lack of changes in the environment (e.g., riding alone along a straight segment).

To visualize the impact of bicycle facilities, Figure 5.1 shows the locations with the highest stress levels along the route; this map was made by standardizing stress levels across subjects and then identifying hotspots of stressful events. To standardize stress level, for each subject we identified the events with stressful levels above two standard deviations from the mean (we hypothesized these were the most stressful events). After having all these events identified for the different subjects, we merged this information to create a hotspot map. Locations with high stress levels represent locations with high density of events above two standard deviations. Most of the stressful sections are located at bike lanes and shared roadway facilities. Throughout the facilities that were completely separated from traffic the subjects didn't experience significant levels of stress. For one section of the bike lane (west), levels of stress changed because its design changed from a nonprotected to protected (buffered) bike lane; the one-way protected bike lane is combined with a parking lane that provides a physical barrier between the bike lane and the vehicle travel lane. From Figure 5.1 we can also observe that the most stressful event is located at an intersection with high volumes of traffic and two merging lanes. Finally, the findings suggest there is also a stressful event at the end of the Hawthorne Bridge section. This can be explained by the change from facility type (from bike lane to multiuse path) and the design of this connection, which is a curvilinear ramp. 


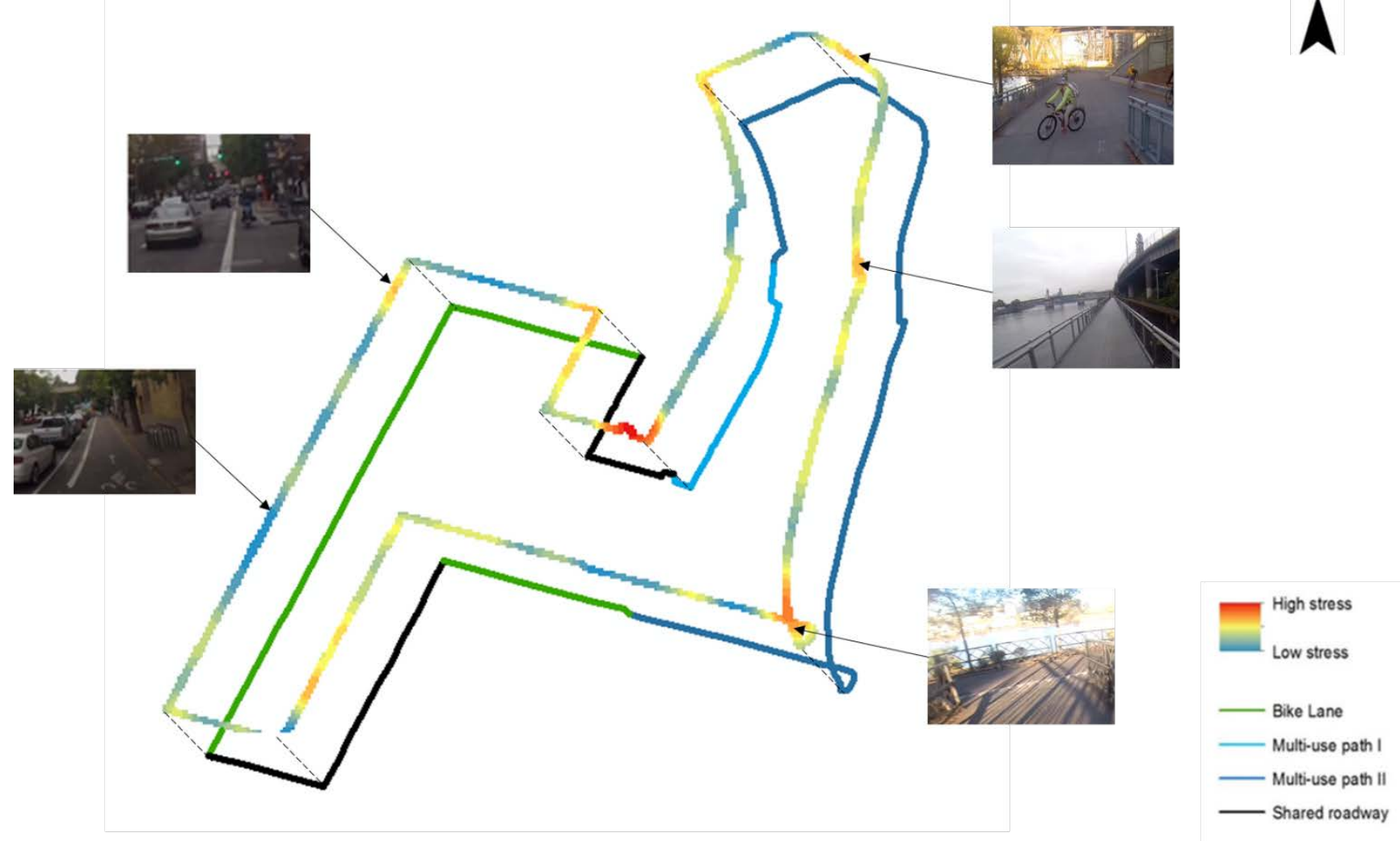

Figure 5.1: Multisubject stress levels across bicycle facilities

\subsection{TRAFFIC CONDITIONS}

To reduce variability and increase the number of observations varying only one variable at the time, data collection efforts focused on many bicycle trips utilizing a single rider. The same route was travelled at peak and off-peak traffic times.

To compare GSR levels at peak and off-peak times, an ANOVA test was used. Test results indicate that GSR levels at peak hours are higher than GSR levels at off-peak hours with a significant difference (p-value $<0.05$ ). The ratio of GSR levels at peak to off-peak hours was 1.75. Figure 5.2 shows how stress levels differed across various facilities when the subject was riding at peak and off-peak hours. 

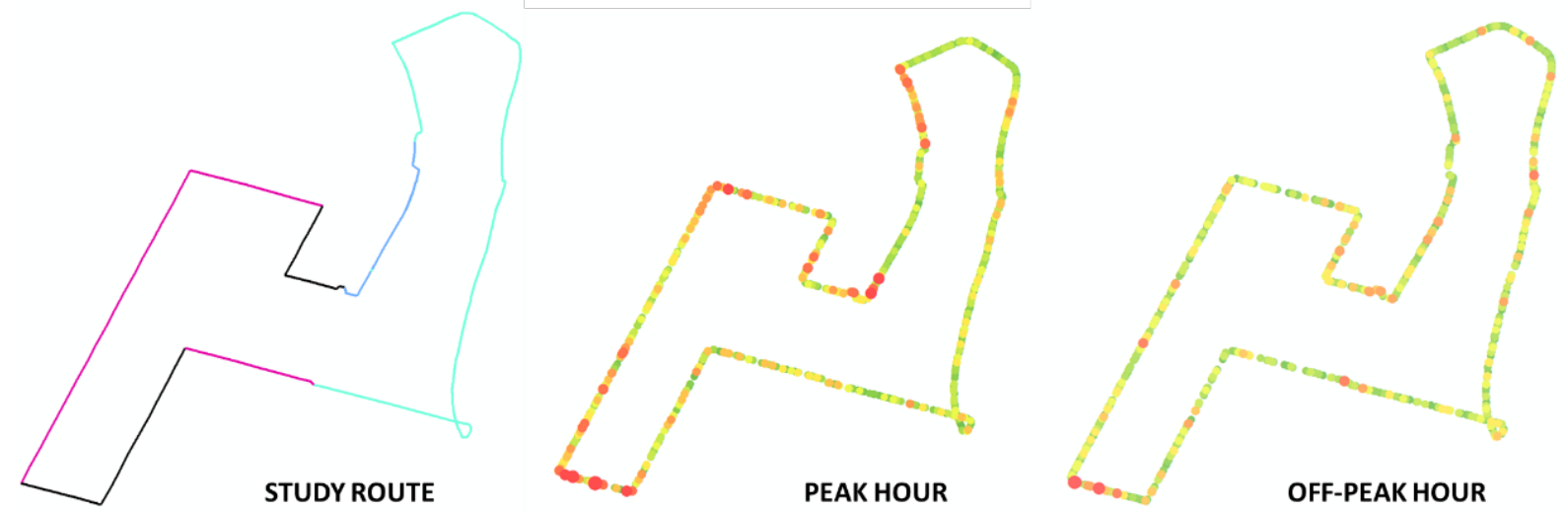

- $0.05-0.25$

$0.26-0.48$

$0.49-0.74$

$0.75-1.02$

1.03- 1.39

$1.40-1.89$

2 $1.90-2.72$

2.73- 4.46

$4.47-7.02$

- $7.02-14.88$

Figure 5.2: Stress levels across the bicycle facilities

The only variable that changes is time of day; morning peak hours resulted in more stressful rides for cyclists due to higher traffic volumes. Stressful events tended to occur mostly at locations where the subject was riding in a shared roadway or in a bike lane adjacent to mixed traffic. At off-peak hours, GSR tended to be low across facilities with few peaks on shared roadways.

\subsection{INTERSECTIONS}

Most of the stressful events were located at intersections where the cyclist had to be more aware of motorized traffic movements. Figure 5.3 below shows that at peak hours, GSR levels for signalized intersections were higher than stress levels for segments of the route, with a statistically significant difference (p-value $<0.05$ ). The ratio for GSR level for signalized intersection to corridor was 1.7. At off-peak hours GSR levels between route segments and signalized intersections were not statistically different.

Comparing signalized intersections at peak hours against off-peak hours, the subject was more stressed during peak hours (p-value $<0.05$ ). At signalized intersections, the ratio for GSR levels of peak to off-peak hours was 1.5. To investigate stress at segments, the intersections were excluded to avoid the interference of high GSR levels reported at these locations. The ratio of GSR levels for segments of the route for peak to off-peak hours was 1.3 (p-value $<0.05$ ). Figure 5.3 shows the ratio of GSR levels for segments and intersections to GSR levels at intersections during peak hours. During off-peak hours the GSR ratio decreases for intersections and segments relative to the stress experienced at intersections during peak hours. 


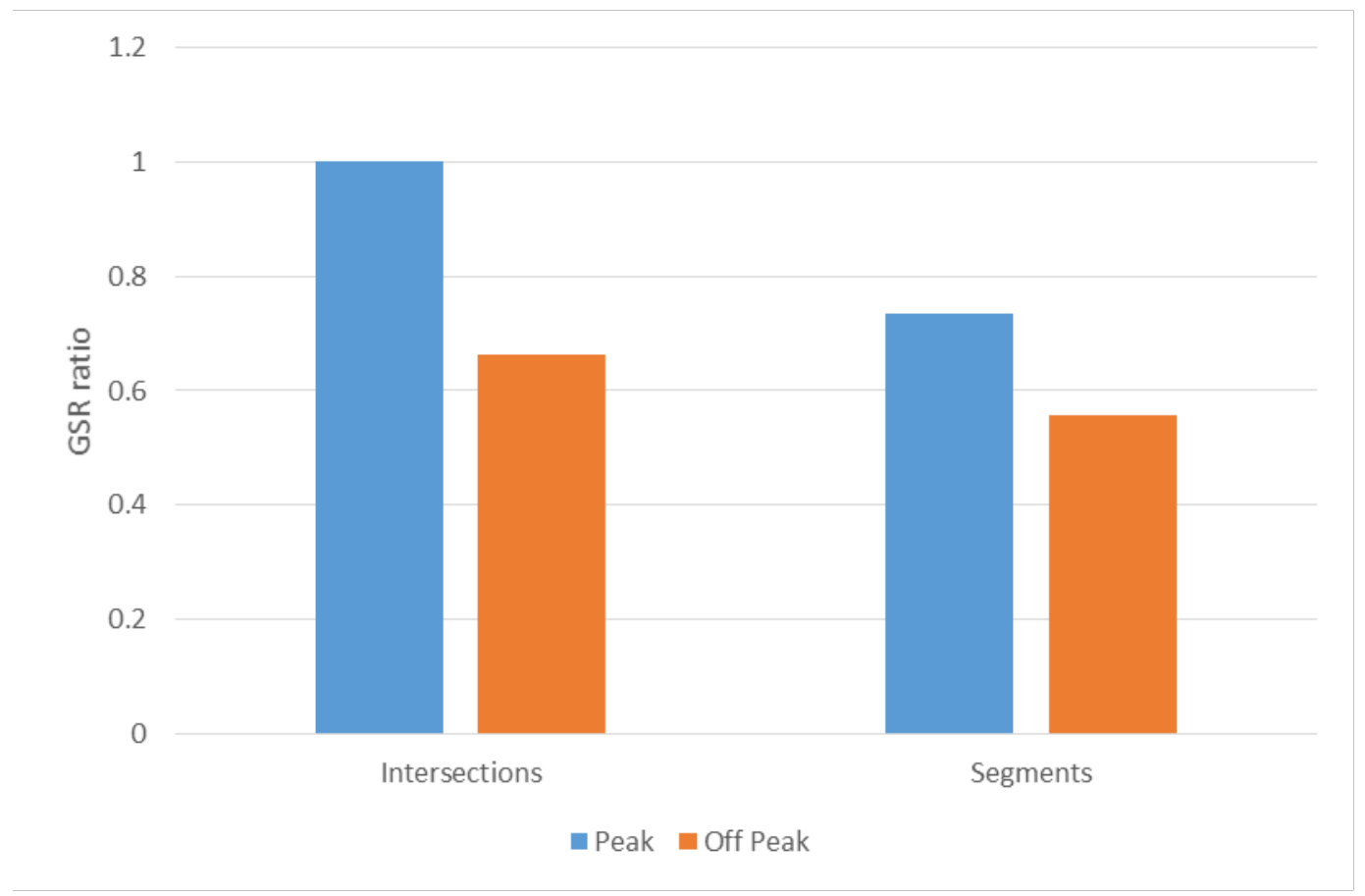

Figure 5.3: Signalized intersection vs segment GSR ratios

\subsection{FACILITY TYPE}

Figure 5.4 shows the ratio of GSR levels for various types of facilities to the GSR level in a bike lane during peak hours. Across various facilities, GSR level was higher in peak than off-peak hours. During peak hours, the findings suggest that there is not a statistical difference between GSR levels in shared roadway and bike lanes. Although the bike lane segments of the route were separated from the motorized traffic by a painted lane, the lack of physical separation did not provide a comfortable environment to ride in an urban area. Proximity to motorized traffic had a clear effect on physiological stress levels, which in the mid and long term will affect cyclists' perception. Results for off-peak hours showed that GSR levels decreased the most at bicycle lanes when traffic reduced, (i.e., at off-peak times the stress of riding in bicycle lanes is reduced more than in mixed traffic).

The findings also suggest that multiuse path I and multiuse path II were not statistically different in terms of stress. There was not enough evidence to state that high pedestrian volume affects cyclist stress levels. Comparing bicycling between a shared roadway with a physically separated bicycle infrastructure (multiuse path I and II) results in high GSR levels for the first facility (pvalue $<0.05$ ). Also, riding through bike lanes showed a higher GSR level than riding through the multiuse paths (p-value $<0.05$ ). 


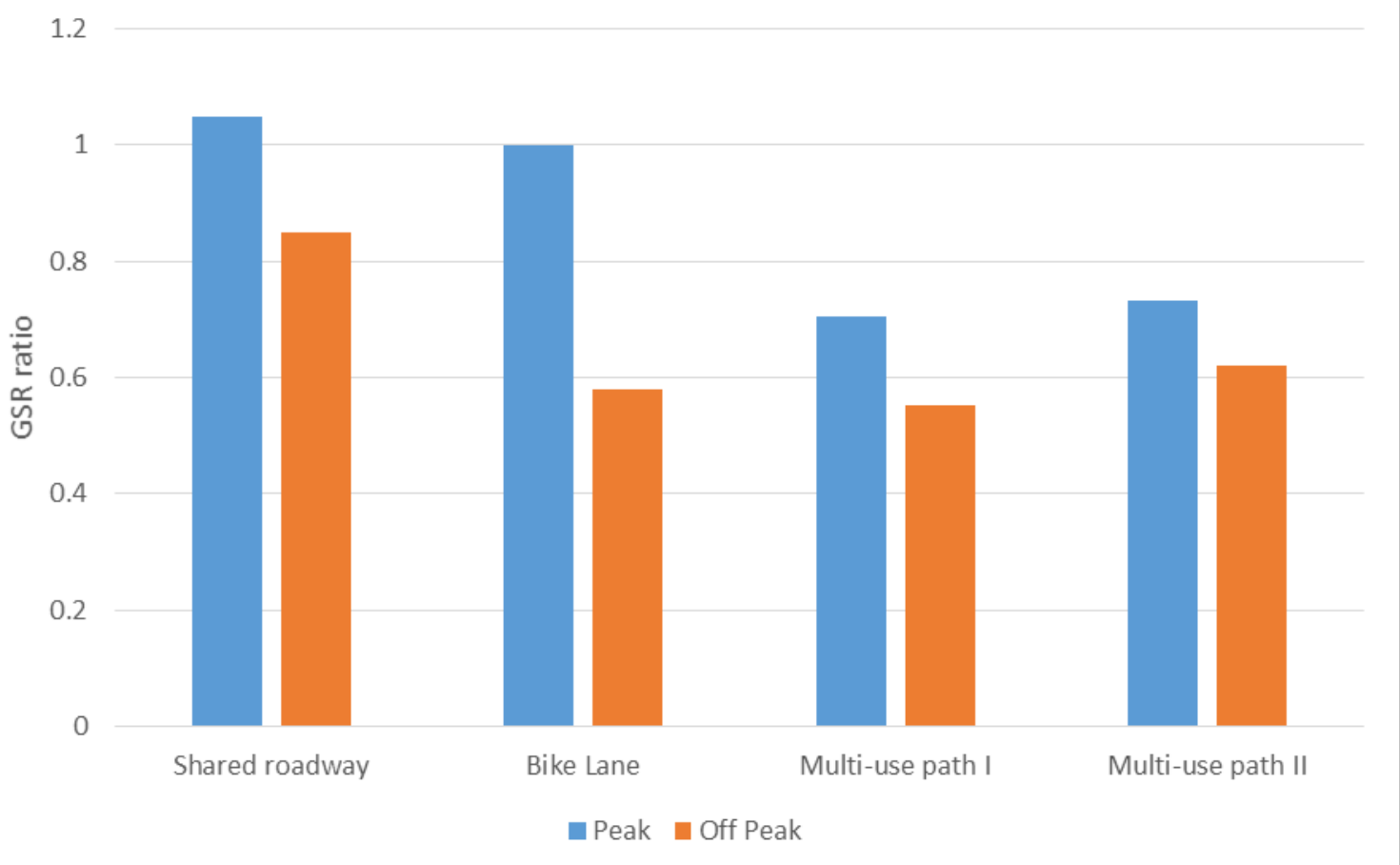

Figure 5.4: GSR ratios across bicycle facilities

This analysis clearly shows the impact of riding close to motorized traffic as a stressor. This finding supports the results found by Blanc and Figliozzi (2016): Stated comfort levels significantly drop if automobile and/or commercial vehicle traffic are identified by the cyclist as a stressor. However, if the cyclists identify that the source of stress is bicycle traffic, there is no drop in comfort levels (Blanc \& Figliozzi, 2016). High bicycle traffic on popular separated facilities has a negative impact on comfort, but the effect of not having traffic results in an overall positive effect on comfort levels. 


\subsection{CONCLUSIONS}

This is the first research effort to utilize video and GSR data to quantify physiological stress experienced by cyclists. Video and GSR peak data suggest that stress levels increase at locations where the riders feel more threatened, when the path is blocked or where decision making is more complex. The results of the data analysis indicate that bicycle facilities such as separated paths decrease stress whereas no bike facilities tend to increase these levels. Results also show that intersections and peak traffic impact bicycle stress levels. Separated bicycle infrastructure has, on average, the lowest stress levels.

The novel results include the quantification of relative stress levels. Stress while riding during peak hours averaged 1.75 times higher than while riding at off-peak hours on the same routes and facilities. During peak hours, riding in bike lanes or shared roadways had no difference on stress levels. Separated bicycle infrastructure, such as multiuse paths, during peak and off-peak hours showed the lowest stress levels. Signalized intersections were hotspots for cyclists' stress; During peak hours at intersections, stress levels were 1.7 times higher than at road segments connecting intersections during off-peak periods.

Novel contributions include not only the quantification of the impacts of time of the day, intersections and bicycle facilities on stress levels, but also that the results are statistically significant. The statistical analysis and quantification of stress levels are not only novel but also align well with previous research results. The methodology developed in this research can be utilized to complement other modeling efforts. For example, models utilizing data from smartphone apps that focus on measurements of comfort levels (Blanc and Figliozzi, 2016).

A limitation of many cyclist studies is the lack of consideration of actual stress measurements while the cyclist is riding; the approach presented in this project allows the researcher to have a better picture of what the cyclist is actually experiencing. Rather than having an average stress measure for the travel route, it is possible to precisely identify the places and/or situations where the cyclist is feeling more stressed. By measuring how different facility types and riding conditions affect the distribution of stress levels among users, transportation engineers and planners may in the future incorporate stress as a performance measure.

One goal of this research was to analyze the suitability of video and GSR data to study cyclists' responses to their environment. Years of research in the psychological field indicate that stress and emotional arousal can be measured by using physiological information such as GSR due to their high correlation. This research effort confirms that it is also possible to apply GSR data to quantify the stress of different bicycle facility types.

The reader should also be mindful of the limitations of this research. This is the first research effort using GSR in the bicycle transportation context, and results are specific for the conditions and facilities found in Portland, OR.

Future research efforts should include more cities, facilities and subjects. Future research efforts may also include the integration of computer vision algorithms that can identify and track moving objects such as automobile, bicycles, and pedestrians. 


\subsection{REFERENCES}

Ax, A. (1953). The phsysiological differentiation between fear and anger in humans. Psychosomatic Medicine, 55, 466-445.

Benedek, M., \& Kaernbach, C. (2010). Decomposition of skin conductance data by means of nonnegative deconvolution. Psychophysiology, 647-658.

Bigazzi, A., \& Figliozzi, M. (2014). a Portable, Low-cost, and Networked Device for Assessing Cyclists’ Exposure to Air Pollution. The Portland ACE Documentation.

Bigazzi, A., Luo, W., Figliozzi, M., Pankow, J., \& Isabelle, L. (2014). Measuring urban bicyclists' uptake of traffic-related volatile organic compounds using ambient and breath concentrations. Proceedings of the 93rd Transportation Research Board Annual Meeting.

Blanc, B., \& Figliozzi, M. (2016). Modeling the Impacts of Facility Type, Trip Characteristics, and Trip Stressors on Cyclists’ Comfort Levels Utilizing Crowdsourced Data. Submitted for presentation at the 95th Annual Meeting of the Transportation Research Board and for publication in Transportation Research Record.

Boucsein, W. (2012). Electrodermal Activity. New York: Springer.

Campbell, K., \& Linda, M. (2008). Developing Measures to Improve Highway Safety: The Safety Focus Area of the Strategic Highway. Research Program 2, TR News, Number 255.

Carter, D., Hunter, W., Zegeer , C., \& Stewart, J. (2007). Pedestrian and Bicyclist Intersection Safety Indices: User Guide. Federal Highwat Administration.

Chi, D., Dill, J., \& Monsere, C. (2009). An Observational Evaluation of the Safety Effectiveness of Marked and Unmarked Crosswalks at Unsignalized Intersections. Proceedings of the 88th Annual Meeting of the Transportation Research Board.

Chuang, K., Hsu, C., Lai, C., Doong, J., \& Jeng, M. (2013). The use of a quasi-naturalistic riding method to investigate bicyclists’ behaviors when motorists pass. Accident Analysis \& Prevention, 32-41.

Chuang, K.-H., Hsu, C.-C., Lai, C.-H., Doong, J.-L., \& Jeng, M.-C. (2013). The use of a quasinaturalistic riding method to investigate bicyclists' behaviors when motorists pass. 56, 32-41.

Dawson, M., Schell, A., \& Filion, D. (2007). Handbook of psychophysiology. Cambridge: University Press.

Dill, J., \& Voros, K. (2007). Factors affecting bicycling demand: initial survey fidnings from the Portland Oregon, region. Transportation Research Record: Journal of the Transprotation Research Board, 2031(1), 9-17.

Dozza, M., Werneke, J., \& Fernandez, A. (2012). Piloting the Naturalistic Methodology on Bicycles. Helmond, The Netherlands: Proceedings, International Cycling Safety Conference 2012 .

Durrant-Whyte, H., \& Bailey, T. (2006). Simultaneous Localization and Mapping (SLAM): Part I The Essential Algorithms. Robotics and Automation Magazine, 13(2), 99-110. 
Ekman, P., Levenson, R., \& Friesen , W. (1983). Autonomic nervous system activity distinguishes among emotions. Science, 221, 1208-1201.

EMOTIV. (2015, 08 09). EPOC+. Retrieved from Specifications: http://emotiv.com/epoc/

Figliozzi, M., Wheeler, N., \& Monsere, C. (2013). A Methodology to Estimate Bicyclists’ Acceleration and Speed Distributions at Signalized Intersections. Transportation Research Record 2387, 66-75.

Forrest, C. (2013). This ain’t your grandma safety research. TR News, Number 289.

Fowles , D., Christie, M., Edelberg, R., Grings, W., Lykken, D., \& Venables, P. (1981). Publication Recommentadionts for Electrodermal Measurements. Psychophysiology, 232239.

Friedlund, A., \& Izard, C. (1983). Electromyographic Studies of Facial Expressions of Emotions and Patterns of Emotions. In J. Cacioppo, \& R. Petty, Social Psychophysiology: A Sourcebook, (pp. 243-286). Guilford Press.

Garder, P., Leden, L., \& Pulkkinen, U. (1998). Measuring the Safety Effect of Raised Bicycle Crossings Using a New Research Methodology. Transportation Research Record, 1360, 64-70.

Harley , R., \& Zisserman, A. (2004). Multiple View Geometry in Computer Vision. Cambridge University Press.

Harvey, F., Krizek, K., \& Collins, R. (2008). Using GPS data to assess bicycle commuter route choice. Transportation Research Board 87th Annual Meeting. Washington DC.

Healy, J. (2000). Wearable and Automotive Systems for Affect Recognition from Physiology. Massachusetts Institute of Technology.

Healy, J., \& Picard, R. (2005). Detecting Stress During Real-World Driving Tasks Using Physiological Sensors. IEEE Transactions on Intelligent Transportation Systems, 6(2), 156-166.

Helander, M. (1978). Applicability of drivers' electrodermal response to the design of the traffic environment. Journal of Applied Psychology, 481-488.

Hong, J.-H., Ramos, J., \& Dey, A. (2012). Stress Recognition: A step outside the lab. New York: UbiComp '12 Proceedings of the 2012 ACM Conference on Ubiquitous Computing.

Johnson, Marilyn, Charlton, J., \& Oxley, J. (2010). The application of a naturalistic driving method to investigate on-road cyclist behavior: A feasibility study. Road \& Transport Research: A Journal of Australian and New Zealand Research and Practice .

Kim, J., Kim, S., Ulfarsson, G., \& Portello, L. (2007). Bicyclist injury severities in bicyclemotor vehicle accidents. 238-251.

Landis, B., Vattikuti, V., Ottenberg, R., Petritsh, T., Guttenplan, M., \& Crider, L. (n.d.). Intersection Level of Service for the Bicycle Through Movement. 1828.

Le, H., Dang, T., \& Liu, F. (n.d.). Towards Long Term Large Scale Visual Health Monitoring Using Cyber Glasses. Proceedings of the 7th International Conference on Pervasive Computing Technologies for Healthcare, 2013.

Li, S., Sayed, T., Zaki, M., Mori, G., Stefanus, F., Khanlooa, B., \& Saunier, N. (2012). Automating Collection of Pedestrian Data Using Computer Vision Techniques. Proceedings of the 91st Annual Meeting of the Transportation Research Board.

Liu, F., Gleicher, M., Wang, J., Jin, H., \& Agarwala, A. (2011). Subspace Video Stabilization. ACM Transactions on Graphics, 4:1-4:10. 
Monsere, C., McNeil, N., \& Dill, J. (2012). Multi-User Perspectives on Separated, On-Street Bicycle Infrastructure. Transportation Research Record: Journal of the Transportation Research Board of the National Academies.

Pecchinenda, A., \& Smith, C. (1996). Affective significance of skin conductance activity during difficult problem-solving task. Cognition and Emotion, 481-503.

Picard, R., Vyzas, E., \& Healy, J. (2001). Toward Machine Emotional Intelligence: Analysis of Affective Physiological State. IEEE, 1175-1191.

Prokasy, W., \& Raskin, D. (1973). Electrodermal activity in psychological research. New York: Academic Press.

Sagberg, F., \& Backer-Grondhal, A. (2010). A catalogue of applications and research topics for future naturalistic driving studies. PROLOGUE Deliverable D for the European Community .

Sener, I., Eluru, N., \& Bhat, C. (2009). An analysis of bicycle route choice preferences in Texas, US. Transportation, 36(5), 511-539.

Seyle, H. (1956). The Stress of Life. New York: McGraw-Hill.

Sharma, N., \& Gedeon, T. (2012). Objective measures, sensors and computational techniques for stress recognition and classification: A survey. Computer Methods and Programs in Biomedicine, 1287-1301.

Shimmer sensing. (2015). GSR+ User Guide Revision 1.8. Realtime Technologies Ltd.

Shimmer sensing. (2015, 08 15). Publications. Retrieved from Shimmer. Discovery in motion: http://www.shimmersensing.com/support/publications/

Shimmer sensing. (2015, 08 15). Shimmer3 ECG unit. Retrieved from Shimmer. Discovery in Motion: 2015

Sorton, A., \& Walsh, T. (1994). Bicycle Stress Level as a Tool to Evaliate Urban and Suburban BIcycle Compatibility. Transportation Research Record, 1438, 17-24.

Thompson, S., Monsere, M., Figliozzi, M., Koonce, P., \& Obery, G. (2013). Bicycle-Specific Traffic Signals: Results from a State of the Practice. Transportation Research Record 2387, 1-9.

Tomasi, C., \& Manduchi, R. (1998). Bilateral Filtering for Gray and Color Images. Proceedings of the International Conference on Computer Vision, 839-846.

Transportation Research Board. (2010). Highway Capacity Manual 2010. Washington D.C.: Transportation Research Board.

Viola, P., \& Jones, M. (2001). Rapid Object Detection Using a Boosted Cascade of Simple Features. Proceedings of the IEEE International Conference on Computer Vision and Pattern Recognition, 511-518.

Weihong, Z., Zhu, Z., \& Quiang Ji. (2005). A Real-Time Human Stress Monitoring System Using Dynamic Bayesian Network. Proceedings of the 2005 IEEE Computer Society Conference on Computer Vision and Pattern Recognition (CVPR'05) .

Wilfrid, J., \& McLachlan, M. (1992). Characteristics of function-specific pathways in the sympathetic nervous system. Perspectives, 15(12), 475-481.

Winters, M., Davidson, G., Kao, D., \& Teschke, K. (2011). Motivators and deterrents of bicycling: comparing influences on decisions to ride. Transportation, 38(1), 153-168.

Zhang, F., \& Liu, F. (2014). Parallax-tolerant Image Stitching. Proceedings of the IEEE International Conference on Computer Vision and Pattern Recognition.

Zhang, K., Zhang, L., \& Yang, M. (2013). Real-Time Object Tracking via Online Discriminative Feature Selection. IEEE Transactions on Image Processing, 664-677. 


\section{APPENDIX A}

\section{BICYCLE FACILITIES}

During seven days in 2015 (including weekends), GSR and Global Positioning System (GPS) data was collected for the same route in Portland, Oregon. The route was comprised of segments with four distinct types of bicycle facilities: a shared roadway with mixed traffic conditions (1.49 $\mathrm{km})$, urban streets with bike lanes $(2.27 \mathrm{~km})$, a multi-use path I $(0.74 \mathrm{~km})$, and a multi-use path II $(3.20 \mathrm{~km})$. Data was collected at morning peak and off-peak hours.

\subsection{SHARED ROADWAY}

Shared roadways are the facilities where the cyclist has to share the street with motorized vehicles and he/she doesn't have segregated infrastructure. For this project this facility made up to $1.49 \mathrm{~km}$ in total length.
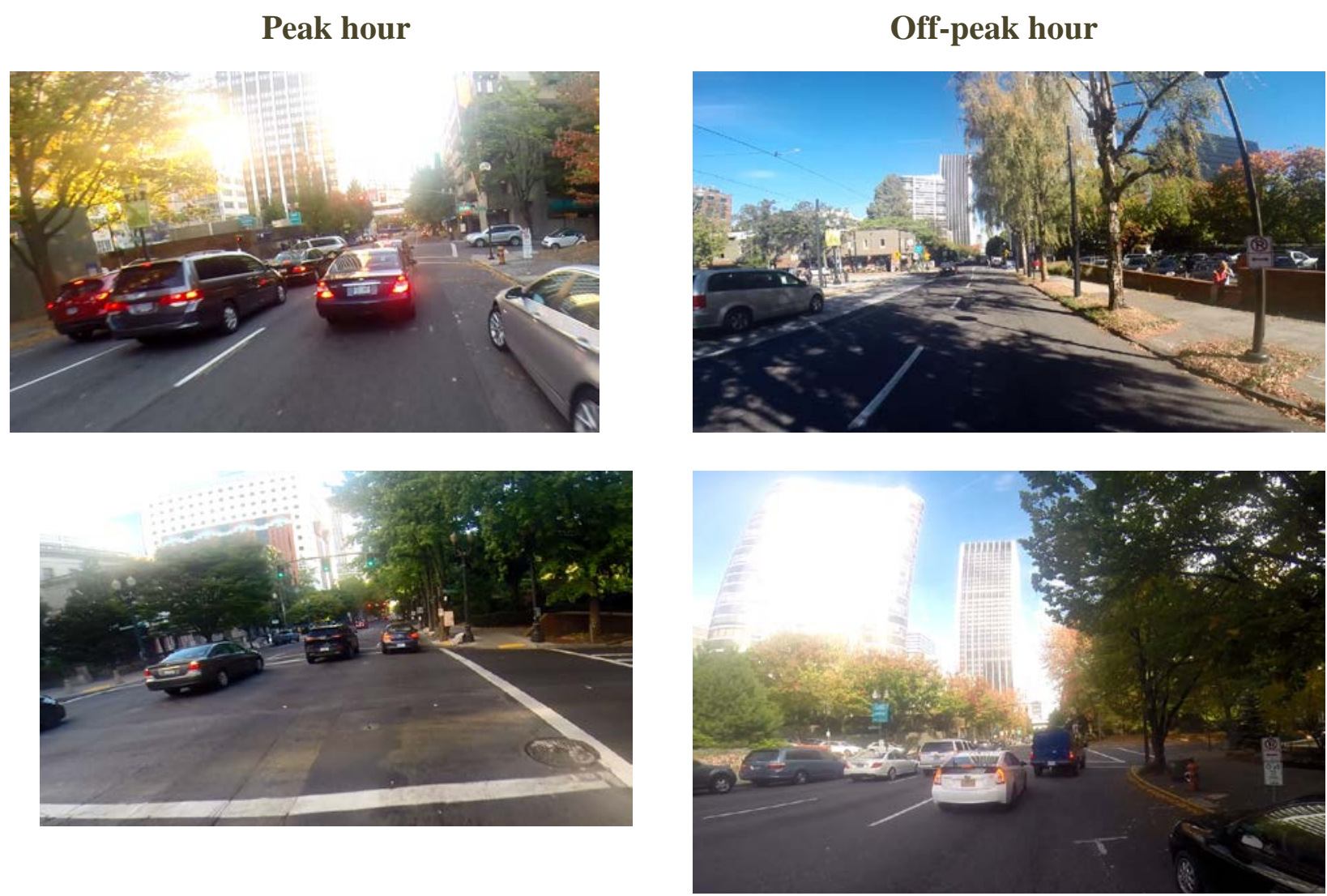

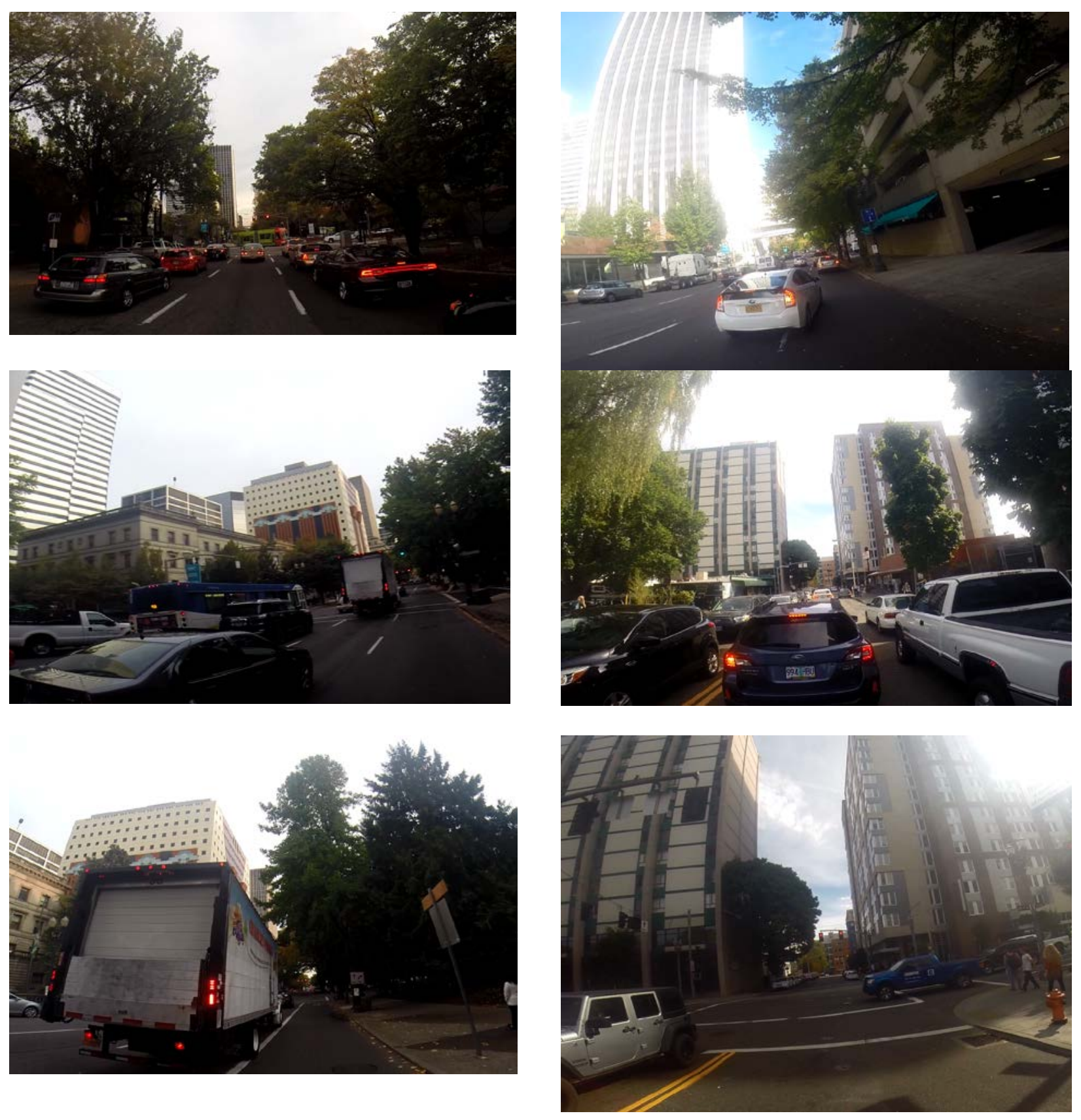

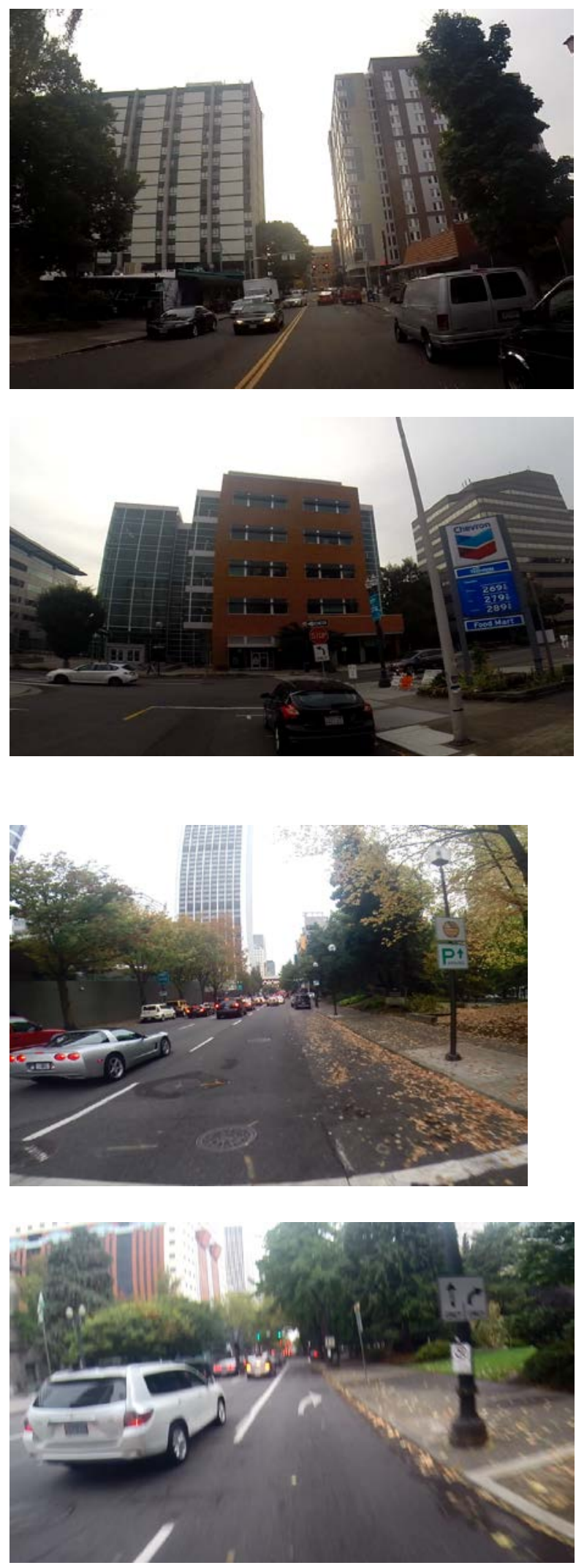
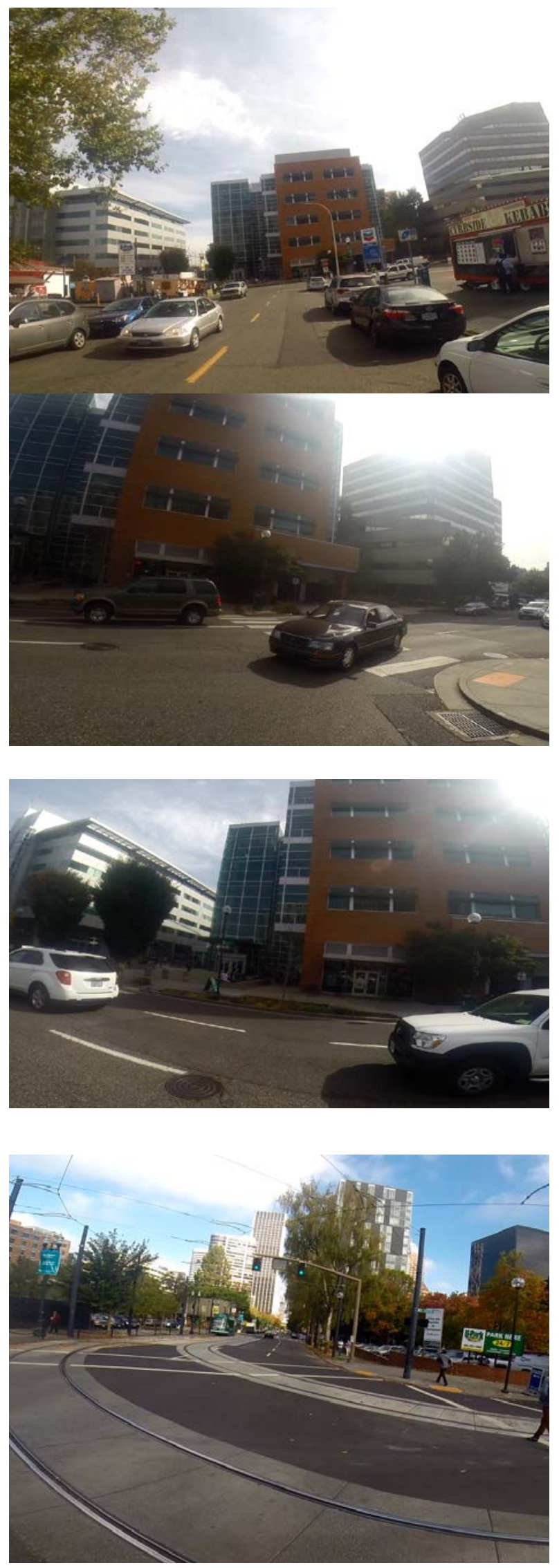

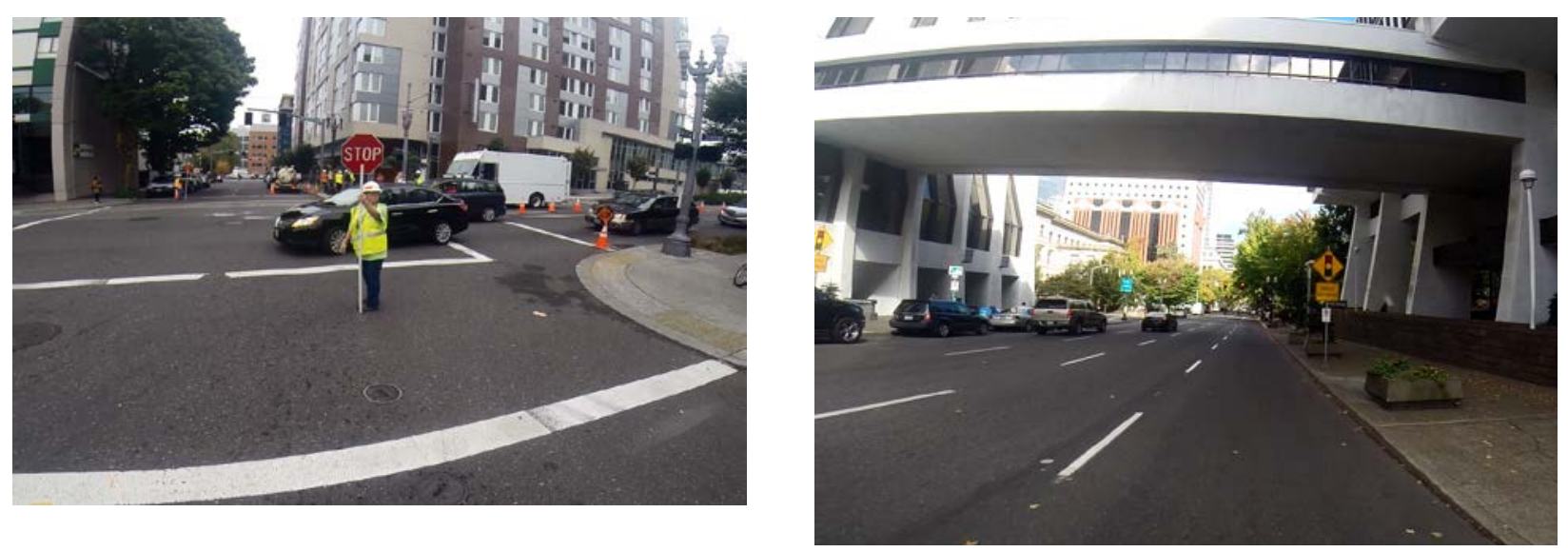


\subsection{BIKE LANE}

Bike lanes are facilities where the cyclist ride through a delineated exclusive bike lane. Drivers cannot drive through this facility. For this project all types of bike lanes were included in this category, the only restriction was having a clear demarcated lane. This facility made up to 2.27 $\mathrm{km}$ in total length.

\section{Peak hour}
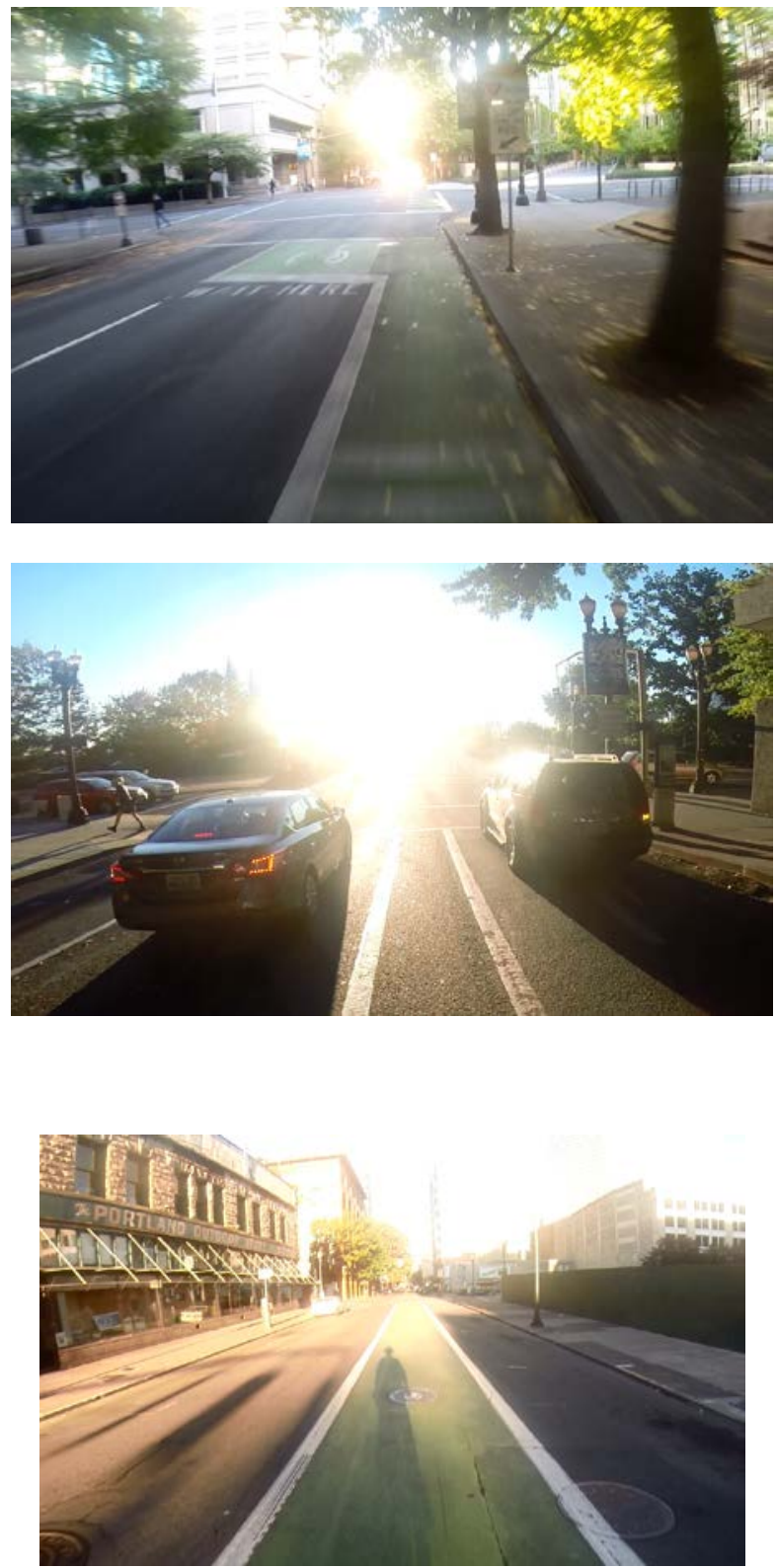

\section{Off-peak hour}
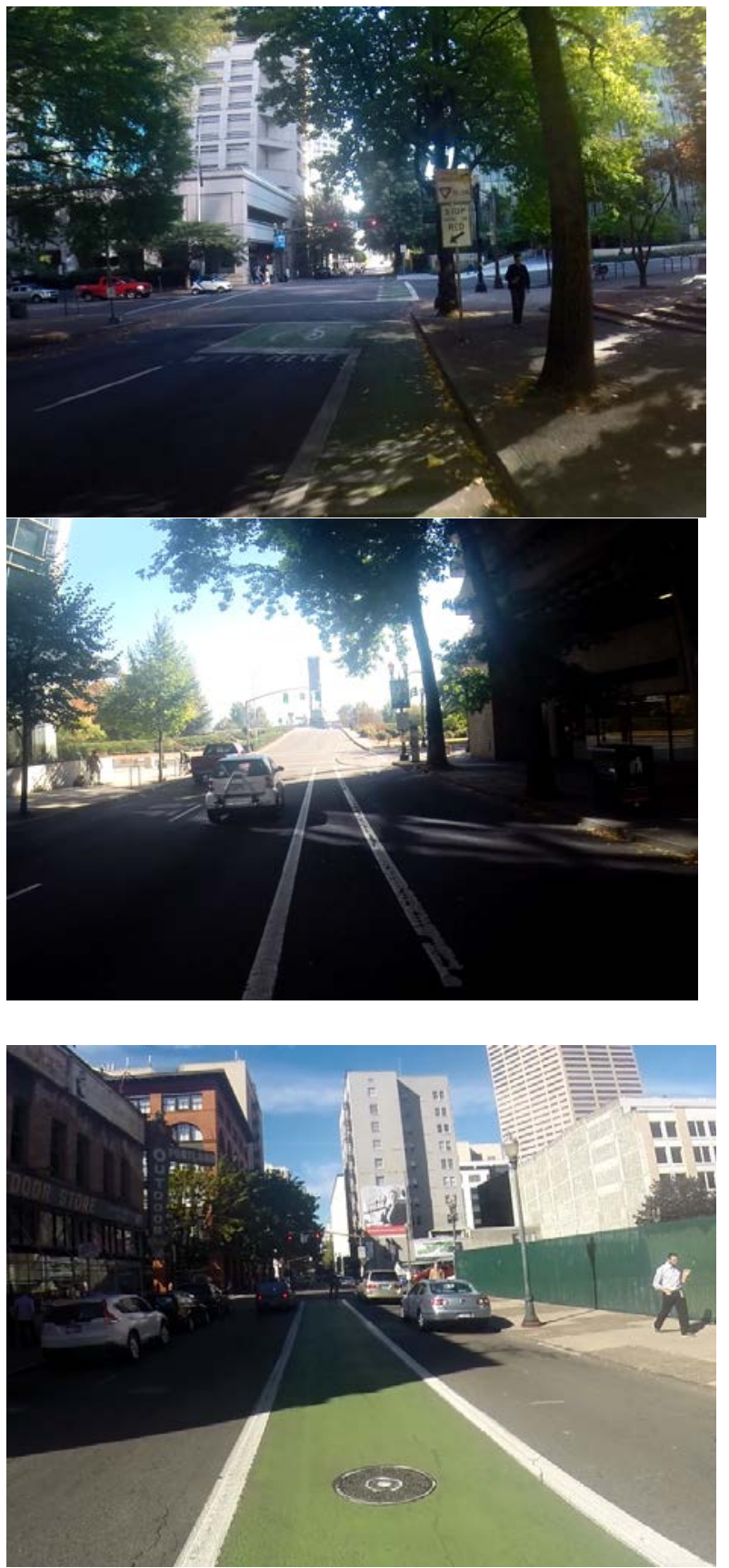

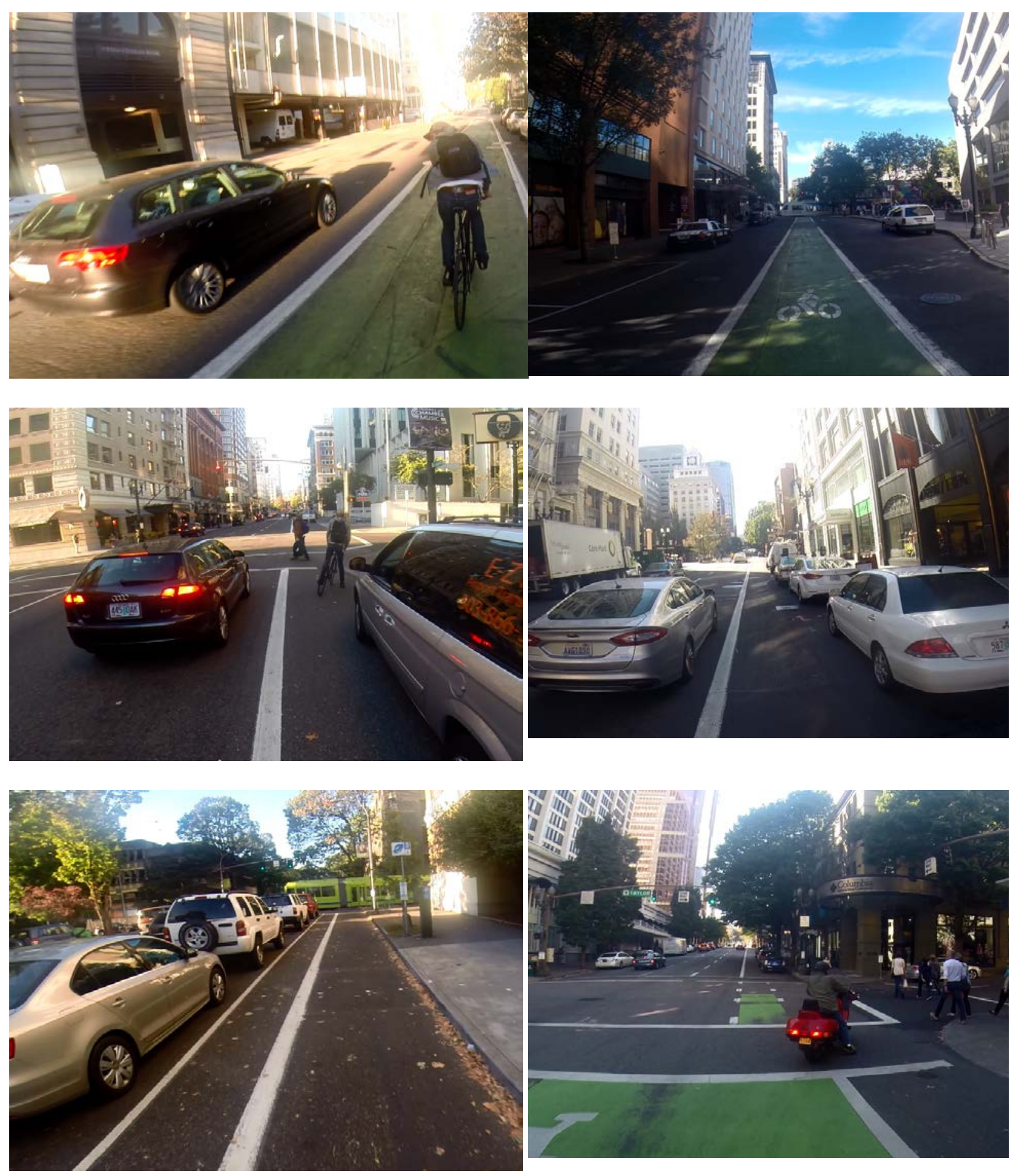

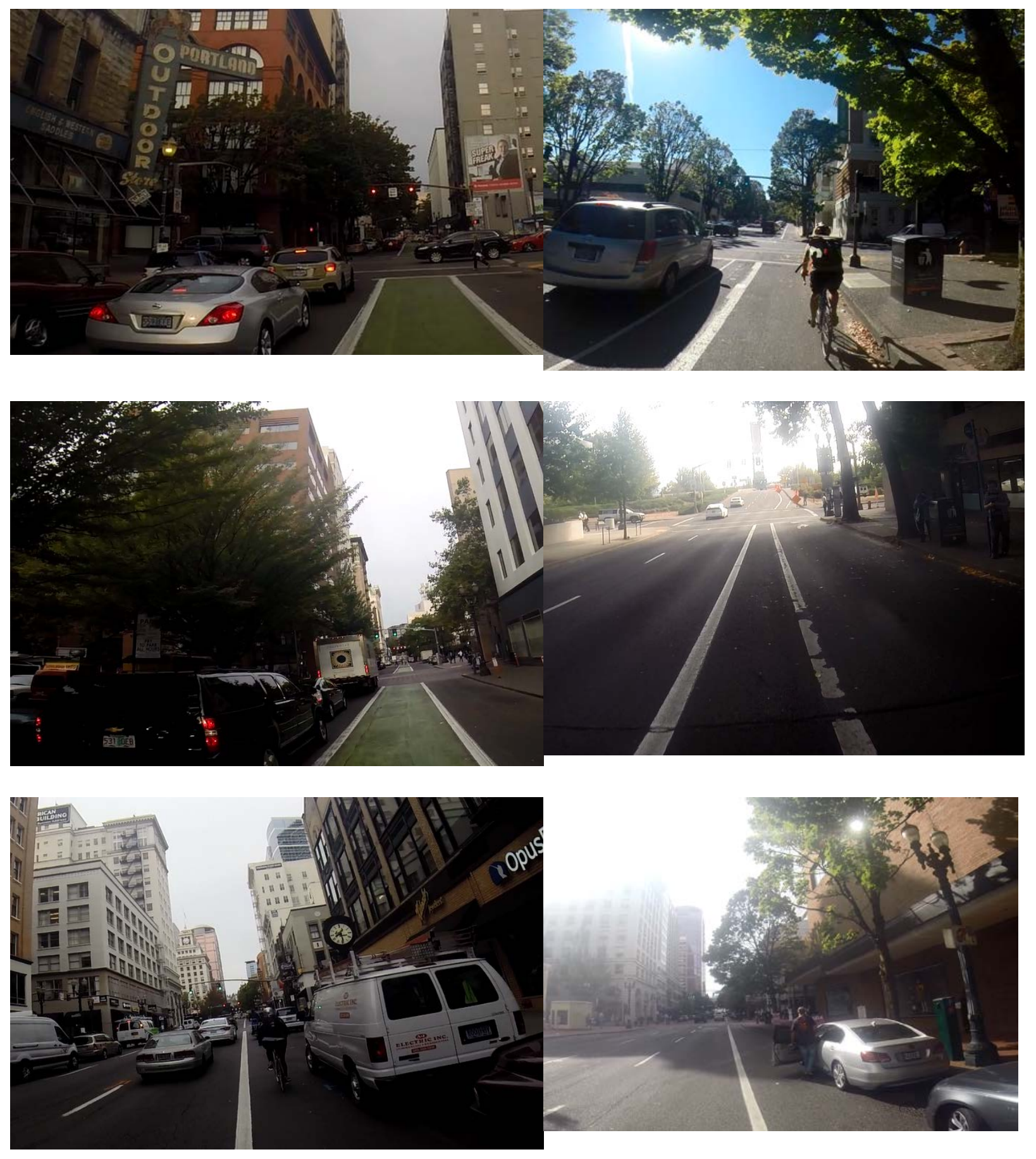

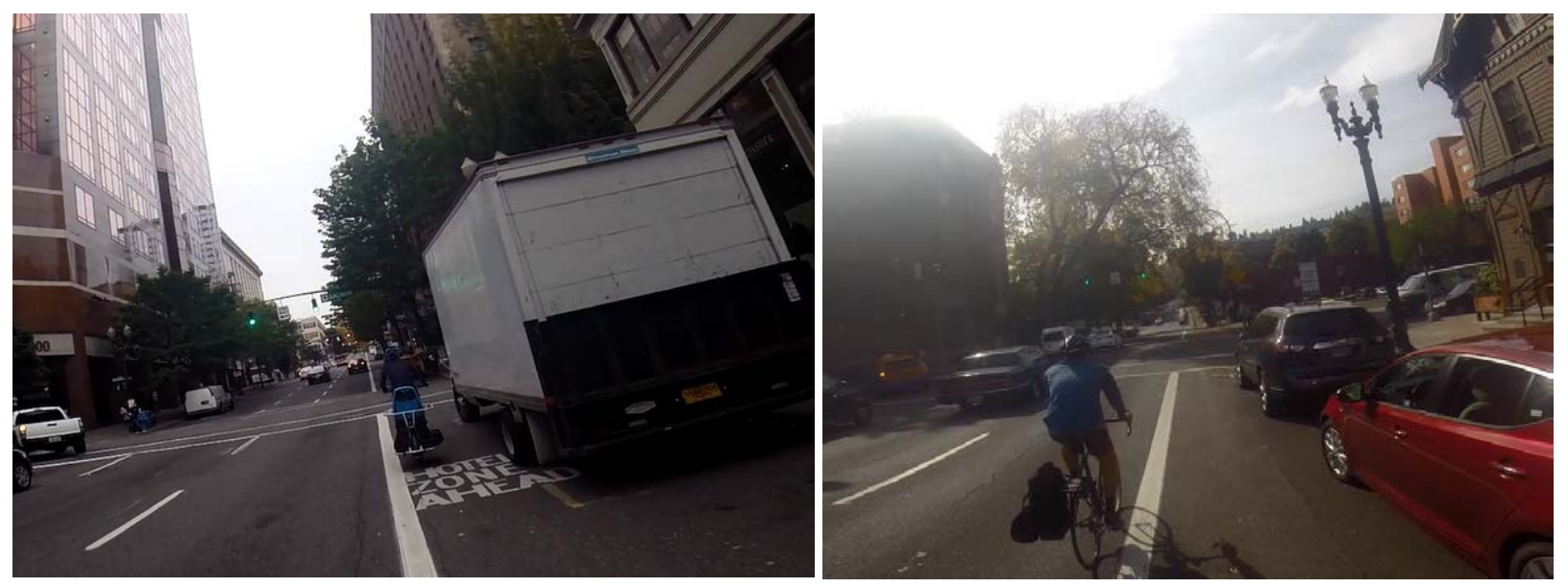


\subsection{MULTI-USE PATH I}

A multi-use path is a lane physically separated from motorized traffic used mainly by pedestrians and cyclists. This facility was categorized into two levels due to the significant differences in pedestrian volumes: multi-use path I had significantly higher volumes of pedestrians than multiuse path II. This facility made up to $0.74 \mathrm{~km}$ in total length.

\section{Peak hour}

Off-peak hour
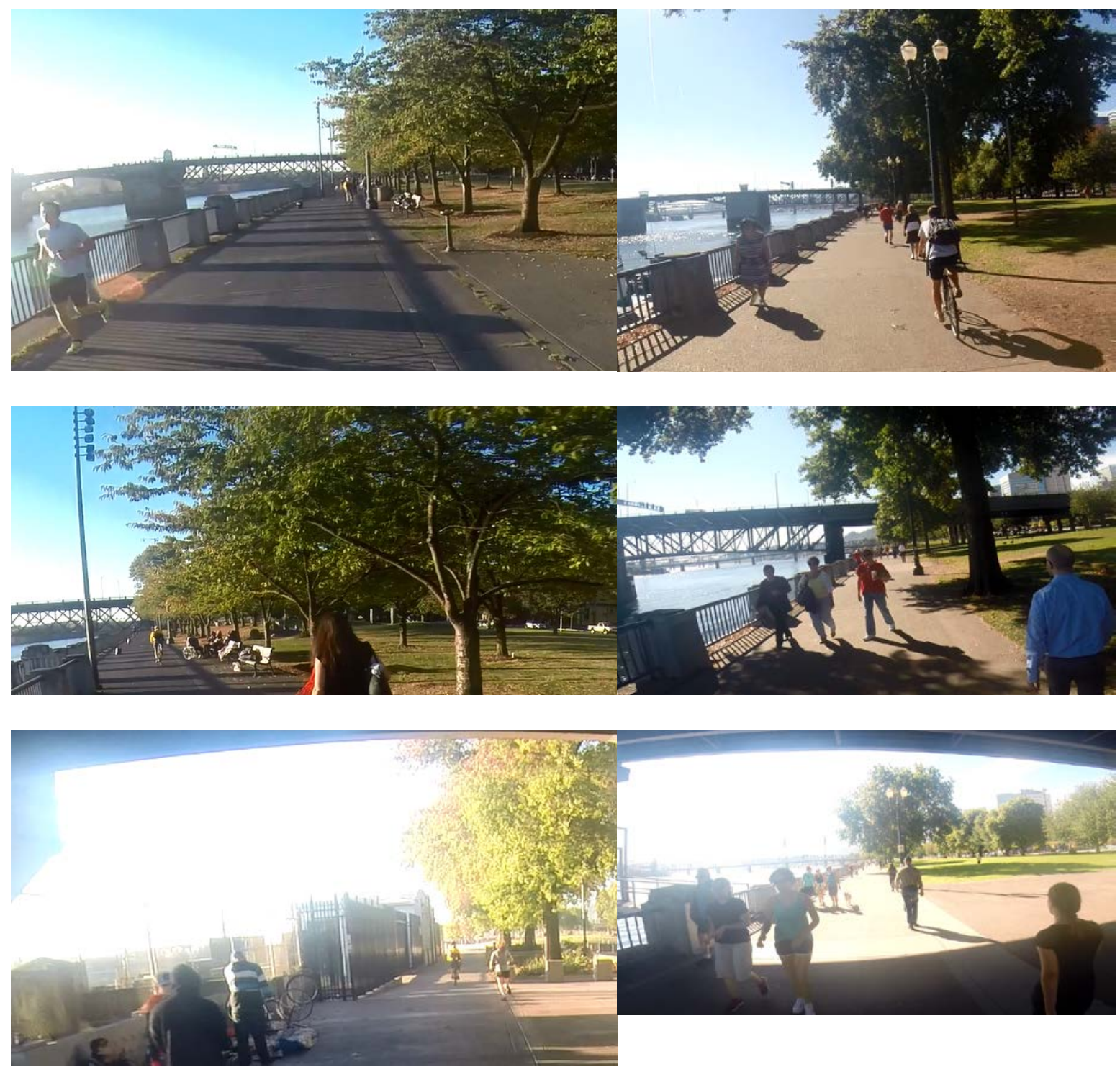

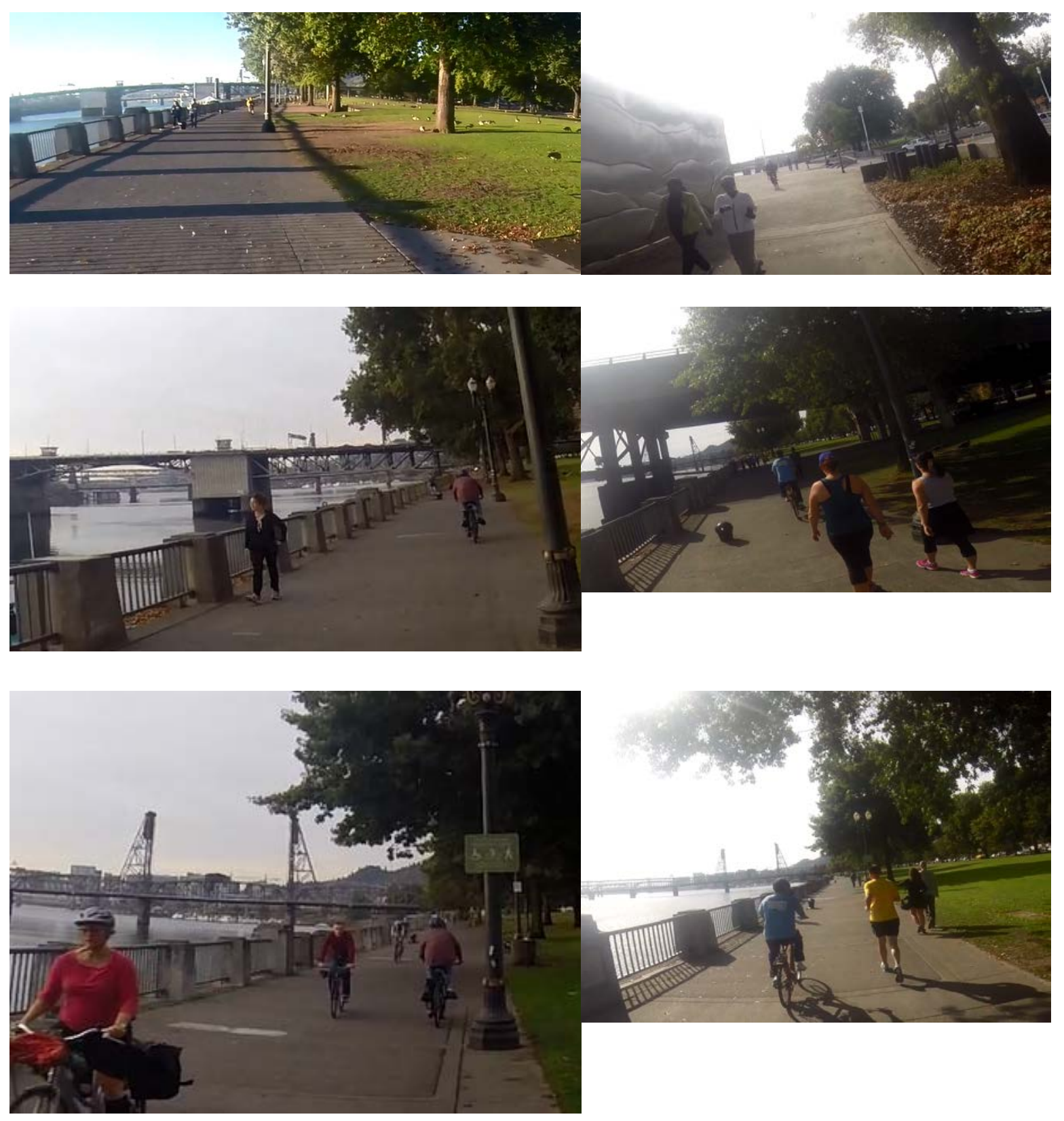


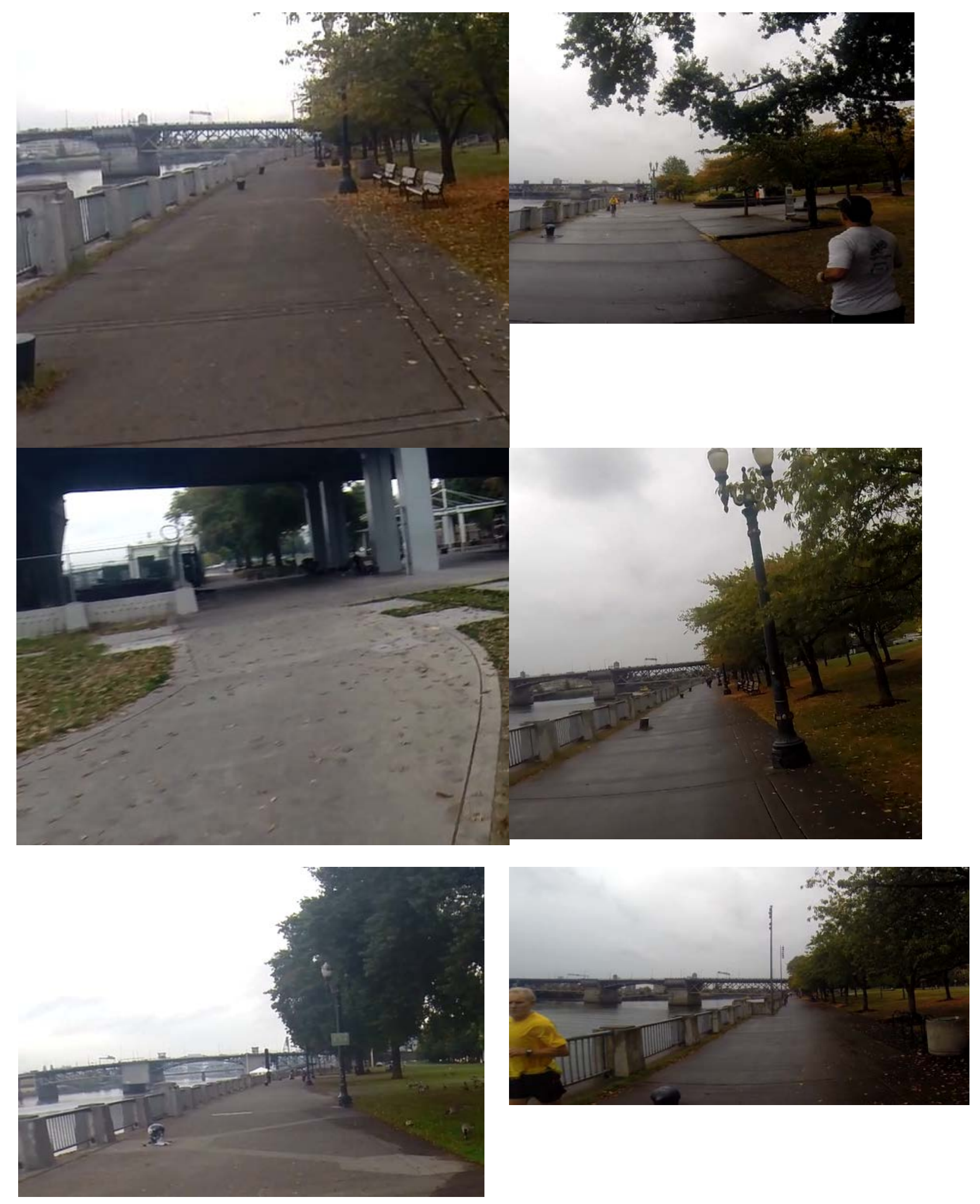




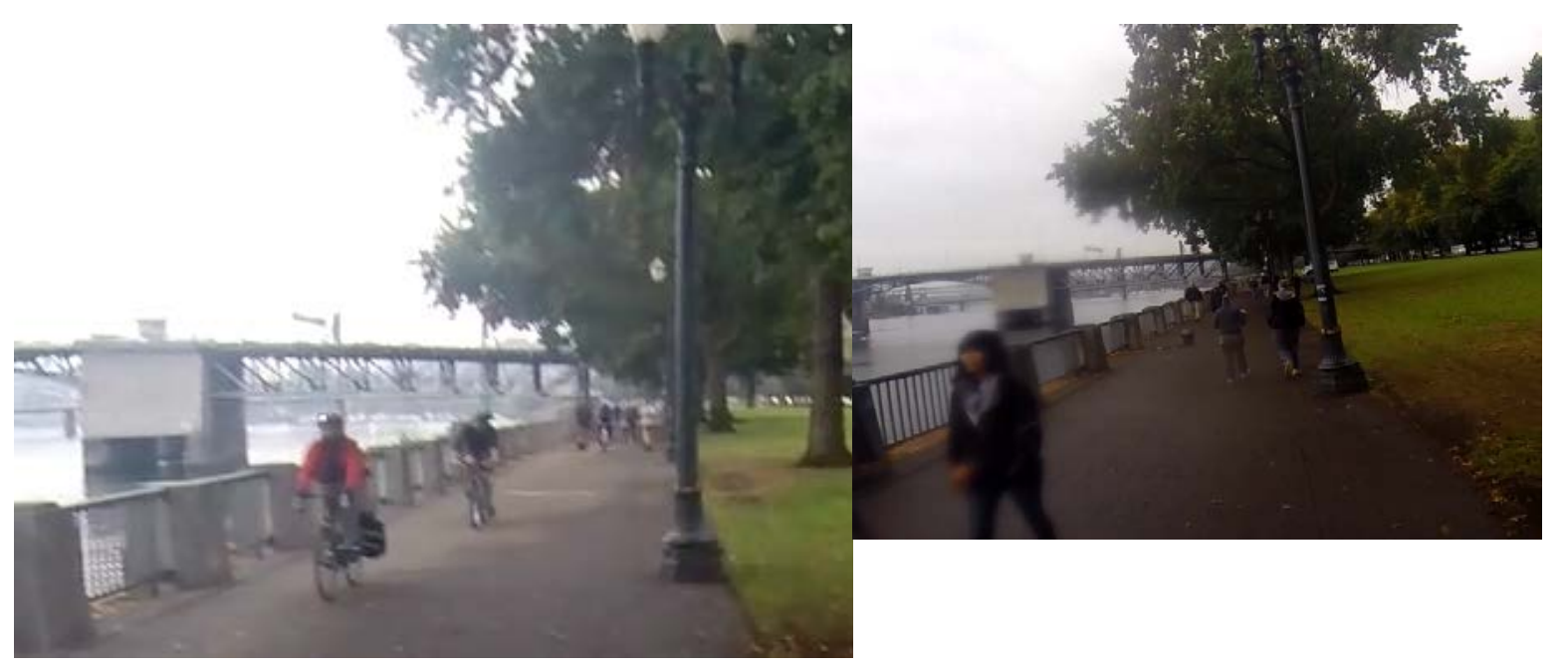




\subsection{MULTI-USE PATH II}

A multi-use path is a lane physically separated from motorized traffic used mainly by pedestrians and cyclists. This facility was categorized into two levels due to the significant differences in pedestrian volumes: multi-use path I had significantly higher volumes of pedestrians than multiuse path II. This facility made up to $3.20 \mathrm{~km}$ in total length.
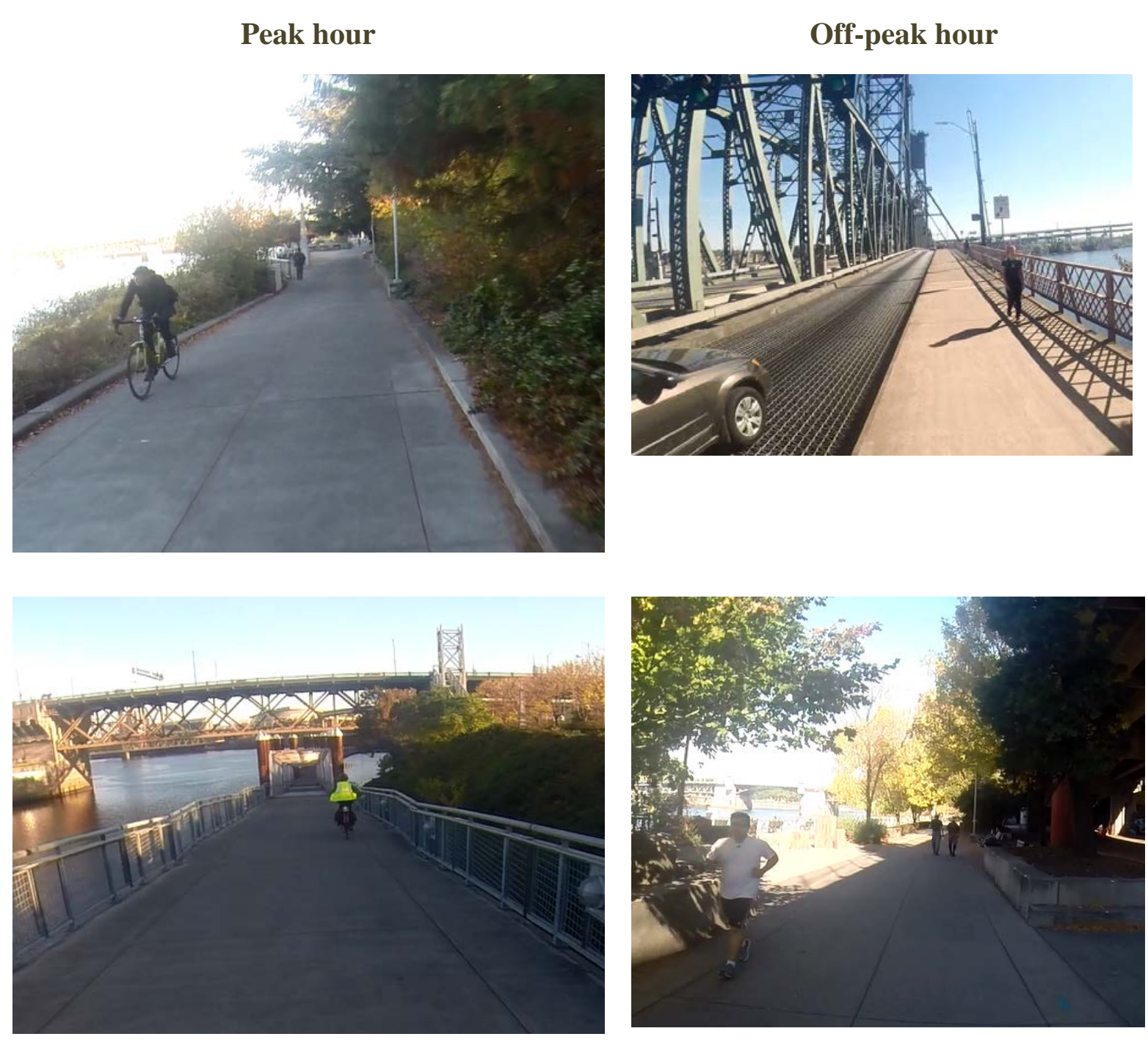

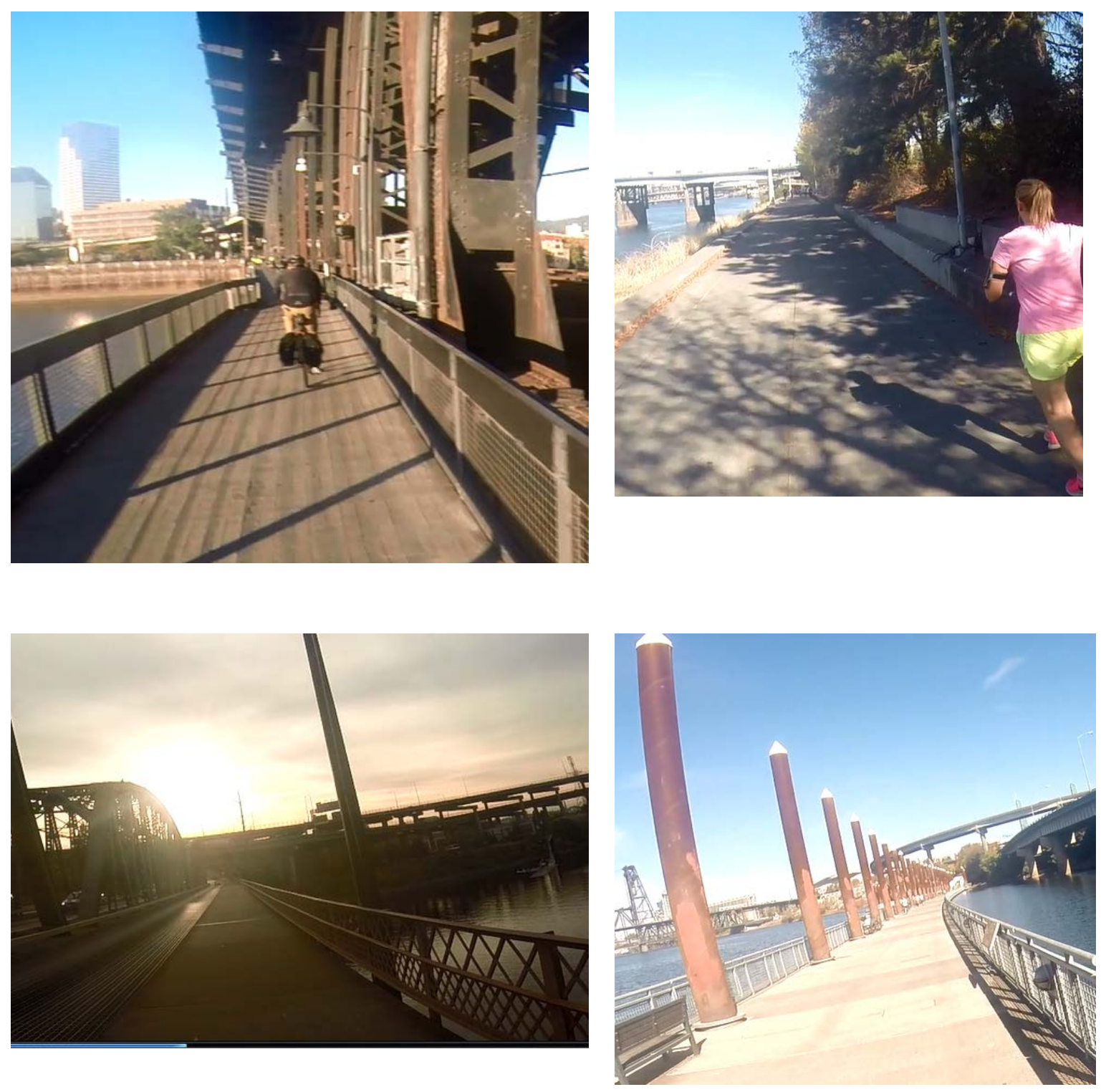

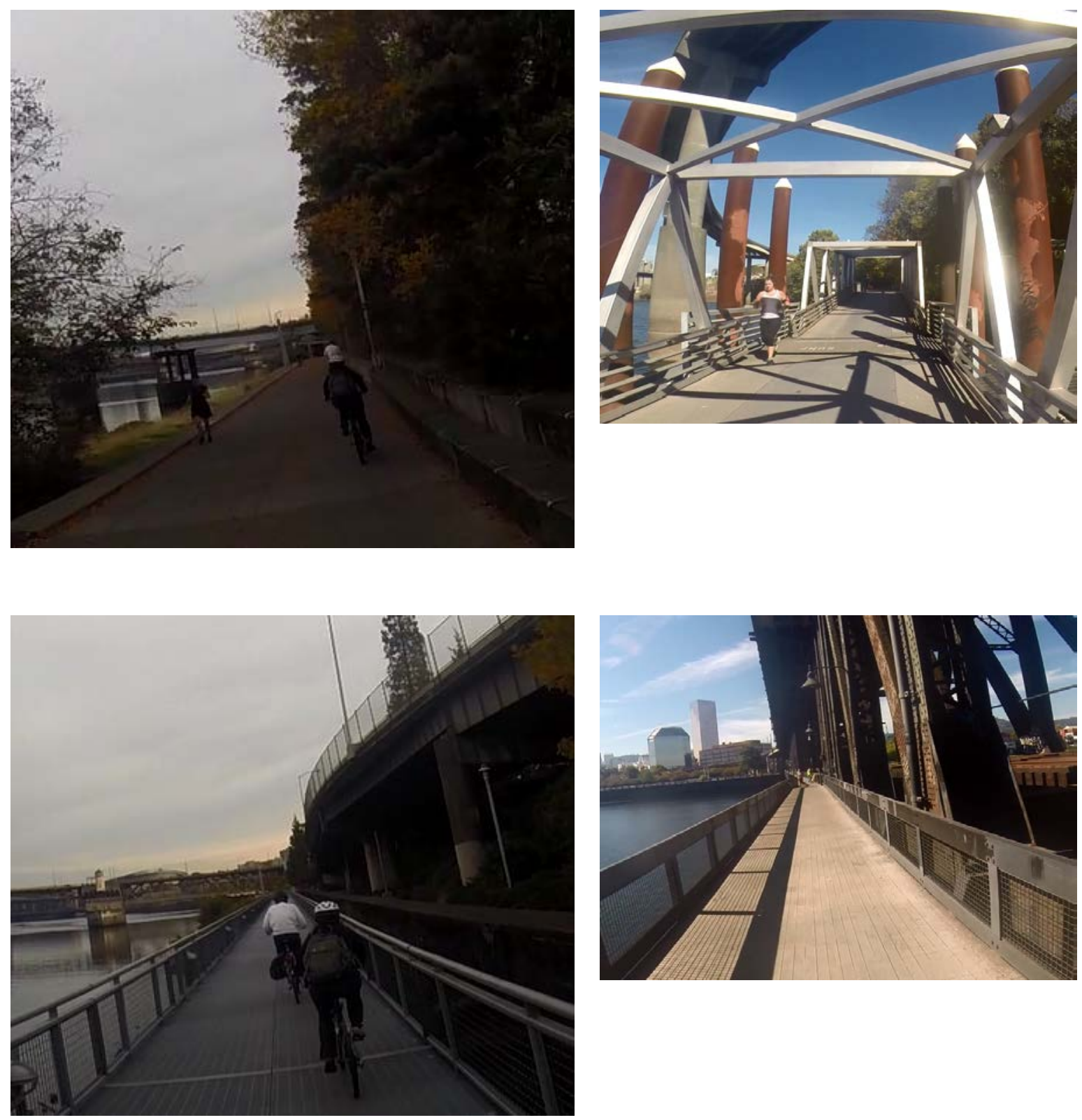

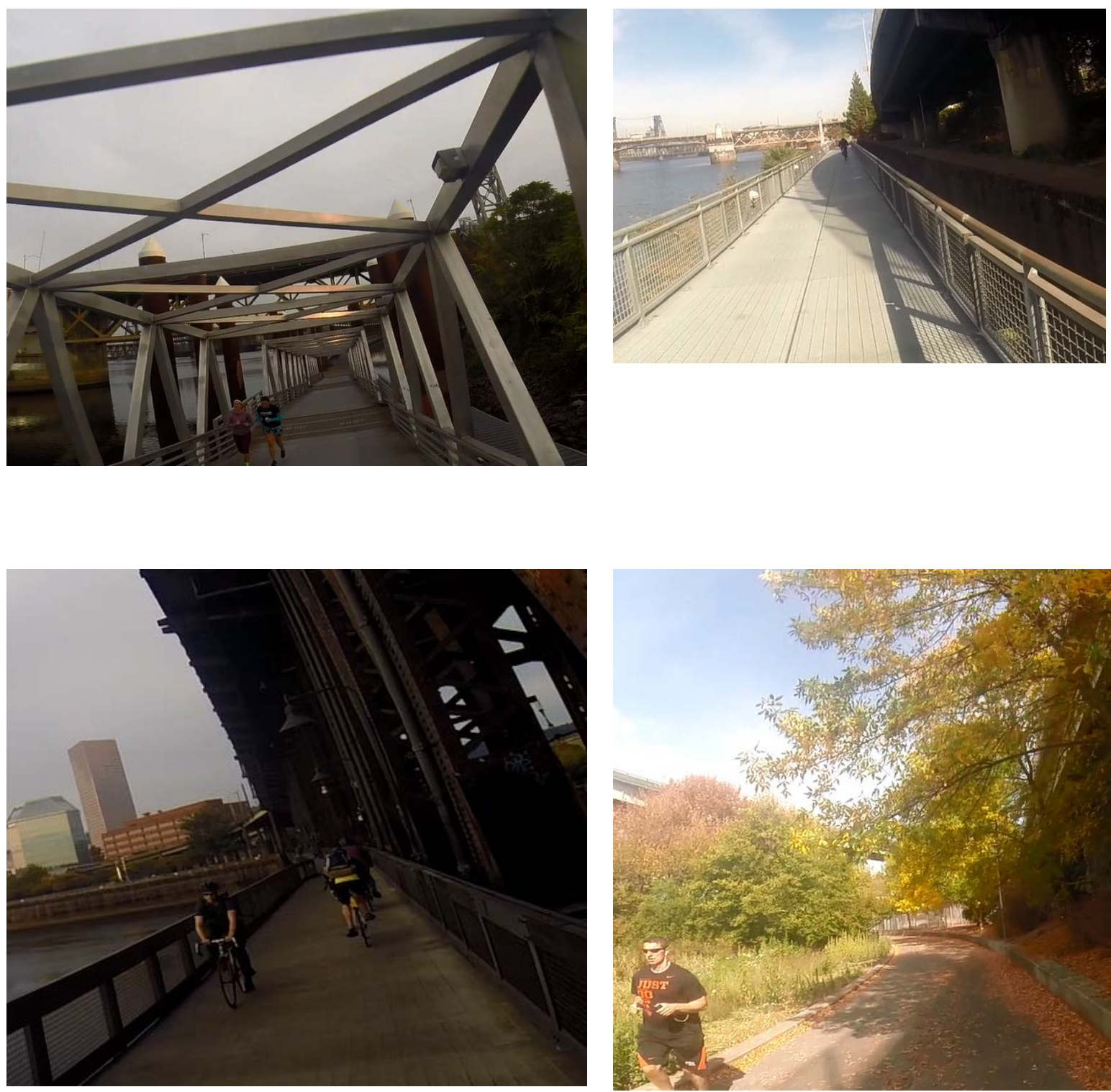

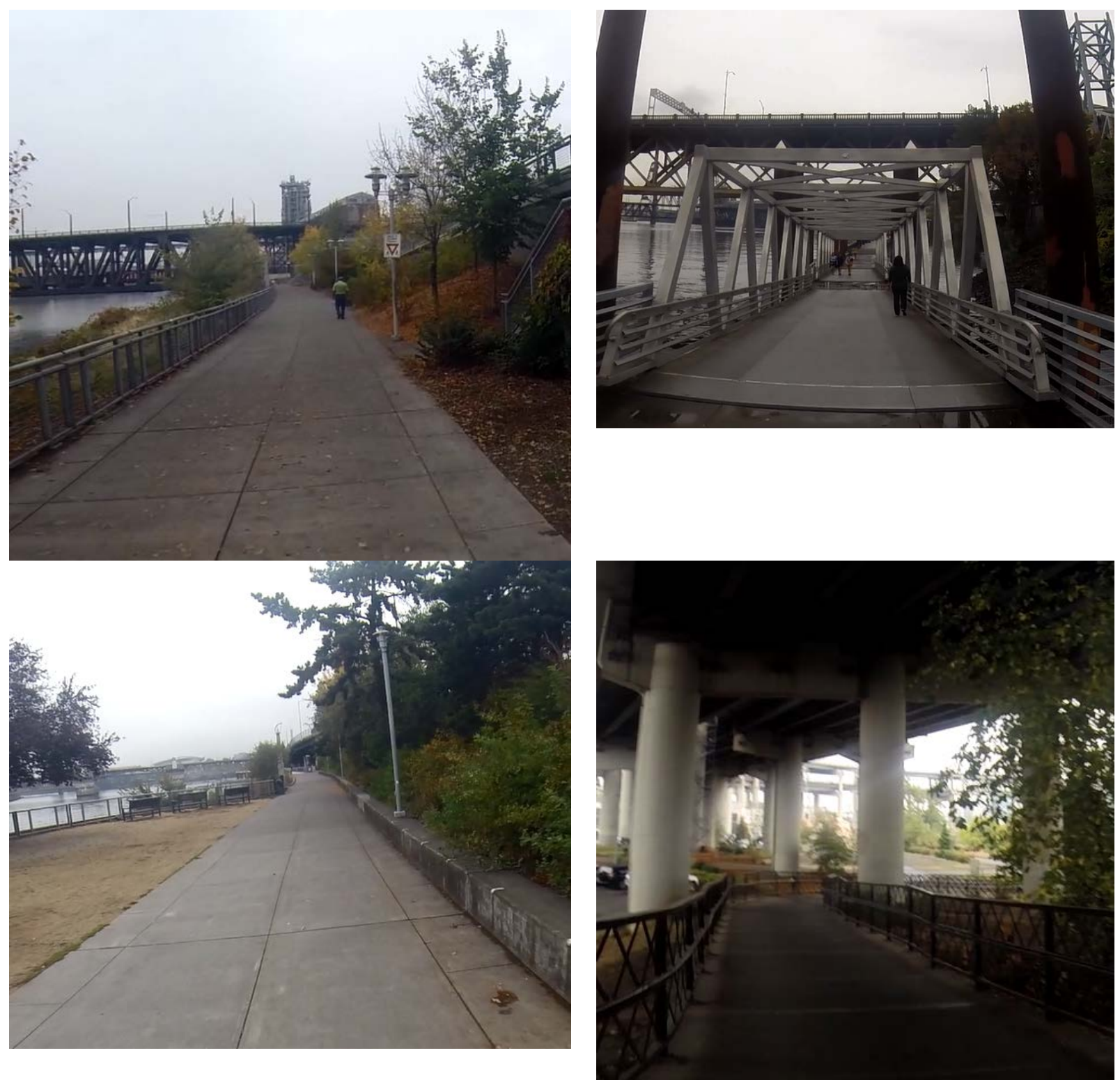


\section{APPENDIX B}

\section{MULTI-SUBJECT STRESSFUL EVENTS}

This appendix contains detailed information of stressful events by subject. Each map contain numbers that are referenced below with a photo and a brief description.

\section{Subject \# 1}
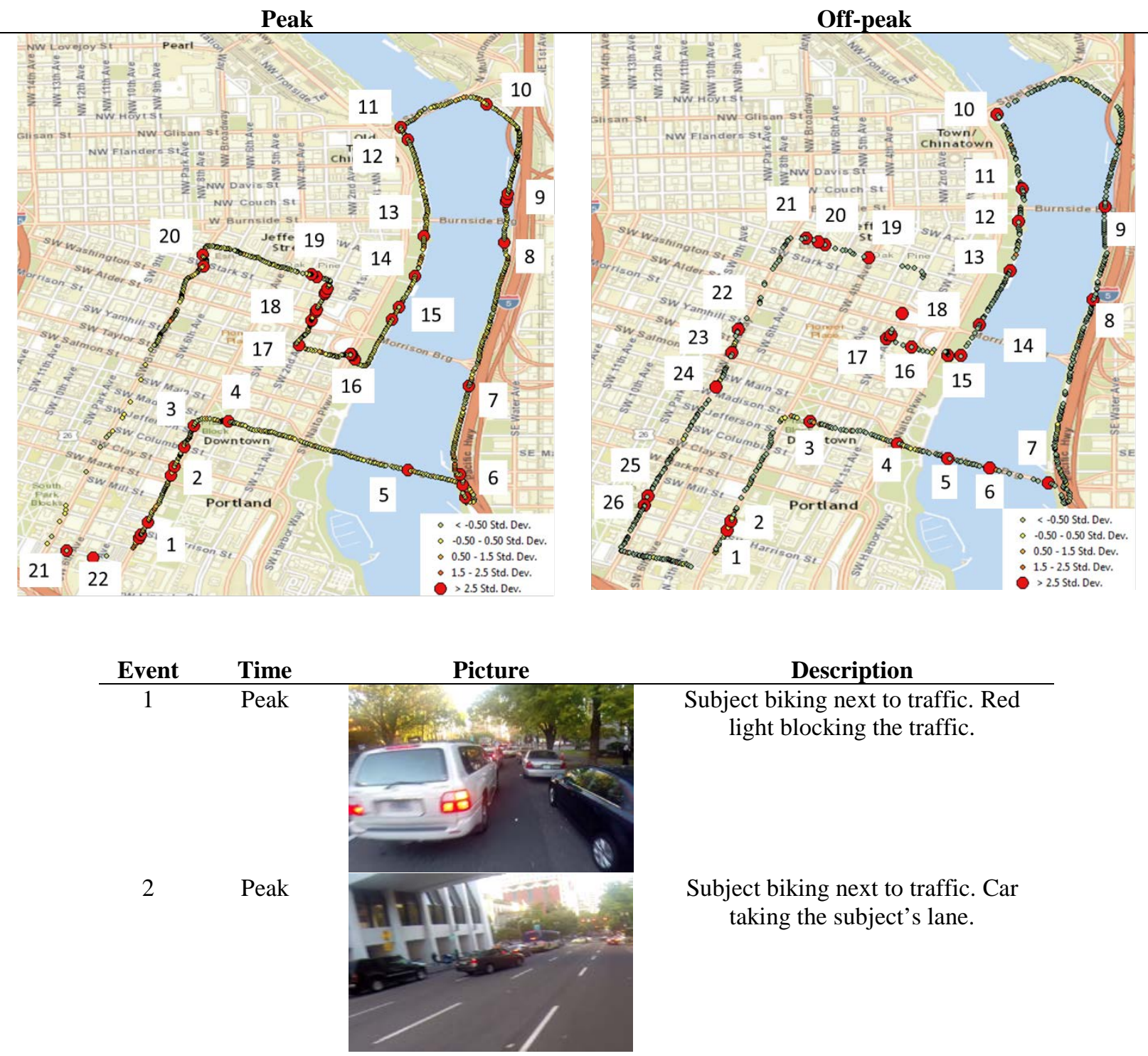
Peak

5

Peak

6

Peak

7

Peak

8

9

Peak

10

Peak

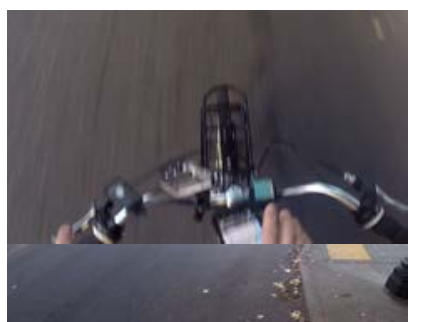

The subject was touching the electrodes, interfering with the stress signals.

Subject biking next to traffic. Bus was approaching the subject to make a stop.

Bike lane merging into the multi-use path. Subject looking in both directions.

The subject was touching the electrodes, interfering with the stress signals.

The subject was waiving her/his hand to warn subjects behind she/he was turning left. It is likely this movement affected the stress measures.

Subject biking down through a ramp.
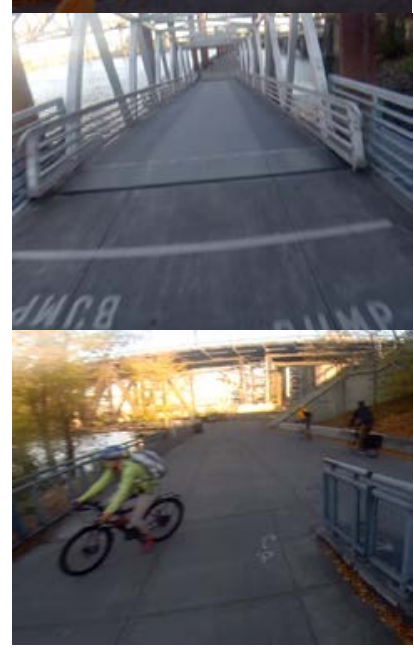

At this location the stress levels increased because another subject was turning left, blocking subject's movement. 
11

Peak

12

Peak

13

Peak
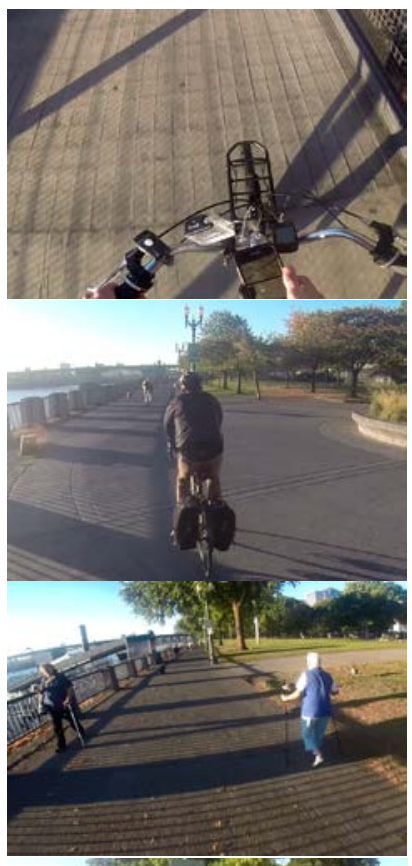

14

Peak

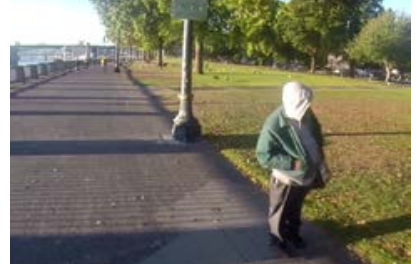

15

Peak

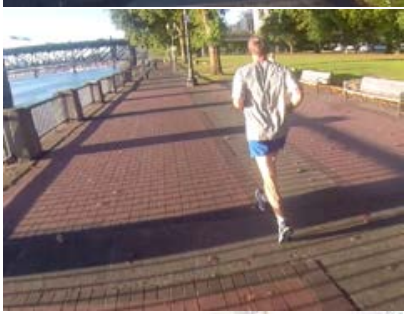

16

Peak

17

Peak

18

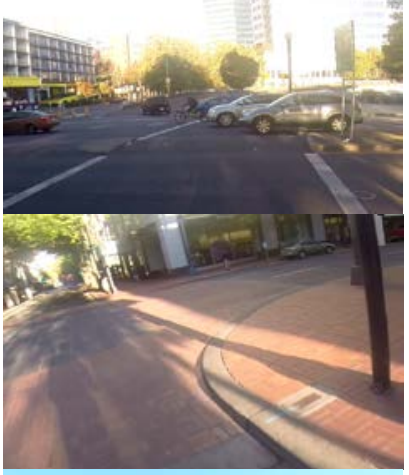

Peak

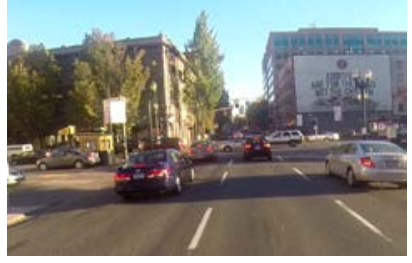

The subject was touching the electrodes, interfering with the stress signals.

Subject overtaking and passing the cyclist.

Stress levels increased because the subject was approaching a senior.

A pedestrian was walking next to the subject.

Subject biking next to a runner.

Subject waiting for the green light to cross a busy in resection.

Subject waiting for the green light to cross right. No particular stimulus.

Subject biking next to traffic. 
Peak

20

Peak

21

22

Peak

1

Off-peak

2

Off-peak

3

Off-peak

4

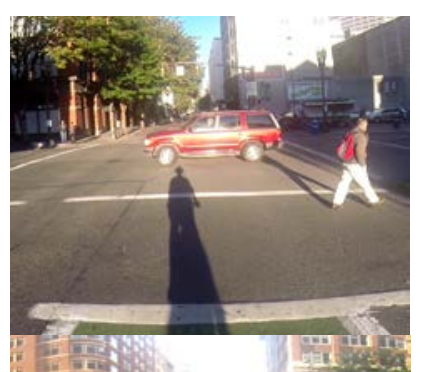

Subject biking next to traffic, Narrow bike lane.

Subject waiting for the green light. No particular stimulus.
In this location the pavement quality is poor. While the subject was crossing through this intersection, the vibration caused by the holes affected the stress measures.

The subject was waiting for the green light, looking at both sides of street for pedestrians and motorized traffic.

Subject biking next to traffic. Traffic stopped to allow pedestrian crossing the street.

Subject biking next to traffic. Traffic stopped to allow pedestrian crossing the street.

The subject was turning left, just before a couple of pedestrians crossed the intersection.

Car overpassing the subject. 


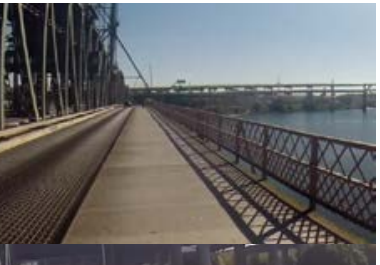

Off-peak

7

Off-peak

8

Off-peak

9

Off-peak

10

Off-peak

11

Off-peak

12
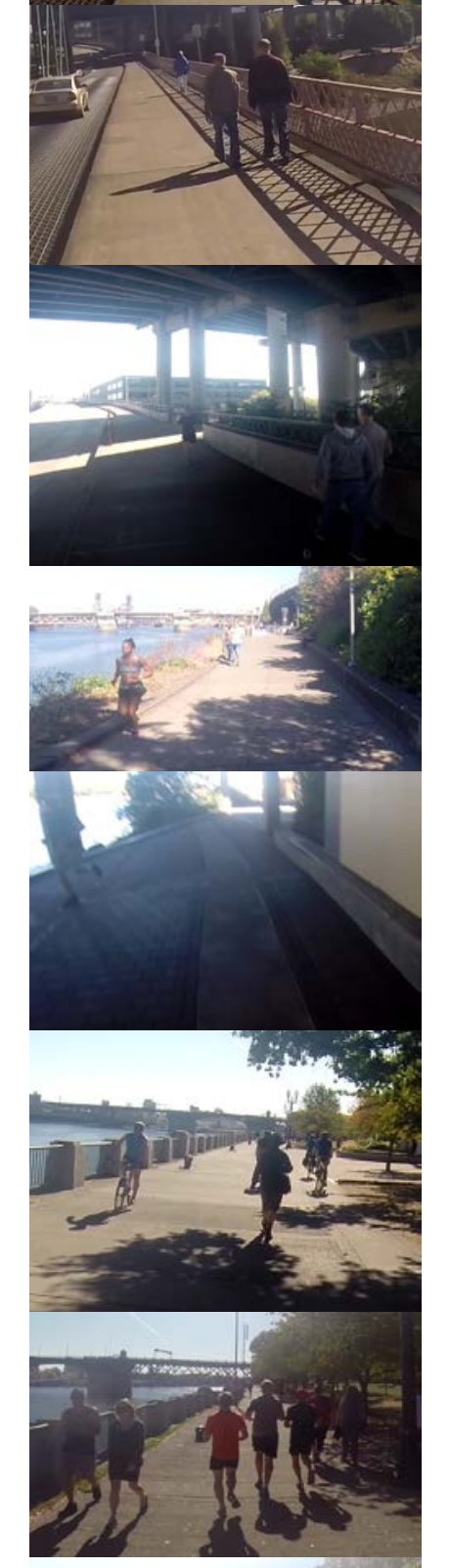

Off-peak

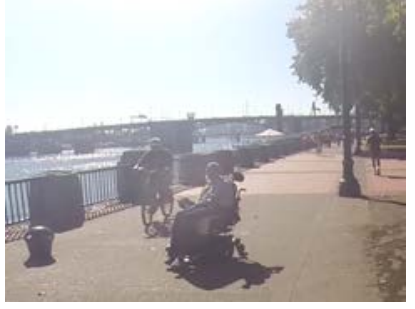

Subject crossing the bridge without any particular stimulus.

The subject had to avoid a group of pedestrians by reducing his speed and waiting for a space to move.

The subject had to avoid a group of pedestrians to take the ramp on the right.

Subject biking next to runners.

Subject biking next to runners.

The subject had to avoid a group of pedestrians by reducing his speed and waiting for a space to move.

The subject had to avoid a group of pedestrians by reducing his speed and waiting for a space to move.

The subject had to avoid a group of pedestrians by reducing his speed and waiting for a space to move. 
13

$$
\text { Off-peak }
$$

14

Off-peak

15

16

Off-peak

17

$$
\text { Off-peak }
$$

18

19

Off-peak

17 (n)

Off-peak
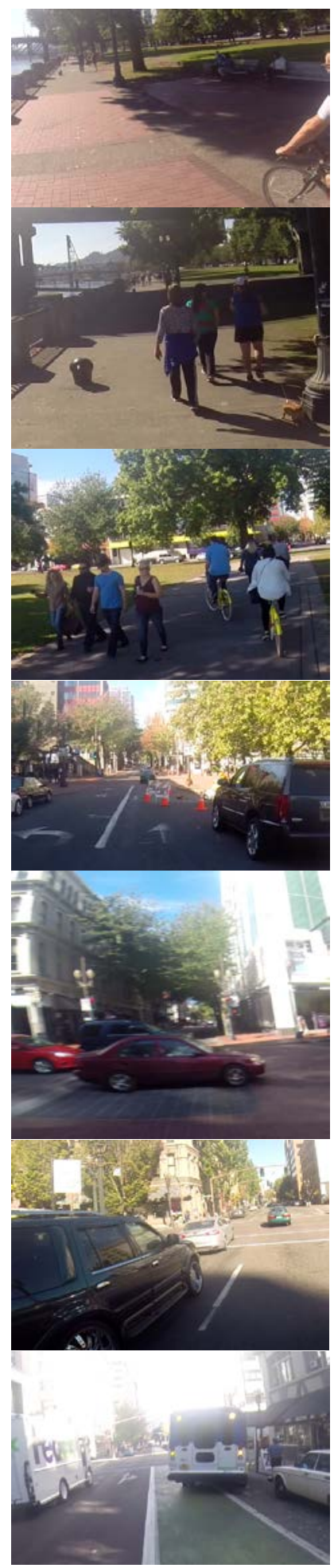

A cyclist was overtaking the subject.

The subject had to avoid a group of pedestrians by reducing his speed and waiting for a space to move.

The subject had to avoid a group of pedestrians by reducing his speed and waiting for a space to move.

Cones were blocking the lane.

Subject waiting for the green light to cross right.

Subject biking next to traffic. One truck was driving next to the subject.

Trimet bus parking on the right lane. 
Off-peak

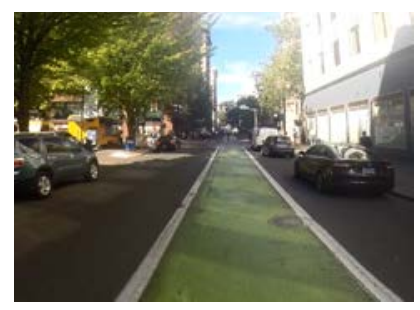

21

22

23

24

25
Off-peak

Off-peak

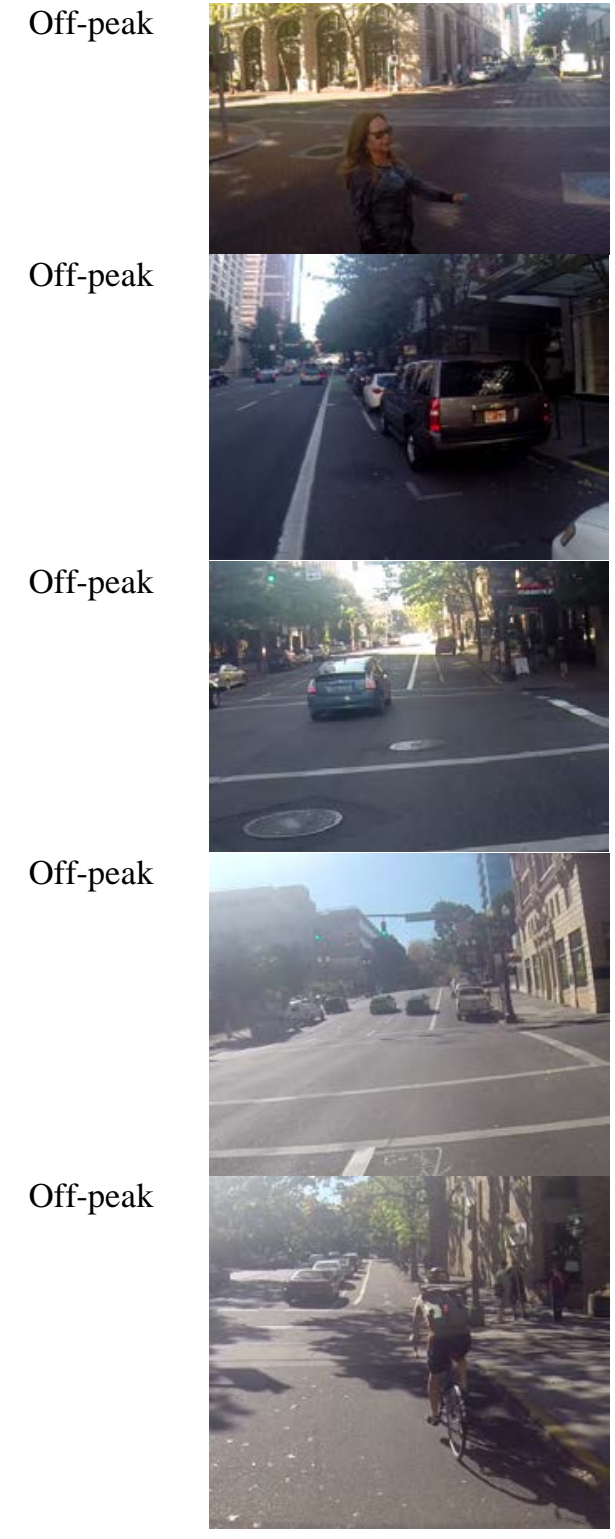

The biker was going through a demarcated bike lane, with no adjacent traffic. There are two possible reasons stress levels increased. One, the subject was playing with the electrodes. Two, the subject was experiencing stress due to reasons that were not observable to the researcher (e.g. stress generated by memories or future tasks).

Subject waiting for the green light. One pedestrian was crossing the sidewalk.

Narrow bike lane

Subject biking next to traffic.

Subject biking next to traffic.

A cyclist was overtaking and passing the subject. 


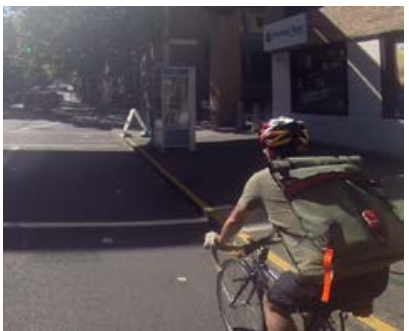

The subject was trying to pass the cyclist. 


\section{Subject \# 2}

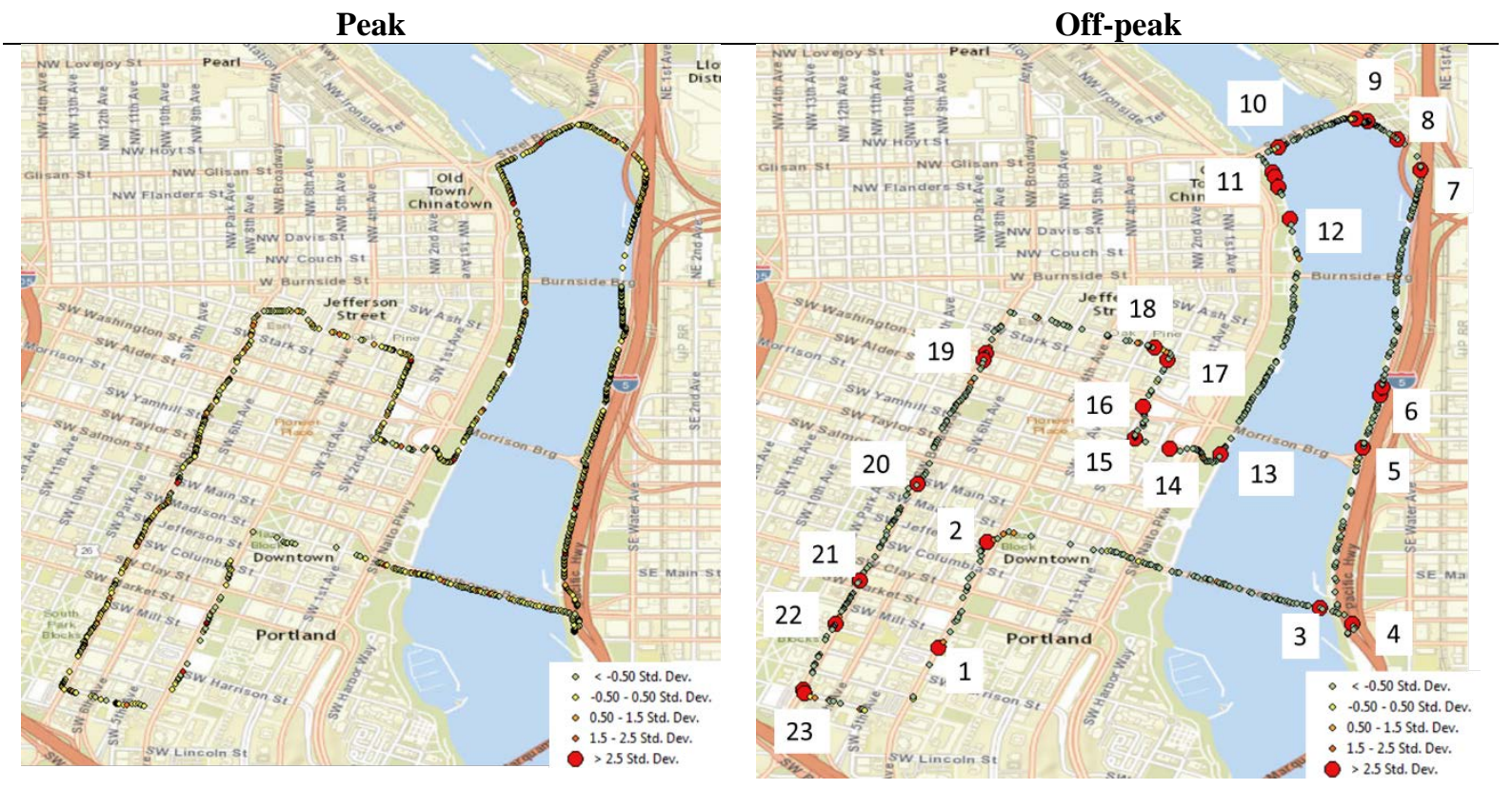

\begin{tabular}{cccc} 
Event & Time & Picture \\
\hline 1 & Off-peak & \\
3 & Off-peak & Off-peak \\
4 & Off-peak
\end{tabular}

\section{Description}

Subject crossing a sidewalk. Pedestrian waiting to cross.

Car trying to take the right lane by overtaking and passing the subject.

Pedestrian walking next to the subject.

Bike lane merging into the multi-use path. Subject looking in both directions. 
6

Off-peak

7

Off-peak

8

Off-peak

9

Off-peak

10

Off-peak

11

Off-peak
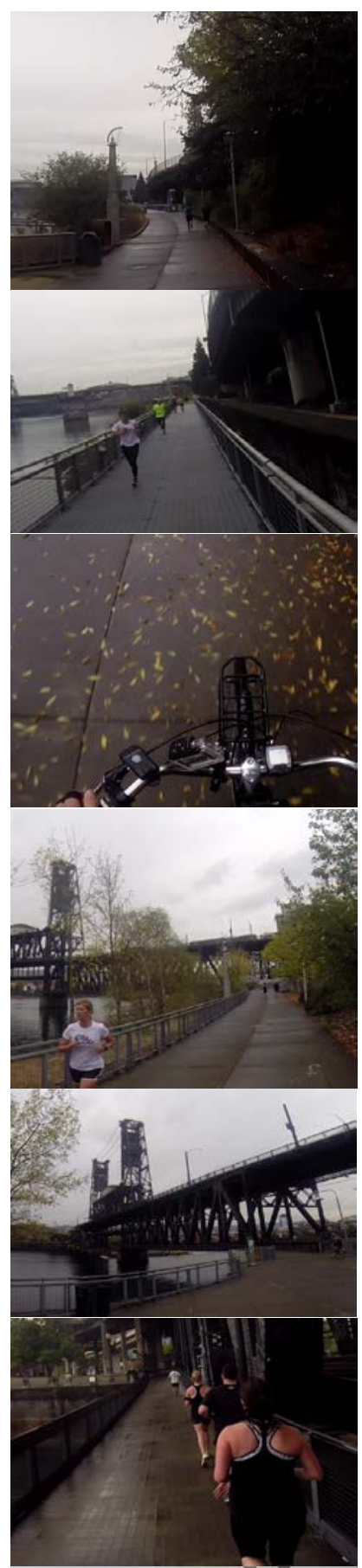

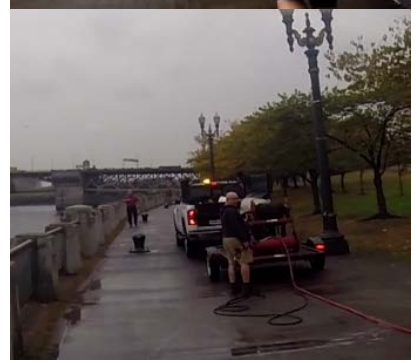

The subject had to avoid a group of pedestrians by reducing his speed and waiting for a space to move.

The subject was touching the electrodes, interfering with the stress signals.

Subject biking next to runners.

Subject had to stop because the bridge was closed.

The subject had to avoid a group of pedestrians by reducing his speed and waiting for a space to move.

A maintenance truck was blocking most of the path. 
12

$$
\text { Off-peak }
$$

13

Off-peak

14

Off-peak

15

Off-peak

16

Off-peak

17

Off-peak

18

Off-peak
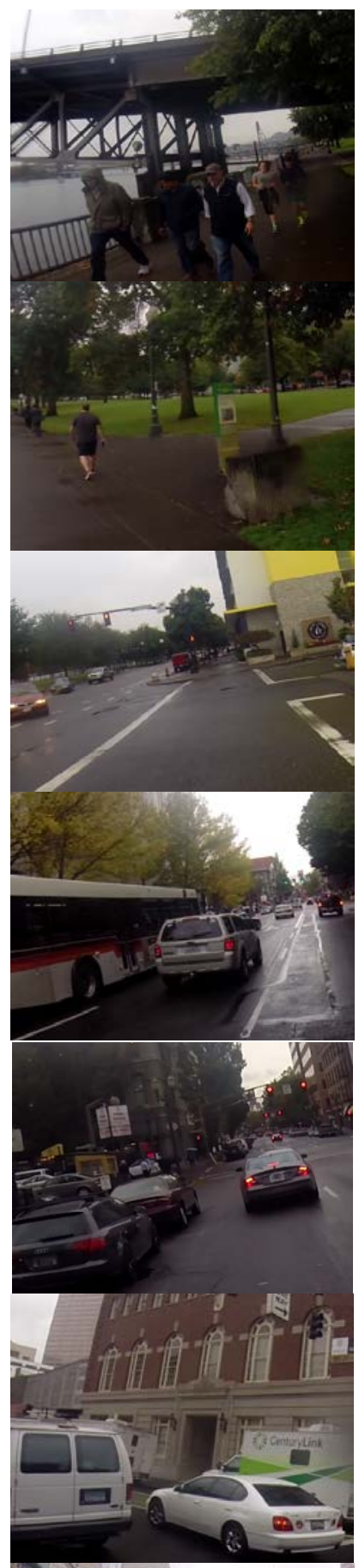

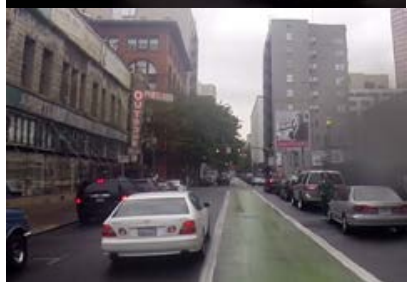

The subject had to avoid a group of pedestrians by reducing his speed and waiting for a space to move.

Subject was confused about taking this path.

Subject biking next to relative high traffic.

Subject biking next to traffic.

Subject taking the left at the same time a car was doing it.

No particular stimulus. 
19

$$
\text { Off-peak }
$$

20

Off-peak

21

Off-peak

22

Off-peak

23
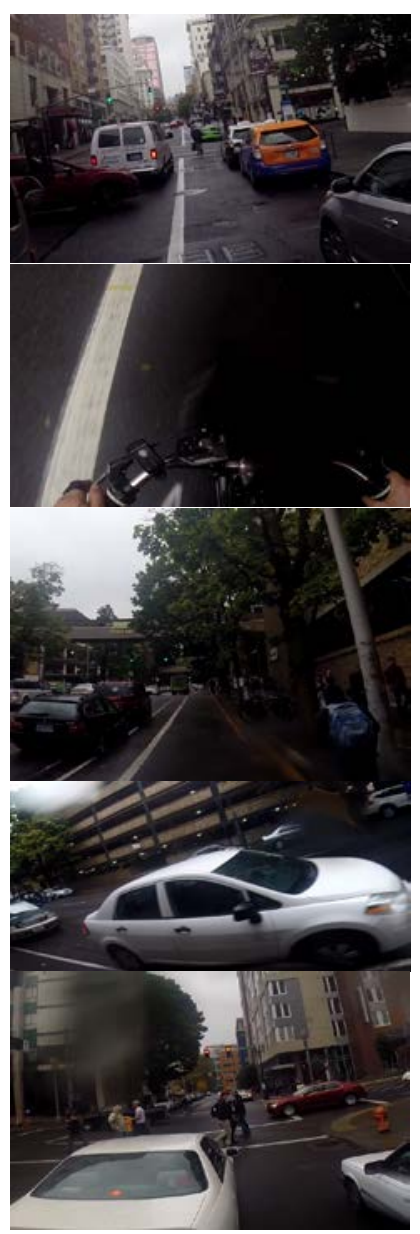

Subject biking through a narrow bike lane next to traffic and parking. Pedestrian crossing.

The subject was touching the electrodes, interfering with the stress signals.

A pedestrian was walking along the bike lane, increasing the stress levels of the subject.

The subject was biking along the bike lane; however, the distance between parked cars and cyclists was minimal

At this intersection the volume of cars was relatively high, the biker had to wait until the car in front of him turn left in order to cross the intersection. 


\section{Subject \# 3}

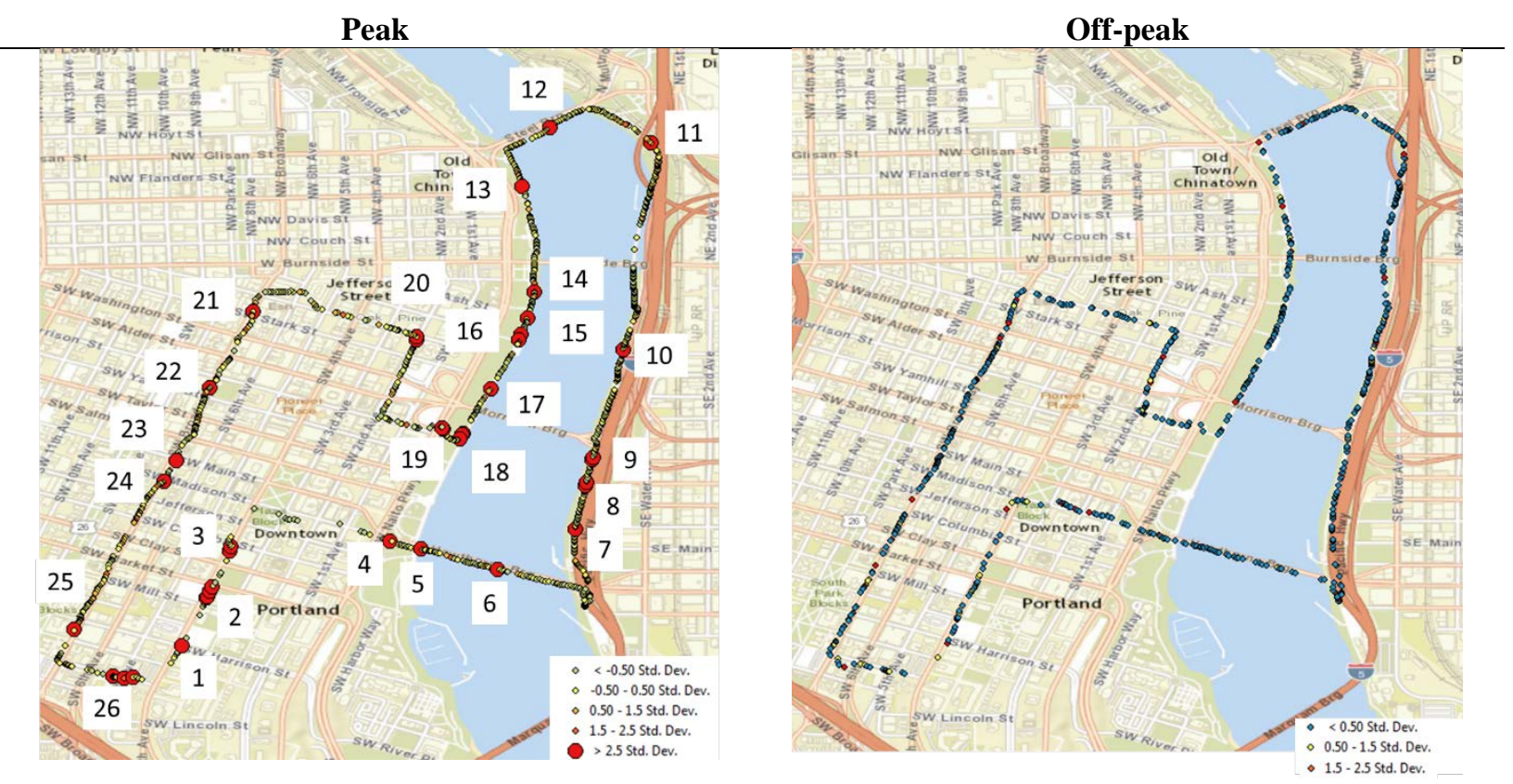

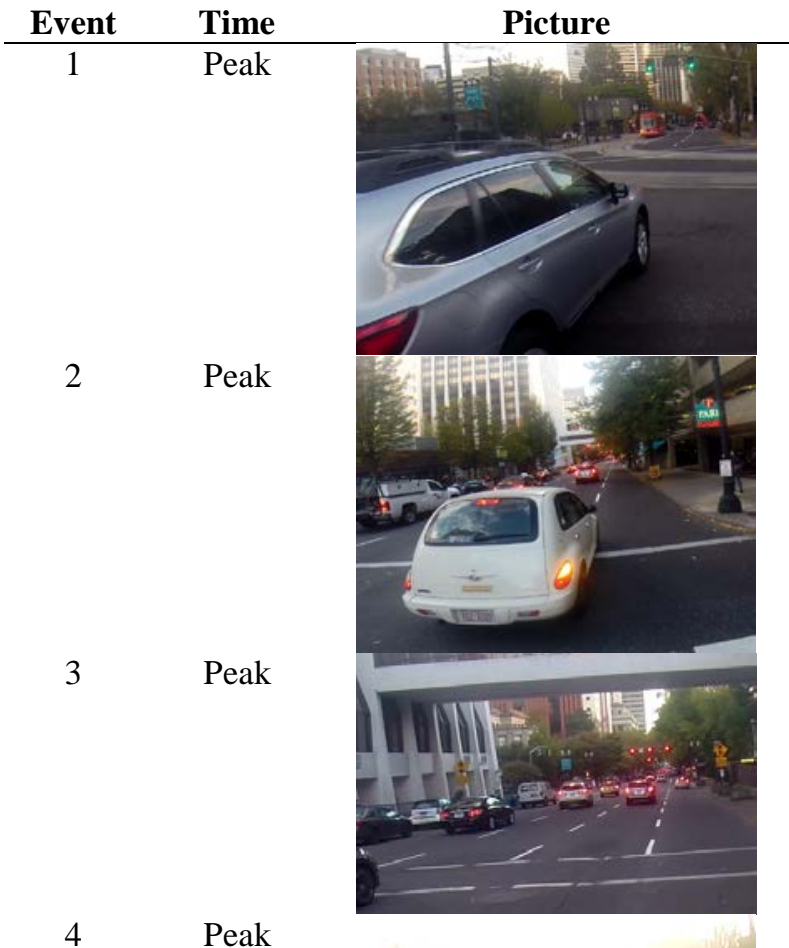

Car turning right and blocking subject movement.

Car turning right and blocking subject movement.

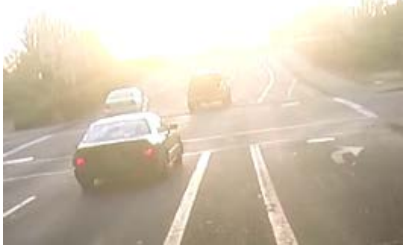

Subject biking next to traffic. 
5

Peak

6

Peak

7

Peak

8

Peak

9

10

Peak

11

Peak

12

Peak

Peak
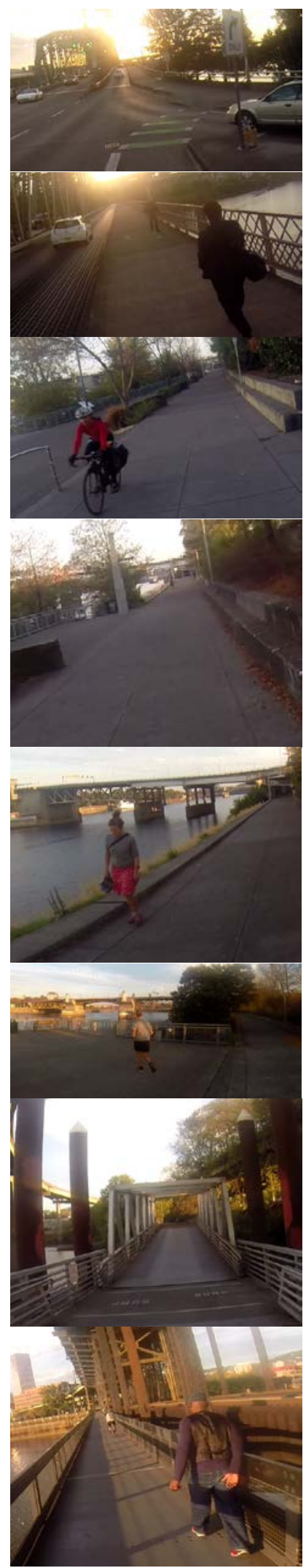

Subject crossing the lane. Driver waiting for the subject to cross the intersection.

The subject had to avoid a group of pedestrians by reducing his speed and waiting for a space to move.

Cyclist biking next to the subject.

No particular stimulus

Subject biking next to a pedestrian.

The subject was biking along the multi-use path trying to avoid a pedestrian in order to take the ramp.

Subject was biking along this ramp with multiple bumps.

Subject biking next to a pedestrian in a narrow facility. 
Peak

15

16

17

18

Peak

19

Peak

Peak

Peak

Peak
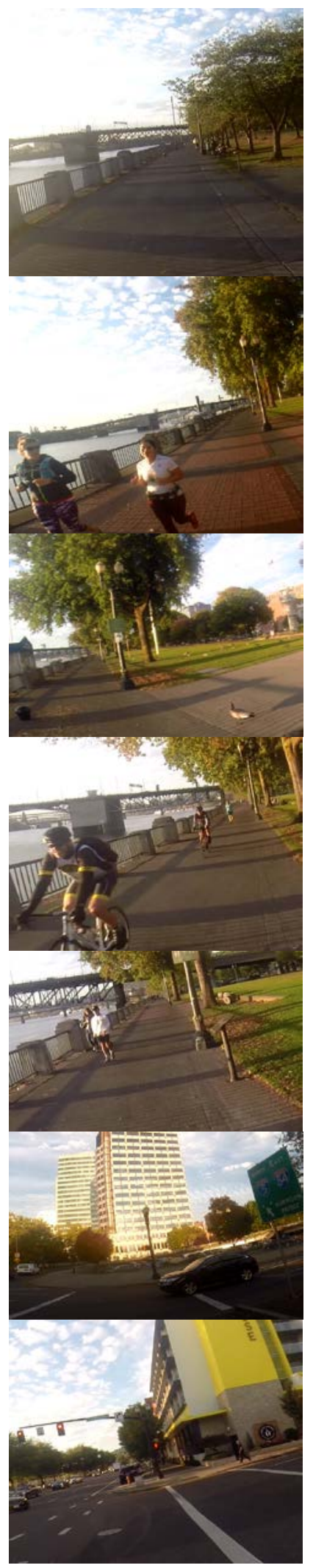

The subject was going along the multi-use path without pedestrian traffic, stress levels increased because there was an interference in the stress signals of due to internal stress that was not observable by the researcher.

Stress levels increased because the biker was trying to avoid to pedestrians that were going to his direction.

No particular stimulus.

The subject had to avoid a group of pedestrians by reducing his speed and waiting for a space to move.

The subject had to avoid a group of pedestrians by reducing his speed and waiting for a space to move.

This intersection is problematic for cyclists, in order to take the street that was part of the route, the cyclist had to avoid three conflict points and wait for two green lights.

The subject had to turn right crossing through two busy streets. 
Peak

22

23

$$
\text { Peak }
$$

24

Peak

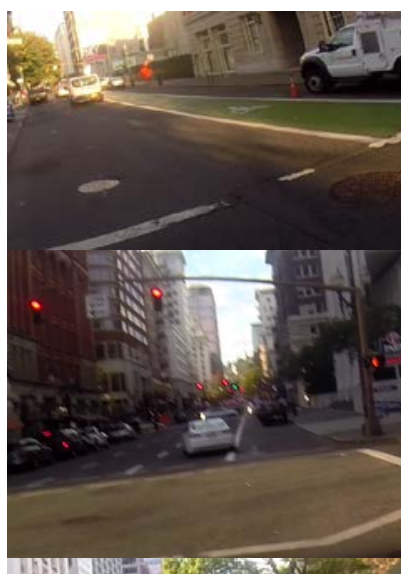

Peak
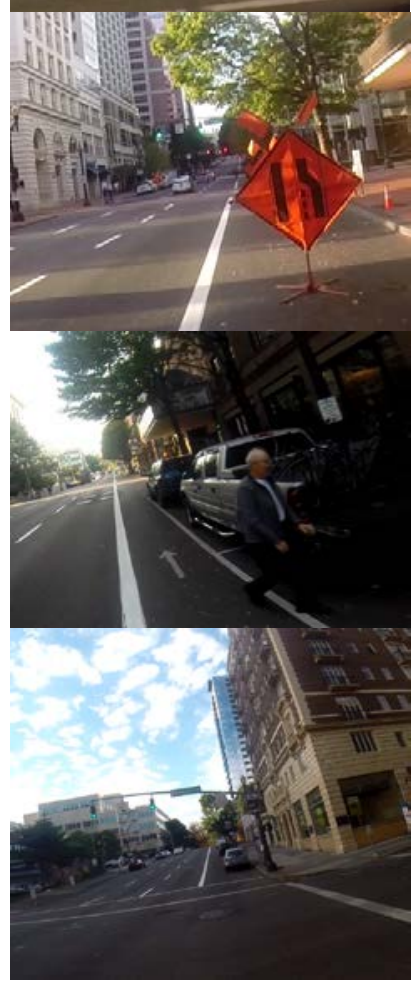

25

Peak

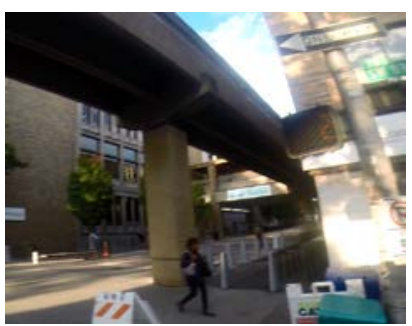

Subject taking the bike lane. The subject was coming from a shared roadway.

Subject waiting for the green light.

Traffic sign was blocking the bike lane. The subject had to merge into the traffic lane.

The subject was biking along the demarcated bike lane; however, a pedestrian crossed the street blocking his movement for a moment.

The subject was crossing the intersection and didn't have to wait because the light was green. No adjacent traffic. There are two possible reasons stress levels increased. One, the subject was playing with the electrodes. Two, the subject was experiencing stress due to reasons that were not observable to the researcher (e.g. stress generated by memories or future tasks).

The subject was crossing an intersection, but he noticed the light was about to turn red, so he biked faster. 


\section{Subject \# 4}
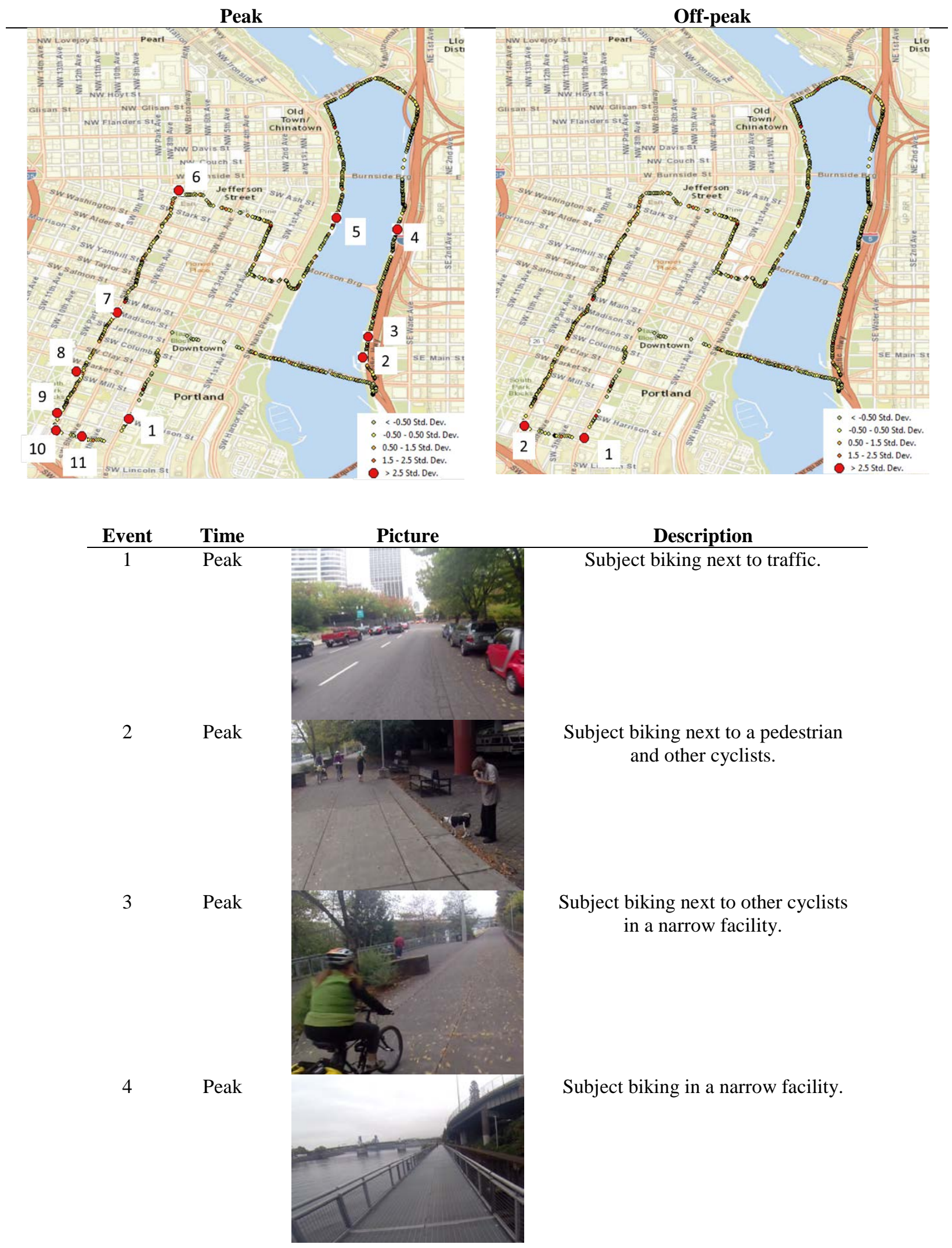

Description

Subject biking next to traffic.

Subject biking next to a pedestrian and other cyclists.

Subject biking next to other cyclists in a narrow facility.

Subject biking in a narrow facility. 


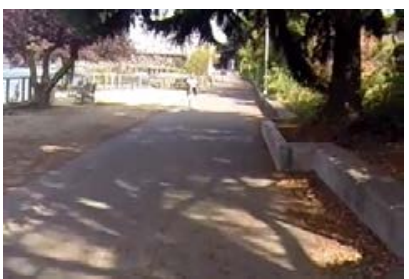

No particular stimulus.

6

Peak

7

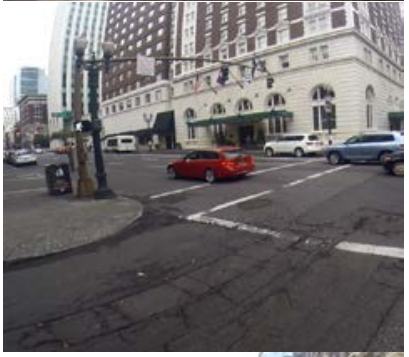

Peak

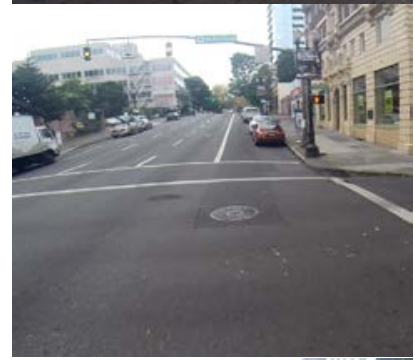

8

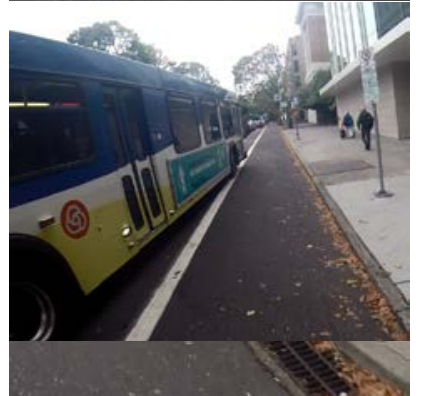

The subject was biking along the bike lane when a Trimet bus suddenly appeared almost blocking the lane.

The subject was about to cross the street when the light turned red. He hastily stopped the bicycle.

Peak

Peak
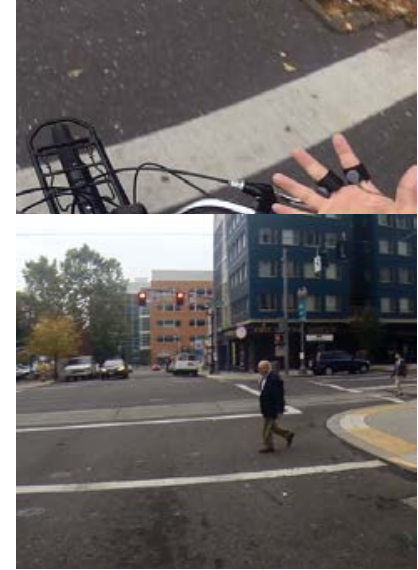

The subject was trying to turn left. To do this, he waited until the light was red, then he crossed the sidewalk to be in the left side of the road and then wait for the green light to turn left.
The subject was touching the electrodes, interfering with the stress signals.

The subject was waiting for the green light when a pedestrian started to cross the sidewalk. 


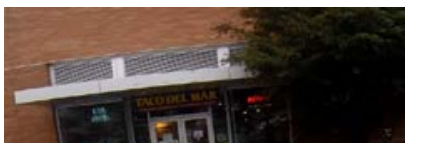

While entering to the last section of the route, a pedestrian walked in front of the subject, blocking his movement and reducing his speed.

The subject was going along the mixed traffic street, noticing one car waiting for the green light in front of him.

2 Off-peak

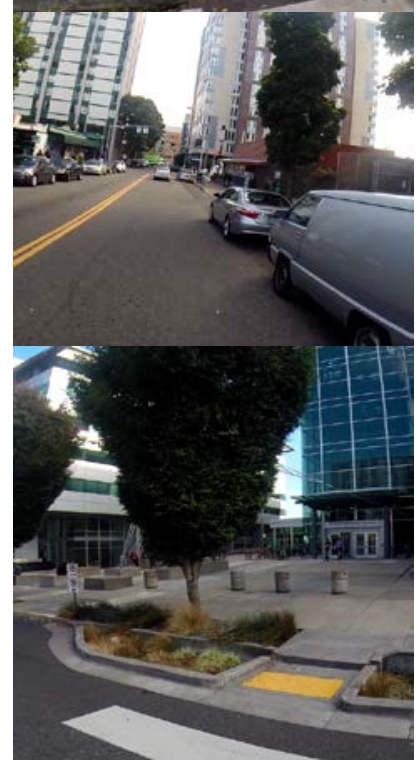

The subject was finishing the route when the stress level increased. This could be due to the fact that the subject didn't see the researcher at the end of the study or the subject was experiencing stress due to reasons that were not observable to the researcher (e.g. stress generated by memories or future tasks). 


\section{Subject \# 5}
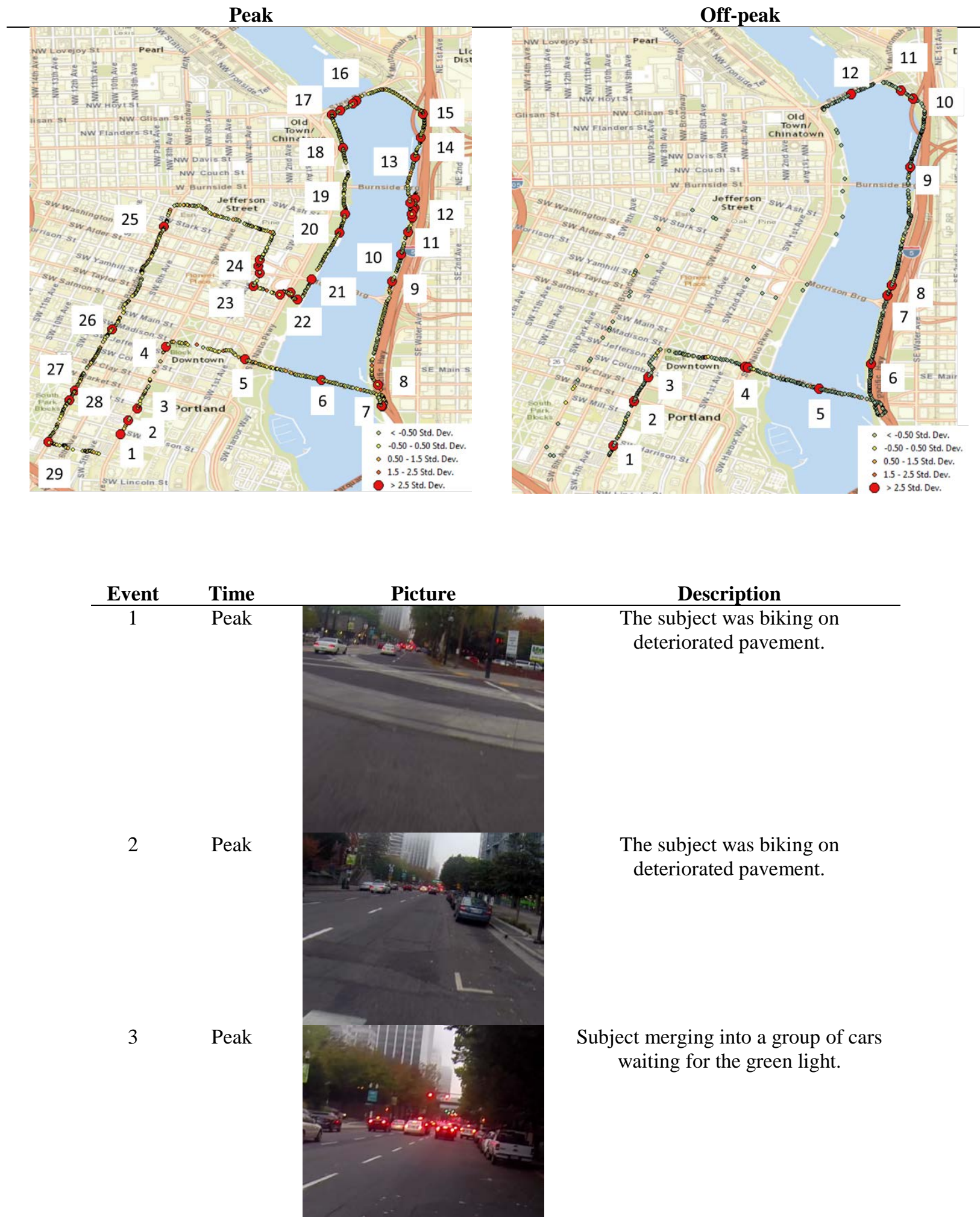

Description

The subject was biking on deteriorated pavement.

The subject was biking on deteriorated pavement.

Subject merging into a group of cars waiting for the green light. 
4

Peak

5

Peak

6

Peak

7

Peak

8

Peak

9

Peak

10

Peak

11

Peak

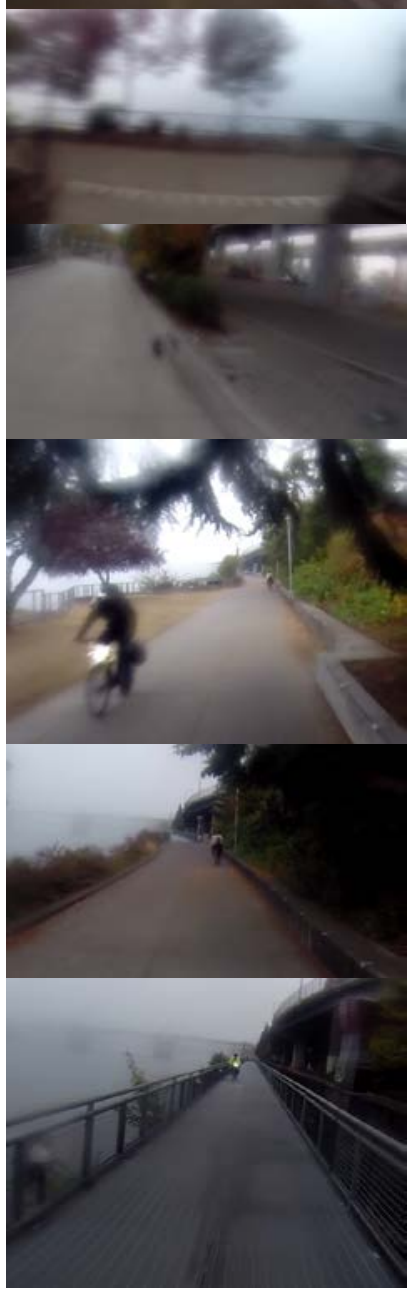

Subject was turning right. The subject was not on the right lane.

Subject biking next to traffic. Car turning right without blocking subject's movement.

\section{No particular stimulus. Smoggy} environment.

Bike lane merging into the multi-use path. Subject looking in both directions.

A group of pigeons started to fly next to the subject.

Cyclist biking next to the subject.

No particular stimulus.

Subject biking on a narrow path. 
Peak

Peak

Peak

Peak
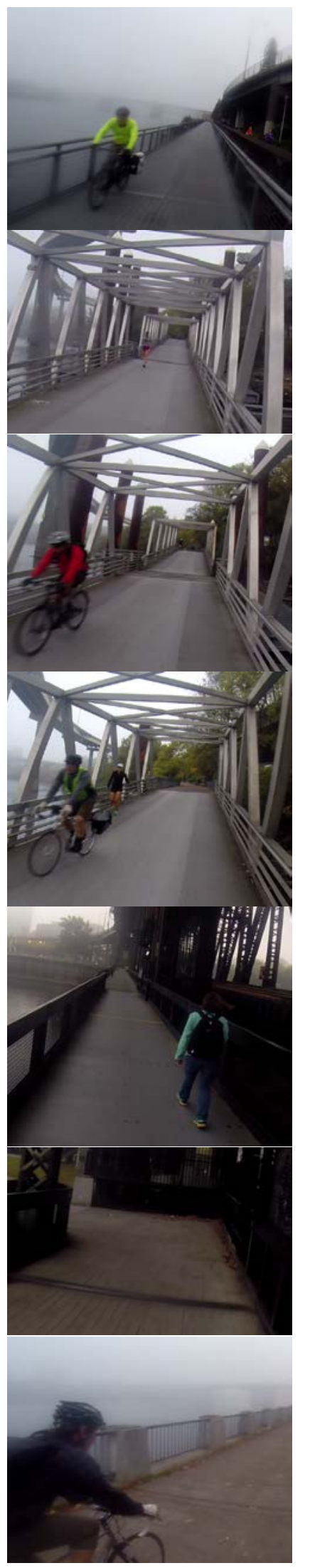

Subject biking next to other cyclists in a narrow facility

Subject was biking along this ramp with multiple bumps. Runner on the left side.

Subject was biking along this ramp with multiple bumps. A cyclist was biking down.

Subject was biking along this ramp with multiple bumps. A cyclist was biking down.

The subject had to avoid a group of pedestrians by reducing his speed and waiting for a space to move.

Bump.

A cyclist was overtaking and passing the subject. 
19

Peak

20

Peak

21

Peak

22

Peak

23

Peak

24

Peak

25

Peak
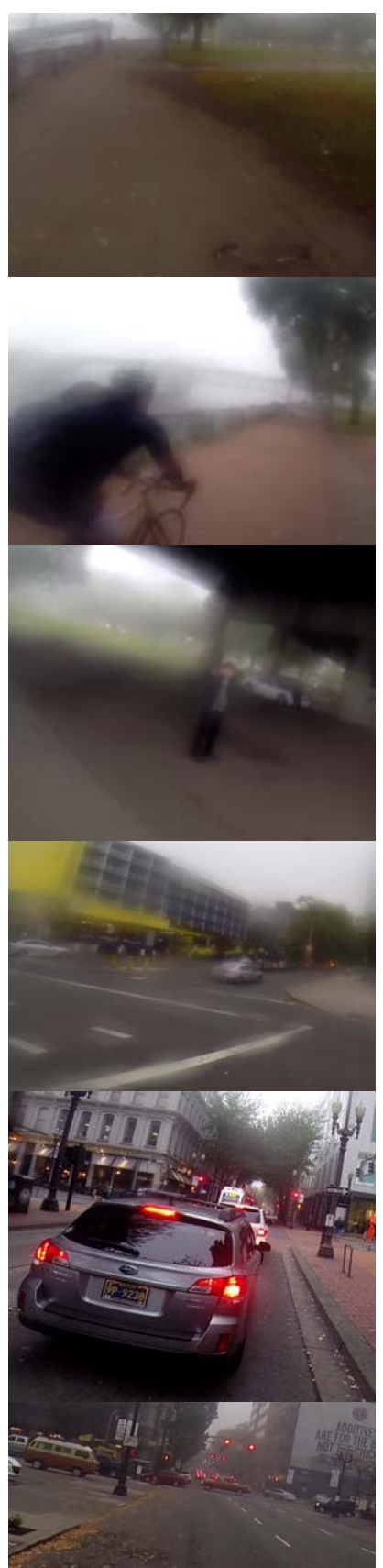

.

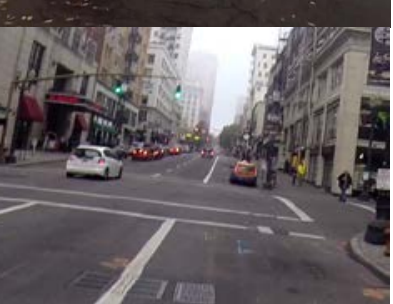

Subject was avoiding gooses that were blocking the path.

A cyclist was overtaking and passing the subject.

There was an event under the bridge.

The subject had to turn right crossing through two busy streets.

Car turning right and blocking subject movement.

The subject was biking on deteriorated pavement.

Subject biking next to traffic. 
Peak

27

Peak

28

Peak

29

Peak

1

Off-peak

2

Off-peak

3
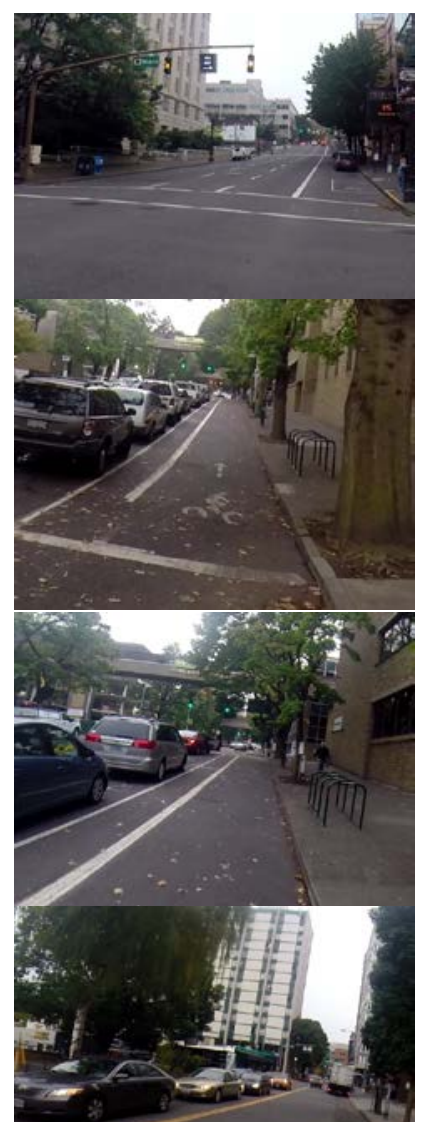

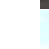
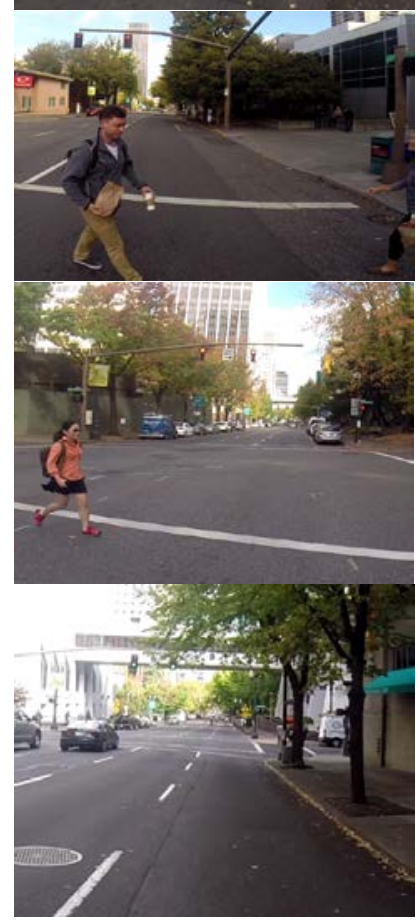

Subject was crossing the intersection on green; but the light started to shift to red.

No particular stimulus.

The subject was touching the electrodes, interfering with the stress signals.

Next to the subject there was a significant number of drivers waiting for the green light. Also, in front of her there were one car and one truck also waiting for the green light.

Subject waiting for the green light. A pedestrian was crossing the sidewalk.

Subject waiting for the green light. A pedestrian was crossing the sidewalk.

Subject biking next to traffic. 


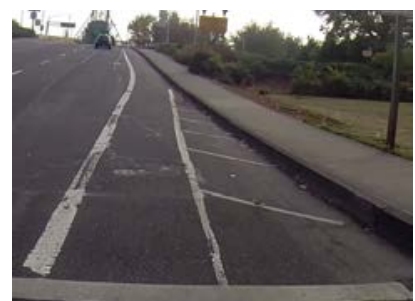

5

Off-peak

6

Off-peak

7

Off-peak

8

Off-peak

9

10

Off-peak

11

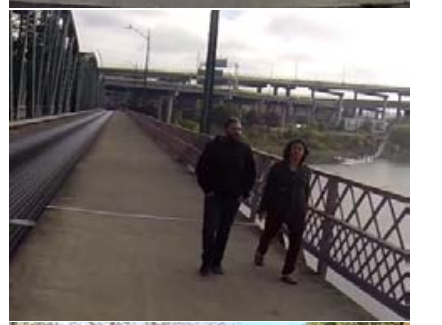

The subject had to avoid a group of pedestrians by reducing his speed and waiting for a space to move.

The subject had to avoid a group of pedestrians by reducing his speed and waiting for a space to move.

The subject had to avoid a group of pedestrians by reducing his speed and waiting for a space to move.

The subject had to avoid a group of pedestrians by reducing his speed and waiting for a space to move.

No particular stimulus.

Subject was biking along this ramp with multiple bumps.

Subject crossing an intersection where pedestrians and cyclists were merging. 
12 Off-peak

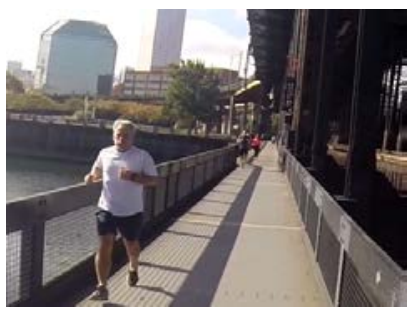

The subject had to avoid a group of pedestrians by reducing his speed and waiting for a space to move. 
Transportation Research and Education Center

Portland State University

1900 S.W. Fourth Ave., Suite 175

Portland, OR 97201 